AGESINALDO MATOS SILVA JUNIOR

Aplicação do ultrassom na coalescência de emulsões água em óleo

São Paulo

2013 
AGESINALDO MATOS SILVA JUNIOR

\section{Aplicação do ultrassom na coalescência de emulsões água em óleo}

Dissertação apresentada à Escola Politécnica da Universidade de São Paulo para obtenção do título de Mestre em Engenharia Mecânica

São Paulo

2013 
AGESINALDO MATOS SILVA JUNIOR

\title{
Aplicação do ultrassom na coalescência de emulsões água em óleo
}

\author{
Dissertação apresentada à Escola \\ Politécnica da Universidade de São Paulo \\ para obtenção do título de Mestre em \\ Engenharia Mecânica \\ Área de Concentração: Engenharia de \\ Automação e Controle \\ Orientador: Prof Dr. Julio Cezar Adamowski
}

São Paulo 
FICHA CATALOGRÁFICA

Silva Junior, Agesinaldo Matos

Aplicação do ultrassom na coalescência de emulsões água em óleo / A.M. Silva Junior. -- São Paulo, 2013.

$116 \mathrm{p}$.

Dissertação (Mestrado) - Escola Politécnica da Universidade de São Paulo. Departamento de Engenharia Mecatrônica e de Sistemas Mecânicos.

1.Ultrassom 2.Ondas (Geração) 3.Emulsão I.Universidade de São Paulo. Escola Politécnica. Departamento de Engenharia Mecatrônica e de Sistemas Mecânicos II.t. 


\section{AGRADECIMENTOS}

Ao meu orientador, Prof. Dr. Julio Cezar Adamowski, por confiar em mim e ter me indicado excelentes caminhos sem os quais eu não teria alcançado as minhas conquistas enquanto pesquisador desde a minha iniciação científica.

Ao Prof. Dr. Marco Aurélio Brizzotti, por ter me co-orientado no mestrado e compartilhado de sua experiência acadêmica desde a minha graduação.

Ao Prof. Dr. Flávio Buiochi, pelas diversas discussões elucidativas sobre os modelos teóricos desenvolvidos durante o mestrado.

À PETROBRAS pelos recursos financeiros necessários ao desenvolvimento deste trabaIho através do convênio Petrobras /ANP-USP-FUSP intitulado "Técnicas de ultrassom para quebra de emulsão água-em-óleo".

Ao CENPES/PETROBRAS, principalmente ao Ricardo A. Guarnieri, Regina C. L. Guimarães e Luiz O. V. Pereira pelo importante apoio na execução deste projeto.

Ao pessoal do Setor de Química Industrial e Ambiental da UFSM, principalmente ao Prof. Dr. Érico M. M. Flores, Fabiane G. Antes e Liange de O. Diehl, pelo importante apoio no treinamento de síntese e análise de emulsões.

Aos meus pais que me apoiaram e não mediram esforços para que eu pudesse seguir o meu caminho em direção a carreira acadêmica.

A minha noiva Fernanda sendo minha inspiração para seguir sempre adiante e pela compreensão pelos momentos que deixamos de passar juntos em prol deste trabalho.

Aos meus colegas de laboratório, João, Rafael, Lucas, Thiago, Tiago e Carlos, por terem compartilhado conhecimentos acadêmicos e não acadêmicos durante os últimos anos.

Aos técnicos Gilberto, Adilson e Wellington pela usinagem das peças fundamentais às células.

Ao Timóteo por ser sempre prestativo ajudando na fabricação dos transdutores. 


\section{RESUMO}

O processo de separação da água em emulsões de petróleo é feita durante o processamento primário do petróleo e consiste na coalescência de gotas de água. Para minimizar o uso de desemulsificantes e acelerar o processo de separação da emulsão alguns equipamentos podem ser utilizados como os separadores acústicos. Neste trabalho a técnica de força de radiação produzida por ondas estacionárias de ultrassom é aplicada na segregação das fases líquidas de emulsões água em óleo. São desenvolvidas células de ultrassom que operam em frequências próximas de $1 \mathrm{MHz}$ através de ressonadores piezelétricos visando a aplicação na coalescência de gotas de água em emulsões do tipo água-óleo. O trabalho envolve simulações do campo acústico através de modelos analíticos unidimensionais e bidimensionais e de um modelo numérico bidimensional pelo método dos elementos finitos para o estado plano de deformações. São realizadas verificações experimentais em protótipos de células de alta potência para separação em batelada através da comparação do potencial de radiação acústica e da impedância elétrica com resultados de modelos computacionais. Diversos ensaios de quebra de emulsões sintetizadas de petróleo são realizados utilizando um aparato experimental de laboratório aplicando potências de até $600 \mathrm{~W} / \mathrm{l}$. Um sistema de controle de frequência de operação é implementado para manter máxima transmissão de potência elétrica para a célula. Os resultados mostraram que a técnica empregada pode reduzir pela metade o uso de desemulsificante químico (de 20 a 10 pom) ou diminuir o tempo de residência em até $60 \%$ (de 20 para $8 \mathrm{~mm}$ ). Uma análise da influência da frequência na eficiência de desemulsificação é realizada e indica que não há sensibilidade no resultado para a faixa de frequência entre 0.8 e 1.5 $\mathrm{MHz}$ a uma temperatura ambiente de aproximadamente $23{ }^{\circ} \mathrm{C}$. A metodologia empregada auxilia no projeto das células e na aplicaçao da técnica mas é insuficiente para explicar integralmente os mecanismos de separação e as diferenças entre o protótipo e o modelo. A aplicação de ultrassom na coalescência de emulsões possui potencial para desenvolvimento em larga escala.

Palavras-chaves: Ultrassom. Ondas. Emulsão. 


\begin{abstract}
The oil water separation process of petroleum emulsions is performed during the primary processing of crude oil and consists of water droplets coalescence. To minimize the use of demulsifiers and accelerate the emulsion separation process some equipment may be used such as acoustic separators. In this work, a radiation force technique produced by ultrasound standing waves is applied to the water phase separation in oil emulsions. Ultrasound cells operating at ultrasonic frequencies near $1 \mathrm{MHz}$ are developed using piezoelectric resonators applied to the coalescence of water droplets in oil emulsions. This work involves simulations of the acoustic field through one-dimensional and two-dimensional analytical models and a numerical model for two-dimensional plane strain finite element analysis. Furthermore, experimental verification is performed using high power prototypes for batch separation by comparing the acoustic radiation potential and electrical impedance with computational models results. Several tests of synthesized petroleum emulsions breaking are performed using an experimental laboratory apparatus applying up to $600 \mathrm{~W} / \mathrm{l}$. A frequency control system is implemented in order to maintain maximum electric power transmission to the cells. The results showed that the technique can halve the use of chemical demulsifier ( from 20 to 10 ppm) or decrease the residence time of up to $60 \%$ ( from 20 to $8 \mathrm{~mm}$ ). An analysis of the frequency influence on demulsification efficiency is performed and indicates that there is no parameter sensitivity in the frequency range between 0.8 and $1.5 \mathrm{MHz}$ at room temperature of approximately $23^{\circ} \mathrm{C}$. It is demonstrated that the design methodology is consistent and the application has potential for large-scale development.
\end{abstract}

Keywords: Ultrasound. Waves. Emulsion. 


\section{LISTA DE ILUSTRAÇÕES}

Figura 1 - Esquema da técnica de aplicação de ultrassom na coalescência de emul-

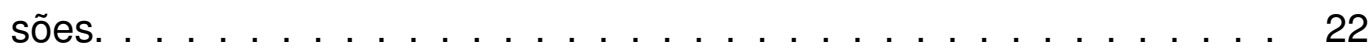

Figura 2 - Esquema do protótipo da célula de separação. . . . . . . . . . . 22

Figura 3 - Diagrama do volume de controle fixo mostrando a taxa de fluxo de massa. 26

Figura 4 - Superfície de fase constante de um onda plana harmônica no plano $x y$. 27

Figura 5 - Elemento elástico unidimensional e suas tensões internas em cada face. 30

Figura 6 - Orientação das tensôes em um elemento de volume infinitesimal. . . . . 31

Figura 7 - Sistema de coordenadas escolhido para o problema unidimensional. . . 34

Figura 8 - Reflexão e transmissão de uma onda plana de incidência normal em uma interface plana entre dois fluidos de impedâncias característica diferentes. 37

Figura 9 - Reflexão e transmissão de uma onda plana de incidência normal em uma interface de espessura uniforme. . . . . . . . . . . . . 38

Figura 10 -Condições de contorno consideradas em cada camada. . . . . . . . . 42

Figura 11 -Possíveis condições de contorno do modelo elétrico. . . . . . . . . . 43

Figura 12 -Divisão estrutural de uma organização de camadas arbitrárias . . . . . 46

Figura 13 -Modelo unidimensional do ressonador multicamadas. . . . . . . . . . 48

Figura 14 -Resultado analítico do espectro de impedância elétrica da cerâmica piezeletrica. . . . . . . . . . . . . . . . . . . 61

Figura 15 -Resultado analítico do espectro de impedância elétrica da conjunto transdutor. . . . . . . . . . . . . . . . . . . . 62

Figura 16 -Resultado analítico do espectro de impedância elétrica da conjunto transdutor mais a camada de fluido. . . . . . . . . . . . . . . . . . . . . . . 62

Figura 17 -Resultado analítico do espectro de impedância elétrica do ressonador completo. . . . . . . . . . . . . . . . . . 63

Figura 18 -Distribuição espacial da amplitude de velocidade, fluxo de energia e densidades de energia no ressonador modelo A preenchida com água. . . . 64

Figura 19 -Secção transversal do ressonador utilizado no modelo bidimensional plano analítico e numérico. . . . . . . . . . . . . . . . . . . . . . 65

Figura 20 -Potencial de radiação acústica obtido pelo modelo analítico da célula modelo A nas frequência 1.02 $\mathrm{MHz}$ (acima) e $1.12 \mathrm{MHz}$ (abaixo). . . . . 66

Figura 21 -Discretização em elementos finitos, tipo de elementos utilizados e condições de contorno do modelo do ressonador. . . . . . . . . . . 67

Figura 22 -Espectro de impedância elétrica do ressonador obtido por MEF. . . . . . 68 Figura 23 -Potencial de radiação acústica obtido pelo MEF da célula modelo A nas frequências $1.03 \mathrm{MHz}$ (acima) e $1.10 \mathrm{MHz}$ (abaixo). . . . . . . . . 69 
Figura 24 -Desenho esquemático de usinagem e montagem do conjunto de cerâmicas para as células modelo $\mathrm{A}$ e B. . . . . . . . . . . . . 70

Figura 25 -Vista explodida da montagem da célula modelo A (acima) e B (abaixo). .71

Figura 26 -Fotos das células modelo A (esquerda) e modelo B (direita). . . . . . . 72

Figura 27 -Comparação do espectro de impedância elétrica da célula de $1.0 \mathrm{MHz}$. 73

Figura 28 -Comparação do espectro de impedância elétrica da célula de $0.8 \mathrm{MHz} . \quad 74$

Figura 29 -Comparação do espectro de impedância elétrica da célula de $1.5 \mathrm{MHz} . \quad 75$

Figura 30 -Foto da célula modelo $\mathrm{A}$ operando a uma frequência de $1.04 \mathrm{MHz}$ no ensaio com esferas de vidro. . . . . . . . . . . . . . . . . . 76

Figura 31 -Sequência de imagens do ensaios com amido de milho ilustrando o fenômeno de separação. . . . . . . . . . . . . . . . . . . . . . 77

Figura 32 -Sequência de imagens do ensaios com amido de milho ilustrando o fenômeno de aprisionamento. . . . . . . . . . . . . . . . . . . 77

Figura 33 -Sequência de imagens do ensaios com amido de milho ilustrando o fenômeno de correnteza acústica. . . . . . . . . . . . . . . . 78

Figura 34 -Comparação do espectro de impedância elétrica do ressonador utilizando emulsão de petróleo para análise da carga. . . . . . . . . . . 81

Figura 35 -Distribuição espacial da amplitude de velocidade, fluxo de energia e densidades de energia no ressonador modelo A preenchida com emulsão. . 82

Figura 36 -Esquema geral da instrumentação para os ensaios. . . . . . . . . . 83

Figura 37 -Foto em detalhe do preparo de emulsões: UltraTurrax (esq.), micropipeta (cen.), desemulsificante diluído (dir.). . . . . . . . . . . . . . . . . 84

Figura 38 -Foto em detalhe da visualização da interface óleo-água (esq.) e do sensor de temperatura (dir.). . . . . . . . . . . . . . . . 85

Figura 39 -Foto geral da bancada de ensaio. . . . . . . . . . . . . 85

Figura 40 -Exemplo de monitoramento de temperatura. . . . . . . . . . . . 86

Figura 41 -Evolução dos ensaios de comparação entre potências aplicadas. . . . . 87

Figura 42 -Evolução dos ensaios de comparação entre quantidade de desemulsificante. . . . . . . . . . . . . . . . . . . . 87

Figura 43 -Evolução dos ensaios de comparação entre frequências aplicadas. . . . 88

Figura 44 -Evolução dos ensaios de comparação entre tratamento por ultrassom. . 88

Figura 45 -Técnica transmissão recepção utilizada para caracterização das propriedades da emulsão. . . . . . . . . . . . . . . . . . . . . . . 97

Figura 46 -Resposta da técnica transmissão recepção para caracterização dos líquidos. . . . . . . . . . . . . . . . . . . . 99

Figura 47 -Malha de controle de frequência. . . . . . . . . . . . . . . 101 
Figura 48 -Exemplo de espectro de impedância elétrica medido durante os ensaios com emulsão de petróleo. . . . . . . . . . . . . . . . . . . . 103

Figura 49 -Exemplo de atuação controle de frequência de operação. . . . . . . . . . 104

Figura 50 -Óleo Bright Stock. . . . . . . . . . . . . . . . . . . . . . . . . . . . 106

Figura 51 -Óleo Neutro Leve. . . . . . . . . . . . . . . . . . . . . . . . . . . . . . 107

Figura 52 -Emulsão 1 após o preparo. . . . . . . . . . . . . . . . . . . . . . . . 108

Figura 53 - Gráfico comparativo dos teores de água das amostras TOPO e FUNDO

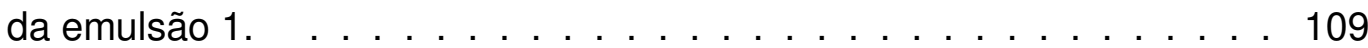

Figura 54 -Gráfico comparativo dos DTG da amostra TOPO da emulsão 1. . . . . . 109

Figura 55 -Gráfico comparativo dos DTG da amostra FUNDO da emulsão 1.0. . . . 109

Figura 56 -Emulsão 1 antes e após aplicação de banho por ultrassom. . . . . . . . 110

Figura 57 -Emulsão 2 após o preparo. . . . . . . . . . . . . . . . . . . . . . . . . . 111

Figura 58 - Gráfico comparativo dos teores de água das amostras TOPO e FUNDO da emulsão 2. . . . . . . . . . . . . . . . . . . . . . . . . . . 111

Figura 59 -Gráfico comparativo dos DTG da amostra TOPO da emulsão 2. . . . . . 111

Figura 60 -Gráfico comparativo dos DTG da amostra FUNDO da emulsão 2. . . . . 112

Figura 61 -Emulsão 2 antes e após aplicação de banho por ultrassom. . . . . . . . . 112

Figura 63 - Gráfico comparativo dos teores de água das amostras TOPO e FUNDO

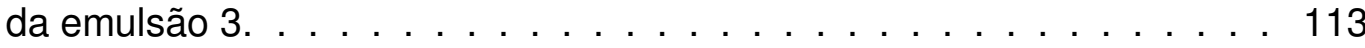

Figura 62 -Emulsão 3 após o preparo. . . . . . . . . . . . . . . . . . . . . . . . . . 113

Figura 64 -Emulsão 3 antes e após aplicação de banho por ultrassom. . . . . . . . . 114 


\section{LISTA DE TABELAS}

Tabela 2 - Dimensões das camadas dos ressonadores . . . . . . . . . . . . . . 60

Tabela 3 - Propriedades dos materiais do modelo unidimensional do ressonador . 60

Tabela 4 - Propriedades dos materiais piezelétricos do modelo unidimensional do ressonador . . . . . . . . . . . . . . . . . . . 61

Tabela 5 - Propriedades dos materiais utilizados no modelo analítico bidimensional. 66

Tabela 6 - Número de onda segundo o modelo de Barmatz e Collas (1985). . . . . 67

Tabela 7 - Características das cerâmicas utilizadas nos projetos das células. . . . 69

Tabela 8 - Dados experimentais obtidos para a caracterização das propriedades dos líquidos . . . . . . . . . . . . . . . . . . . 999

Tabela 9 - Caracterização das propriedades acústicas dos líquidos envolvidos à $23^{\circ} \mathrm{Ce} 1 \mathrm{MHz} \ldots \ldots \ldots \ldots 10 . \ldots \ldots$

Tabela 10 -Cálculo dos parâmetro $K_{c}, T_{i}$ e $T_{d}$ do controlador em malha fechada . . 102

Tabela 11 -Ensaio com banho de ultrassom da emulsão 1 . . . . . . . . . . . . . . . 110

Tabela 12 -Ensaio com banho de ultrassom da emulsão 2 . . . . . . . . . . . . . . . 112

Tabela 13 -Ensaio com banho de ultrassom da emulsão 3 . . . . . . . . . . . . . . 114

Tabela 14 -Propriedades dos materiais usados no modelo de elementos finitos . . 116

Tabela 15 -Propriedades do material PZT8 utilizadas no MEF . . . . . . . . . . . . 116

Tabela 16 -Propriedades do material PZT4 utilizadas no MEF . . . . . . . . . . . . 116 


\section{LISTA DE SÍMBOLOS}

\begin{tabular}{|c|c|}
\hline$\nu_{x}$ & componente velocidade de partícula na direção $\mathrm{x}$ \\
\hline$\vec{\nu}$ & vetor velocidade de partícula \\
\hline$s$ & condensação \\
\hline$\rho_{0}$ & densidade característica do fluido \\
\hline$\rho$ & densidade instantânea \\
\hline$\rho_{s}$ & densidade da esfera \\
\hline$\rho_{f}$ & densidade do fluido \\
\hline$t$ & tempo \\
\hline$p$ & pressão acústica \\
\hline$P$ & amplitude de pressão acústica \\
\hline$c_{f}$ & velocidade de fase em fluidos \\
\hline$c_{s}$ & velocidade de fase em sólidos \\
\hline $\mathfrak{B}$ & módulo de elasticidade volumétrica \\
\hline$\vec{k}$ & vetor número de onda \\
\hline$\hat{n}, n_{j}, n_{k}$ & vetor unitário \\
\hline$k$ & número de onda \\
\hline $\mathrm{k}$ & número de onda \\
\hline$\omega$ & frequência angular \\
\hline$\lambda$ & comprimento de onda \\
\hline$\Phi$ & potencial de velocidade \\
\hline$\Phi_{i n}$ & potencial de velocidade incidente \\
\hline$\Phi_{s c}$ & potencial de velocidade espalhado \\
\hline$E_{p f}$ & energia potencial do fluido \\
\hline$I_{a}(t)$ & intensidade acústica instantânea \\
\hline$I$ & corrente elétrica \\
\hline$\left\langle I_{a}\right\rangle$ & intensidade acústica média \\
\hline $\mathbf{z}$ & impedância acústica específica \\
\hline$Z$ & impedância elétrica \\
\hline$r$ & impedância acústica característica \\
\hline$V$ & volume \\
\hline$V_{0}$ & volume do elemento \\
\hline $\mathcal{U}_{f}$ & densidade de energia potencial fluidos \\
\hline $\mathcal{U}_{p}$ & densidade de energia potencial pizelétrica \\
\hline $\mathcal{U}_{e}$ & densidade de energia potencial elástica \\
\hline $\mathcal{U}_{l}$ & densidade de energia potencial elétrico \\
\hline$U_{a}$ & potencial de radiação acústica \\
\hline
\end{tabular}




\begin{tabular}{|c|c|}
\hline$\langle 2\rangle$ & média quadrática \\
\hline$E_{c}$ & energia cinética \\
\hline $\mathcal{T}$ & densidade de energia cinética \\
\hline $\mathcal{E}_{f}$ & densidade de energia total fluido \\
\hline $\mathcal{E}_{s}$ & densidade de energia total mecânica \\
\hline $\mathcal{E}_{p}$ & densidade de energia total piezelétrica \\
\hline$T, T_{i j}$ & tensão mecânica \\
\hline $\mathbf{T}_{A}$ & coeficiente de transmissão de pressão \\
\hline $\mathbf{R}_{A}$ & coeficiente de reflexão de pressão \\
\hline$T_{i}$ & coeficiente de transmissão de intensidade \\
\hline$R_{i}$ & coeficiente de reflexão de intensidade \\
\hline$S, S_{i j}$ & deformação mecânica \\
\hline$u, u_{i}$ & deslocamento \\
\hline$c$ & constante elástica de rididez \\
\hline$\mu$ & amortecimento viscoelástico \\
\hline$c_{i j k l}$ & tensor de rigidez elástica \\
\hline$\varepsilon_{i j}$ & tensor de permissividade elétrica \\
\hline$e_{k i j}$ & tensor piezelétrico \\
\hline$\Gamma_{i l}$ & tensor de Cristoffel \\
\hline$D$ & deslocamento elétrico \\
\hline$D$ & a deslocamento elétrico constante \\
\hline$E$ & campo elétrico \\
\hline$E$ & a campo elétrico constante \\
\hline$\varphi$ & potencial elétrico \\
\hline $\bar{c}_{z j k z}$ & tensor de rigidez elástica piezelétrica \\
\hline$\eta$ & inverso da velocidade de propagação \\
\hline$n$ & direção de propagação \\
\hline$n$ & número inteiro positivo \\
\hline $\bar{c}^{(n)}$ & conjunto de auto-valores \\
\hline$\beta^{(n)}$ & conjunto de auto-vetores \\
\hline$R$ & raio da partícula \\
\hline$\nu_{\text {in }}$ & amplitude de velocidade incidente \\
\hline$r$ & distância radial \\
\hline$F_{a}$ & força de radiação acústica \\
\hline$l$ & espessura \\
\hline$\alpha$ & coeficiente de absorção espacial \\
\hline$\alpha^{e}$ & fator de multiplicação de massa \\
\hline$\beta^{e}$ & fator de multiplicação de rigidez \\
\hline
\end{tabular}




$\begin{array}{ll}Y & \text { admitância elétrica } \\ Q & \text { carga elétrica } \\ \sigma_{f} & \text { densidade de carga elétrica } \\ \gamma & \text { condutividade elétrica } \\ \text { A } & \text { constante complexa de amplitude } \\ A & \text { área } \\ J & \text { raiz quadrada de }-1 \\ x & \text { coordenada cartesiana } x \\ y & \text { coordenada cartesiana } y \\ z & \text { coordenada cartesiana } z \\ \Pi & \text { vetor de Poynting } \\ P_{e l} & \text { potência elétrica } \\ \Re & \text { parte real } \\ \kappa & \text { fator de acoplamente eletromecânico }\end{array}$




\section{SUMÁRIO}

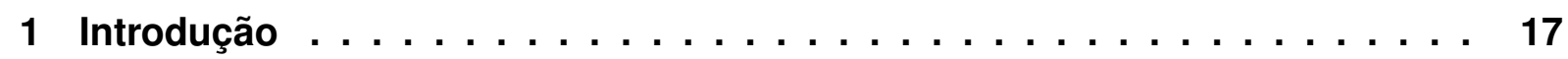

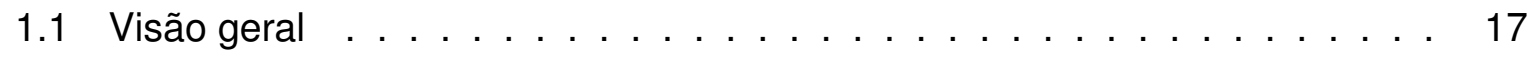

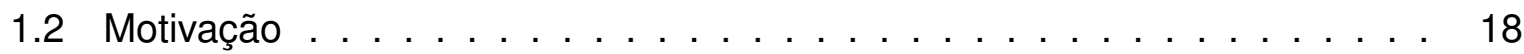

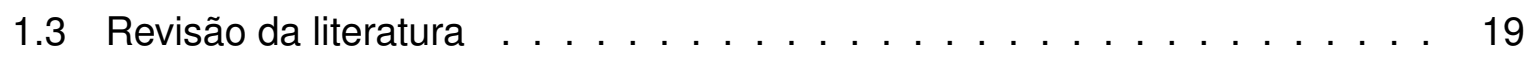

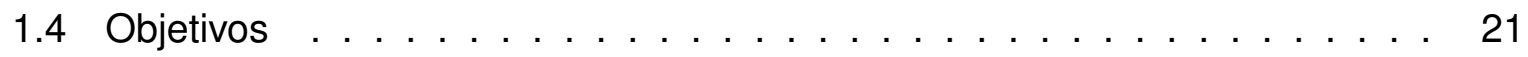

1.5 Metodologia . . . . . . . . . . . . . . . . . . . 21

1.6 Organização do texto . . . . . . . . . . . . . . . 23

2 Propagação de ondas acústicas . . . . . . . . . . . . . 24

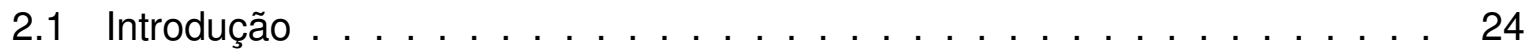

2.2 Teoria de ondas elásticas . . . . . . . . . . . . . . . . . . . . 24

2.2 .1 Ondas em fluidos . . . . . . . . . . . . . . . . . . . 25

2.2 .1 .1 Energia em fluidos . . . . . . . . . . . . . . 28

2.2 .1 .2 Intensidade em fluidos . . . . . . . . . . . . . . . . . . 29

2.2 .1 .3 Atenuação em fluidos . . . . . . . . . . . . . . . 30

2.2 .2 Ondas em sólidos . . . . . . . . . . . . . . . . . . . . . 30

2.2.2.1 Energia em sólido . . . . . . . . . . . . . . . 33

2.2 .3 Ondas em materiais piezelétricos . . . . . . . . . . . . 33

$2.2 .3 .1 \quad$ Energia em materiais piezelétricos . . . . . . . . . 36

2.3 Transmissão e reflexão . . . . . . . . . . . . . . . . . . . 37

2.4 Força de radiação acústica $\ldots \ldots \ldots \ldots$. . . . . . . . . . . . . . 39

3 Modelo unidimensional . . . . . . . . . . . . . . . . 41

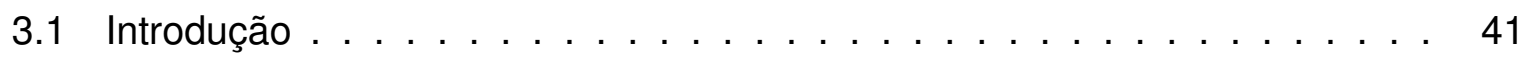

3.2 Matriz de transferência . . . . . . . . . . . . . . . . . . . . . . 41

3.2 .1 Matriz Piezelétrica . . . . . . . . . . . . . . . . . 41

3.2 .2 Matriz Não-Piezelétrical . . . . . . . . . . . . . . . . . . . . . . . 42

3.2 .3 Matriz dos eletrodos . . . . . . . . . . . . . . . . . 43

3.3 Multicamadas . . . . . . . . . . . . . . . . . . . . 45

3.3 .1 Ressonador multicamadas . . . . . . . . . . . . . . . . . 47

3.4 Modelo de perdas $\ldots \ldots \ldots \ldots \ldots \ldots \ldots$

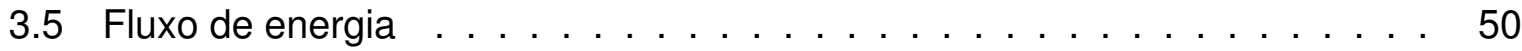

4 Modelo bidimensional. . . . . . . . . . . . . . . . . . 52

4.1 Introdução . . . . . . . . . . . . . . . . . . . . 52

4.2 Modos em câmaras retangulares $\ldots \ldots \ldots \ldots \ldots \ldots \ldots$

4.3 Método de Elementos Finitos. . . . . . . . . . . . . . . . . . . . . . 54 
4.3 .1 Princípio variacional $\ldots \ldots \ldots \ldots \ldots \ldots$

4.3 .2 Elementos finitos plano . . . . . . . . . . . . . . . 56

4.3 .3 Modelagem por elementos finitos . . . . . . . . . . . 58

5 Análise de geração de ondas $\ldots \ldots \ldots \ldots \ldots \ldots$

5.1 Introdução . . . . . . . . . . . . . . . . . . . . . . 59

5.2 Projeto unidimensional $\ldots \ldots \ldots \ldots \ldots$

5.2 .1 Análise da impedância elétrica . . . . . . . . . . . . . 60

5.2 .2 Análise do fluxo de energia . . . . . . . . . . . . . . . . 63

5.3 Projeto Bidimensional . . . . . . . . . . . . . . . . . . . . . . 65

5.3 .1 Modelagem analítica $\ldots \ldots \ldots \ldots \ldots \ldots$

5.3 .2 Modelagem por elementos finitos . . . . . . . . . . . . 67

5.4 Montagem dos protótipos $\ldots \ldots \ldots \ldots \ldots \ldots$

5.5 Comparação dos resultados $\ldots \ldots \ldots \ldots \ldots \ldots$

5.5 .1 Análise da impedância elétrica . . . . . . . . . . . . . 71

5.5 .2 Análise do potencial de radiação . . . . . . . . . . . . . 76

5.6 Discussão dos resultados $\ldots \ldots \ldots \ldots \ldots \ldots \ldots$

6 Aplicação das células $\ldots \ldots \ldots \ldots \ldots \ldots \ldots$

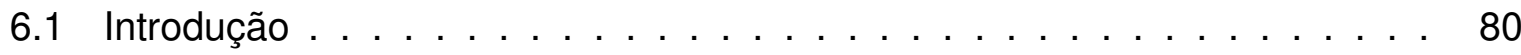

6.2 Síntese e análise de emulsões . . . . . . . . . . . . . . . . . . 80

6.2 .1 Análise de impedância elétrica . . . . . . . . . . . . . . . 80

6.2 .2 Análise do fluxo de energia. . . . . . . . . . . . . . . . . . 82

6.3 Ensaios de coalescência de emulsões . . . . . . . . . . . . . . . . 83

6.3 .1 Conceito de instrumentação . . . . . . . . . . . . . . 83

6.3 .2 Aparato experimentall . . . . . . . . . . . . . . . . . . . . 84

6.3 .3 Resultados do ensaios . . . . . . . . . . . . . . . . . . . . 85

6.4 Análise dos resultados $\ldots \ldots \ldots \ldots$. . . . . . . . . . . . . . 89

7 Conclusões e trabalhos futuros $\ldots \ldots \ldots \ldots \ldots \ldots$

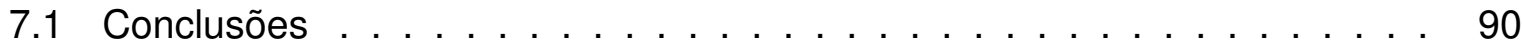

7.2 Trabalhos futuros $\ldots \ldots \ldots \ldots \ldots \ldots \ldots \ldots \ldots$

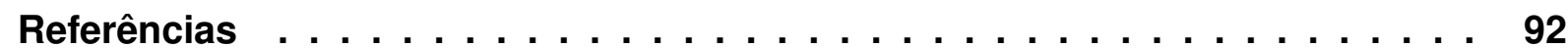

APÊNDICE A Características da emulsão de petróleo $\ldots \ldots \ldots \ldots$. . . . 97

A.1 Introdução . . . . . . . . . . . . . . . . . . . . . . 97

A.2 Técnica de transmissão recepção … . . . . . . . . . . . . . 97

A.3 Resultados . . . . . . . . . . . . . . . . . . . . . . . . . . . . 99

APÊNDICE B Sistema de controle de frequência . . . . . . . . . . . 101 
B.1 Introdução . . . . . . . . . . . . . . . . . . . . . . . . . . . . . . . . . . . 101

B.2 Implementação . . . . . . . . . . . . . . . . . . . . . . 101

B.3 Calibração . . . . . . . . . . . . . . . . . . . . . . . . . . . . . . 102

B.4 Exemplo de aplicação . . . . . . . . . . . . . . . . . . . . . . . . . 103

APÊNDICE C Síntese de emulsão . . . . . . . . . . . . . . . . . . . . . . 105

C.1 Introdução . . . . . . . . . . . . . . . . . . . . . . 105

C.1.1 Síntese . . . . . . . . . . . . . . . . . . . . 105

C.1.2 Procedimentos de análise . . . . . . . . . . . . . . . . 105

C.2 Otimização . . . . . . . . . . . . . . . . . . . . . . . . 106

C.2.1 Bright Stock . . . . . . . . . . . . . . . . . . . . . 106

C.2.2 Neutro Leve . . . . . . . . . . . . . . . . . . . . . . . . . . . 107

C.3 Resultados consolidados . . . . . . . . . . . . . . . . . . . . . . . . 107

C.3.1 Emulsão 1 - (óleo Bright Stock) . . . . . . . . . . . . . . . . . . . 108

C.3.2 Emulsão 2 - (óleo Bright Stock + óleo Neutro Leve). . . . . . . . . . . 110

C.3.3 Emulsão 3 - (óleo Bright Stock + óleo Neutro Leve). . . . . . . . . . . 113

C.4 Discussão e conclusão . . . . . . . . . . . . . . . . . . . . . . . . . . . 114

ANEXO A Propriedades dos materiais no MEF $\ldots \ldots$. . . . . . . . . . . . . 116 


\section{INTRODUÇÃO}

\subsection{VISÃO GERAL}

Emulsão é formada se dois líquidos imiscíveis são misturados e agitados em um recipiente e caracterizada por um conjunto de partículas líquidas, ou gotas, dispersas em uma outra fase líquida. Dois tipos de emulsão podem ser classificadas de acordo com o tipo de líquido que forma a fase contínua. Emulsões do tipo óleo em água ocorrem quando gotas de óleo são dispersas em água e água em óleo quando gotas de água são dispersas em óleo. Além disso, sistemas de emulsão podem ser distinguidas em função de sua estabilidade. Essa característica é avaliada em três processos diferentes: sedimentação, aglomeração e coalescência.

A sedimentação ocorre devido a diferença de densidade entre as duas fases líquidas. $\mathrm{Na}$ aglomeração, duas ou mais gotas se juntam sem que sejam alteradas suas áreas de superfície. Coalescência refere-se ao fenômeno que ocorre quando duas ou mais gotas se juntam formando uma maior com área de superfície reduzida. A aglomeração de gotas pode levar a coalescência e a formação de gotas maiores até que as fases sejam separadas.

As emulsões podem ser estáveis cineticamente apesar de serem instáveis termodinamicamente. A instabilidade termodinâmica se refere ao potencial de desestabilização, ou seja, é necessária a aplicação de algum tipo de energia para que haja formação de emulsões. A estabilidade cinética de uma emulsão depende de como as partículas dispersas interagem quando se encontram. Movimento Browniano, sedimentação e agitação são os fenômenos mais comuns que provocam o encontro dessas partículas. Dois tipos principais de forças afetam a interação entre particulas: de repulsão pelo fenômeno eletroestático e de atração através das forças de Van der Waals. Portanto, a estabilidade quanto a aglomeração é uma das características da cinética de emulsões. No entanto, uma vez que as partículas se juntam, esse sistema pode se manter estável em termos de coalescência. A estabilidade à coalescência envolve as propriedades mecânicas dos filmes interfaciais.

Os fatores que favorecem a estabilidade de emulsões são diversos. Dentre eles podem se destacar a baixa tensão interfacial, baixa fração volumétrica da fase dispersa, pequeno tamanho de gotas e alta viscosidade da fase contínua. A avaliação da estabilidade envolve a determinação da variação de alguma propriedade da emulsão no tempo, como aparência, tamanho de gota e fração em volume da fase dispersa.

A quebra de emulsão ou desemulsificação ocorre em duas etapas. As gotas devem primeiramente se aglomerar e, em seguida, coalescer para que dessa forma haja a separação das fases. A caracterização da emulsão deve ser feita para determinar quais efeitos devem ser uilizados para realizar a desemulsificação em termos mecânicos, químicos, térmicos entre outros. Um processo comum na indústria do petróleo é a desemulsificação da 
emulsão do tipo água em óleo. Alguns dos métodos utilizados são: decantação, aquecimento, desidratação eletrostática, tratamento químico, centrifugação e filtração.

Os métodos mecânicos, como centrifugação e filtração, tem por mecanismo principal o aumento da taxa de colisão das partículas e aplicação de forças que acelerem a coalescência. Através da aplicação de campos eletrostáticos, os métodos elétricos provocam o aumento da área superficial das gotas causando a quebra do filme interfacial. Altíssimas temperaturas causam desidratação devido à evaporação e a desemulsificação de algumas emulsões é obtida através de ciclos de aumento e diminuição de temperatura.

A técnica estudada neste trabalho utiliza a força de radiação acústica produzida por ondas estacionárias de ultrassom. A taxa de colisão entre gotas é aumentada devido ao arrasto provoca nas gotas para regiões de baixo potencial de radiação. A coalescência é intensificada devido à movimentação produzida pelo aumento da temperatura e à redução de viscoside do meio. Em geral, o aumento do contato entre as gotas aumenta a taxa de coalescência provocando a quebra de emulsão.

\subsection{MOTIVAÇÃO}

O petróleo bruto dificilmente é produzido livremente, na maioria dos casos é encontrado misturado com água, acarretando em diversos problemas de produção. Ao produzir água junto com o petróleo, tanto na forma livre como em emulsões, podem ocorrer falhas em equipamentos de separação gás-óleo, produção de petróleo fora da especificação e o aparecimento de gotas de alta pressão em linhas de fluxo (KOKAL, 2005). Por esses motivos, a água deve ser retirada do óleo após sua produção durante o processamento primário do petróleo (GARY; HANDWERK, 2001).

Emulsões de petróleo são formadas principalmente durante a fase de escoamento dos fluidos até a boca do poço, devido à ocorrência de uma intensa agitação entre eles. Além disso, essas emulsões podem ser geradas no reservatório antes mesmo da produção, por exemplo durante o processo de recuperação de petróleo (SCHRAMM, 1992). Dessa forma, a quantidade de água co-produzida pode variar por diversos motivos, sendo elas naturais ou induzidas.

Métodos térmicos, químicos, eletrostáticos e centrifugação são os mais utilizados atualmente para retirar a água co-produzida. De acordo com o teor de água e as propriedades do óleo, alguns desses métodos são utilizados de forma combinada promovendo maior eficiência de desemulsificação(FRISING et al., 2006). Os desemulsificantes químicos não são utilizados com excesso pois contaminam o óleo e seu custo é bastante alto no processo de separação. Os eletrocoalescedores possuem limites de operação ao serem utilizados em emulsões com alto teores de água devido a alta condutividade elétrica dessas emulsões (EOW; GHADIRI, 2002).

Portanto, métodos alternativos, como a desemulsificação assistida por ultrassom, es- 
tão sendo desenvolvidos com o objetivo de aumentar a eficiência do processamento. Por ser um método mecânico largamente utilizado em aplicações não intrusivas, essa técnica tem o potencial de minimizar o consumo de produtos químicos e ser aplicada em emulsões com alto teor de água. Os fenômenos acústicos que ocorrem durante a aplicação de ultrassom na coalescência de emulsões ainda são pouco estudados. Além disso, a técnica mais desenvolvida na indústria atualmente envolve a síntese de emulsões por ultrassom. Porém, dos poucos trabalhos publicados que apresentam resultados experimentais a maioria mostra o aumento de eficiência na separação de emulsões.

\subsection{REVISÃO DA LITERATURA}

A teoria acústica foi desenvolvida por Lord Rayleigh (RAYLEIGH, 1878) em seu primeiro livro, que tratava dos mais importantes avanços na área realizados por matemáticos e físicos. A descoberta do efeito piezelétrico direto foi feita pelos irmãos Jacques e Pierre Curie (CURIE; CURIE, 1880), evidenciando que, quando um cristal hemihedral não-condutor de faces inclinadas é comprimido, há a formação de pólos elétricos e carregados positivamente em um sentido e quando descomprimidos o efeito ocorre no sentido contrário gerando cargas negativas.

A primeira evidência da utilização de ondas elásticas controladas foi durante a Primeira Guerra Mundial (1915) por Paul Langevin, explorando o efeito piezelétrico e utilizando o fenômeno de reflexão de ondas para a detecção de icebergs e submarinos. O primeiro modelo de ressonadores piezelétricos foi desenvolvido baseado em um modelo elétrico de circuito equivalente (DYE, 1926). Desde então, a contribuição da eletrônica foi essencial para o desenvolvimento da acústica.

A partir de então, novos materiais piezelétricos tem sido desenvolvidos, bem como novas técnicas de transformação de energia elétrica em energia acústica tem sido exploradas. Esses materiais podem ser utilizados em diversas aplicações industriais, como estabilizadores de frequência de operação através do uso de cristais de quartzo e filtros passa-banda com ressonadores acoplados (ROYER; DIEULESAINT, 2000). Eles são largamente utilizados pois possuem estrutura atômica assimétrica narural, no entanto, diversas técnicas podem ser utilizados para gerar ondas elásticas tanto em meios fluidos como em meios sólidos.

Uma das técnicas que vem sendo constantemente desenvolvida em diversas aplicações é o uso da força de radiação acústica a partir de campos acústicos estacionários. Diversos trabalhos são encontrados na literatura incluindo verificações experimentais feitas com pequenas esferas de cortiça (RUDNICK, 1951), aprisionamento de pequenas gotas (CRUM, 1971), coalescências grandes gotas (GARDNER; APFEL, 1993), suspensão de material particulado (MANDRALIS et al., 1994), células biológicas (BENES et al., 2001), emulsões água em óleo (PANGU; FEKE, 2009) e suspensões de amido de milho em água 
(SILVA et al., 2012). A força ou pressão de radiação acústica é entendida como sendo a força produzida por ondas acústicas na presença de um objeto (BARMATZ; COLLAS, 1985). Esse fenômeno pode ser utilizado para separar e manipular partículas em meios líquidos que estão sujeitos a esses campos (WOODSIDE et al., 1998; TOLT; FEKE, 1993).

Essas aplicações necessitam da modelagem do potencial de radiação acústica gerados por campos acústicos. O modelo de Gorkov (1961) vem sendo utilizado em diversas aplicações, especialmente pelo fato dela ser válida em qualquer campo acústico para determinar o potencial acústico gerado por um campo acústico arbitrário em um fluido invíscido. A teoria de King (1934) e de Hasegawa e Yosioka (1969) são mais utilizadas para prever a força acústica para os casos de ondas progressivas em fluidos invíscidos (ANDRADE, 2010). Para o caso de fluido viscoso, a teoria de Doinikov (1994) prevê melhor as forças acústicas que atuam em ondas progressivas. As forças acústicas geradas por ondas estacionárias não dependem fortemente da viscosidade (HAAKE, 2004) e podem ser consideradas desprezíveis.

A aplicação dessas forças em câmaras acústicas contendo emulsões auxiliam na separação de uma das fases (PANGU; FEKE, 2004). Além da força de radiação acústica, as forças que atuam nas gotas podem ser devido à gravidade, empuxo, forças de Van der Waals ou interações hidrodinâmicas(ZHENG; APFEL, 1995). Essas forças são estudadas para modelar o transporte e a coalescência de gotas em emulsões sujeitas a campos acústicos estacionários (PANGU; FEKE, 2007). Porém, esse mesmo fenômeno pode ser investigado em aplicações onde há interesse na emulsificação de hidrocarbonetos em água (MARSTON; APFEL, 1979). As forças acústicas já foram utilizadas em um âmbito mais geral envolvendo linhas de pesquisa sobre manipulação de partículas sólidas (HAAKE, 2004).

Diversas técnicas vem sendo desenvolvidas para realizar a medição do teor de água em óleo (PAL, 1994). A determinação da frequência de coalescência de gotas também é estudada experimentalmente na indústria química (TOBIN et al., 1990). A desemulsificação é executada no processamento primário do petróleo (THOMAS, 2004) e há muito interesse na indústria do petróleo a separação da água contida em forma de emulsão no petróleo extraído. As gotas de água contidas no petróleo bruto são muito pequenas e estáveis, podendo conter partículas sólidas como o asfalteno que contribuem para a estabilização de suas emulsões (KUMAR et al., 2001). Por esse motivo, muitas vezes no processo de separação é necessária a utilização de métodos químicos e físicos, como desemulsificação por aditivos e centrifugação ou a combinação deles (EOW; GHADIRI, 2002).

Estudos foram conduzidos atualmente sobre a coalescência induzida em emulsões através da aplicação de campos eletrostáticos (BRESCIANI et al., 2010b; BRESCIANI et al., 2010a). No caso de campos acústicos estacionárias, um trabalho experimental foi desenvolvido para aprisionar gotas de óleo em água (ANDRADE et al., 2012). Dispositivos que utilizam câmaras de separação através da aplicação de campo acústico estacionário 
em canais de fluxo laminar de partículas para descarte de resíduos também são estudados na indústria química (GUPTA et al., 1995).

A coalescência de emulsões por ultrassom também vem sendo estudada quantitativamente de maneira a abranger os efeitos da aglomeração de gotas através força de radiação acústica (NII et al., 2009). Os resultados dessa técnica podem ser avaliados em termos de tempo de aplicação da irradiação do ultrassom, potência de entrada utilizada no sistema e quantificação da separação da emulsão através da análise cinética. Alguns métodos clássicos de medição da estabilidade de emulsões já estão bem estabelecidos (LISSANT, 1983), outros utilizam técnicas mais recentes como espectroscopia por ressonância magnética ou calorimetria exploratória diferencial (CAVALLO; CHANG, 1990) além de técnicas mais simples utilizando equipamentos ópticos (FRISING et al., 2006).

\subsection{OBJETIVOS}

Estudo da eficiência na desemulsificação de emulsões água em óleo mediante a aplicação de força de radiação acústica através da geração de ondas estacionárias de ultrassom em células piezelétricas. Os objetivos específicos são:

- Implementação de modelos computacionais de ondas acústicas para auxiliar no projeto de ressonadores piezelétricos;

- Projeto e aplicação de células de ultrassom para a coalescência de emulsões água em óleo através da força de radição acústica;

- Análise da eficiência da aplicação do ultrassom na desemulsificação de petróleos por meio de ensaios em batelada;

\subsection{METODOLOGIA}

Baseado na teoria de ondas elásticas são desenvolvidos modelos de simulação computacional utilizados para analisar a geração de ondas estacionárias de ultrassom no interior de câmaras ressonantes. Para isso, os modelos de propagação de ondas em fluidos, sólidos, materiais piezelétricos e da pressão de radiação acústica são estudados em um escopo geral.

Em seguida é desenvolvildo um modelo unidimensional baseado em matriz de transferência para simular o comportamento de um ressonador piezelétrico multicamada. A partir desse modelo, são estudados os parâmetros de impedância elétrica e de fluxo de energia para auxiliar no projeto do ressonador. Um modelo de perdas também é estudado para prever as características reais de um ressonador. É possível analisar o funcionamento do método de aplicação de ultrassom na coalescência de emulsões através do esquema mostrado na Figura (1). 
Figura 1 - Esquema da técnica de aplicação de ultrassom na coalescência de emulsões.

Aplicação

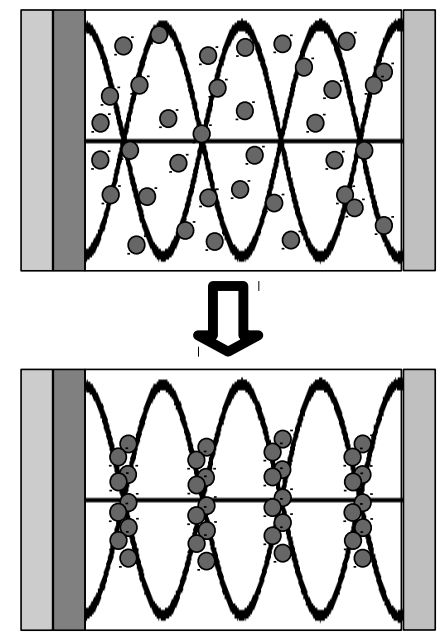

Aglomeração
Coalescência
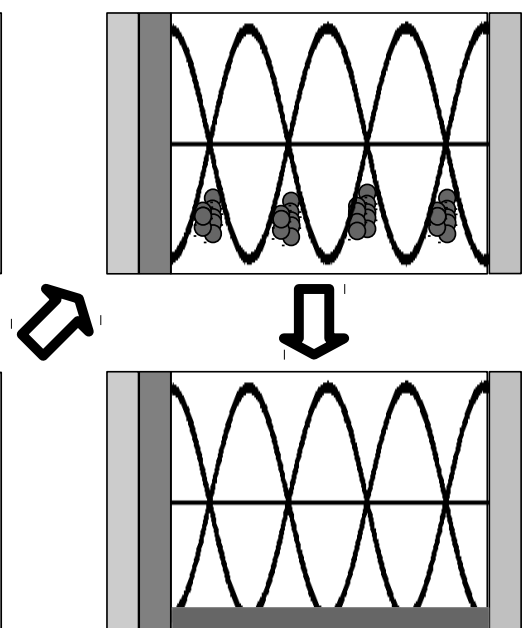

Separação

O potencial de radiação acústica é estudado segundo a formulação de Gor'kov através de modelos bidimensionais. É utilizado um modelo analítico para simular as características do potencial em um câmara retangular e outro modelo numérico baseado no Método dos elementos finitos (MEF) para simular o ressonador completo. Através da montagem de protótipos, cujo esquema é mostrado na Figura (2), verificações experimentais são realizadas e seus resultados são comparados com os resultados simulados.

Finalmente, é montado um aparato experimental para realizar os ensaios de aplicação de ultrassom em emulsões de água em petróleo através de um sistema com controle de operação e monitoramento da eficiência de separação. O procedimento utilizado no preparo das emulsões dos petróleos é baseado na metodologia empregada para a avaliação do desempenho de desemulsificantes em emulsões de petróleo.

Figura 2 - Esquema do protótipo da célula de separação.

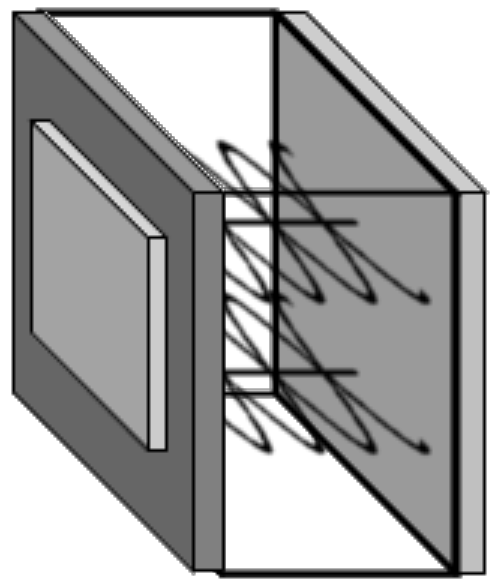




\subsection{ORGANIZAÇÃO DO TEXTO}

Esta dissertação está organizada em 7 capítulos. O Capítulo (2) apresenta a teoria de ondas elásticas e os modelos de propagação de ondas em fluidos, sólidos, materiais piezelétricos e da pressão de radiação acústica. O Capítulo (3) apresenta um modelo unidimensional baseado em matriz de transferência para simular o comportamento de um ressonador piezelétrico multicamada. São estudados os parâmetros de impedância elétrica, fluxo de energia e de perdas. O Capítulo (4) apresenta dois modelos bidimensionais, um analítico e outro numérico para simular o comportamento do potencial de radiação acúsitco em um câmara retangular. O Capítulo (5) apresenta uma análise da geração de ondas estacionárias através da montagem de protótipos e algumas verificações experimentais para comparar com os resultados simulados. O Capítulo (6) apresenta os ensaios de aplicação de ultrassom em emulsões de água em petróleo com uso de desemulsificantes. O Capítulo (7) apresenta as conclusões e as sugestões de trabalhos futuros. O Apêndice (A) apresenta o método por ultrassom utilizado para obter as propriedades do petróleo e da emulsão. O Apêndice (B) apresenta o sistema de controle utilizado para realizar os ensaios com emulsões. O Apêndice (C) apresenta o preparo de emulsões com óleos lubrificantes e um procedimento de ensaio utilzando um método alternativo de aplicação de ultrassom. O Anexo $(A)$ apresenta as propriedades dos materiais utilizados no modelo de elementos finitos. 


\section{PROPAGAÇÃO DE ONDAS ACÚSTICAS}

\subsection{INTRODUÇÃO}

Baseado na teoria de ondas elásticas são desenvolvidos modelos de propagação de ondas em diversos tipos de materiais. A teoria de ondas é apresentada em uma formulação geral em termos da mecânica do contínuo. Esses modelos dão suporte matemático para a elaboração de modelos simplificados para analisar o comportamento das câmaras de ondas estacionárias de ultrassom. Este capítulo trata das características de ondas acústicas descritas para meios fluidos e sólidos, e materiais piezelétricos. Algumas considerações são feitas sobre o fenômeno de transmissão, de reflexão, de atenuação e de força de radiação acústica.

\subsection{TEORIA DE ONDAS ELÁSTICAS}

O termo 'onda' refere-se ao transporte de uma perturbação espacial acompanhado por transferência de energia. Ondas progressivas transmitem energia de vibração a partir de uma condição de equilíbrio de maneira a se distanciar de sua fonte. Dessa forma, a descrição matemática de uma onda envolve parâmetros associados a velocidade, comprimento de onda e energia. Exemplos de ondas ocorrem em meios onde há matéria como em sólidos e fluidos, neste caso são chamadas de ondas mecânicas, ou em meios onde há campo elétrico e magnético, chamadas de ondas eletromagnéticas. A interpretação matemática do fenômeno de propagação de ondas é atribuída a uma formulação geral de onda, não importando o seu mecanismo ou a natureza do distúrbio. A equação que descreve o comportamento de uma onda envolve conceitos de amplitude, espaço e tempo.

Ondas propagantes podem sofrer interferências entre si. Quando duas ou mais ondas de mesma natureza incidem ao mesmo tempo em um posição singular, a onda resultante é dada pela sobreposição das ondas incidentes. Duas ondas de igual amplitude e frequência que viajam em direções opostas sofrem interferência construtiva e destrutiva em posições fixas. O fenômeno de onda estacionária ocorre como resultado dessa interferência na qual não há propagação líquida de energia média. Nesse caso, as posições onde ocorrem interferência destrutivas e construtivas são chamadas de nós e anti-nós, respectivamente. Um exemplo desse fenômeno encontra-se nas Figuras (1) e (2) que ilustram o princípio da técnica estudada.

Ao tratar de ondas elásticas, o termo 'elástico' restringe o escopo a ondas mecânicas, que se propagam em meios elásticos. Meio elástico é uma abstração da matéria no qual qualquer região a amplitude de deformação varia linearmente com a tensão aplicada. $\mathrm{Na}$ mecânica do contínuo, diversos materiais podem retornar ao seu formato original após a aplicação de pequenas tensões seguida da sua remoção. De forma geral, os materiais sólidos correspondem a um dos estados da matéria considerados meios elásticos para 
qualquer direção de tensão. Fluidos também são considerados meios elásticos porém somente para pressão hidrostática cuja amplitude é uniforme para todas as direções. No entanto, um fluido pode se deformar continuamente sob aplicação de tensão de cisalhamento.

Os termos 'elástico' e 'acústico' são utilizados indistintamente para ondas que ocorrem tanto em sólidos como em fluidos. Fluidos invíscidos possuem menor restrição a deformações do que os sólidos. As mudanças de pressão devido à expansão e compressão do fluido geram forças de restauração que são responsáveis pela propagação da onda. Os elementos do fluido se movem para frente e para trás na direção dessas forças, produzindo regiões adjacentes de compressão e rarefação como em uma onda mecânica longitudinal se propagando em uma barra. O tratamento matemático necessário para descrever a propagação de ondas acústicas em sólidos é mais complicado pois suas propriedades podem variar dependendo da direção considerada. Dessa forma, os materiais sólidos podem ser considerados materiais isotrópicos ou anisotrópicos.

Existem dois principais modos de onda que se propagam em um volume sólido, são chamadas de ondas longitudinais e de cisalhamento. Nas ondas longitudinais, o movimento das partículas no meio ocorrem na direção de propagação. Dessa forma, o meio se expande e contrai na mesma direção de aplicação da força. As ondas de cisalhamento são caracterizadas pelo movimento das partículas perpendicular à direção de propagação. Em geral, ocorre um movimento transversal e longitudinal combinado na propagação de ondas acústicas em meios sólidos. Porém, há casos nos quais uma direção de propagação resulta em uma onda com apenas um dos modos principais. Outros modos podem ocorrer próximos à superfície dos materiais sólidos, como por exemplo ondas Rayleigh e Lamb.

\subsubsection{Ondas em fluidos}

O movimento de compressão ou expansão do fluido pode ser explicado analisando a relação entre a velocidade de partícula e sua densidade instantânea (KINSLER, 2000). A equação da continuidade permite fazer essa análise a partir de um volume de controle fixo, ilustrado no diagrama da Figura (3). Nesse diagrama, pode-se analisar um fluido em movimento na direção $x$, com componente da velocidade de partícula $\nu_{x}$ e densidade instantânea, $\rho$. O princípio de conservação exige que o aumento na quantidade de massa presente dentro do volume de controle seja igual à quantidade de massa que passa pela sua superfície.

Considerando o fluido escoando em todas as direções e sendo $\vec{\nu}$ o vetor da velocidade de partícula, obtém-se a equação da continuidade com conservação de massa na forma linearizada. 
Figura 3 - Diagrama do volume de controle fixo mostrando a taxa de fluxo de massa.

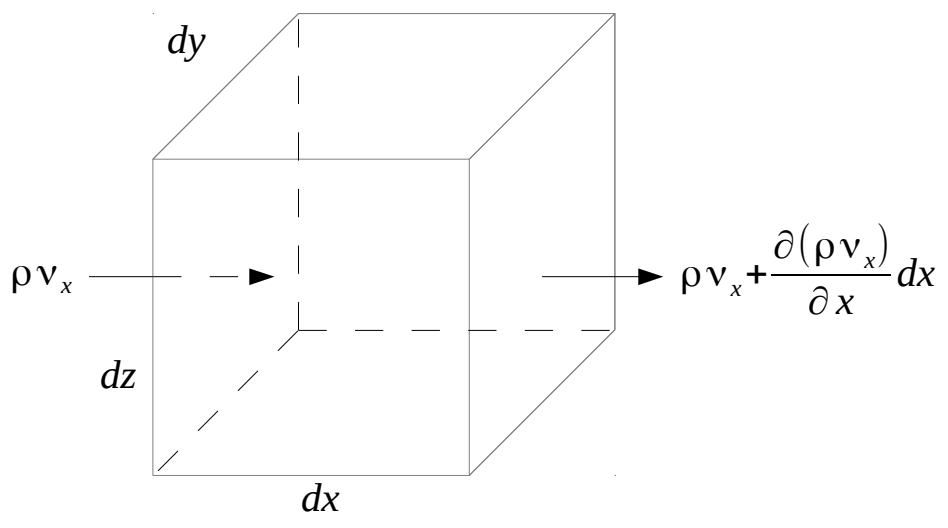

$$
\begin{gathered}
\frac{\partial s}{\partial t}+\nabla \cdot \vec{\nu}=0 \\
s=\left(\rho-\rho_{0}\right) / \rho_{0}
\end{gathered}
$$

sendo que a densidade característica do fluido, $\rho_{0}$ possui pequena variação com o tempo e a condensação, $s$, é definida como a variação relativa entre a densidade instantânea e característica.

Introduz-se um elemento que se move com o fluido e que acelera devido a uma flutuação na pressão estática. A partir da segunda lei de Newton obtém-se a equação de Euler para fluidos invíscidos e pequenas amplitudes na forma linearizada.

$$
\rho_{0} \frac{\partial \vec{\nu}}{\partial t}=-\nabla p
$$

onde $p$ denota a pressão do fluido. Substituindo a derivada no tempo da Equação (2.1) no divergente da Equação (2.3), obtem-se

$$
\begin{aligned}
\nabla^{2} p & =\frac{1}{c_{f}^{2}} \frac{\partial^{2} p}{\partial t^{2}} \\
c_{f} & =\sqrt{\mathfrak{B} / \rho_{0}}
\end{aligned}
$$

onde $c_{f}$ é a velocidade de propagação da onda acústica em fluidos, $\mathfrak{B}$ o módulo de elasticidade volumétrica. A solução da Equação (2.4) corresponde a onda linear sem perdas para propagação do som em fluidos. A solução dessa equação para uma onda plana harmônica propagando na direção $x$ é,

$$
\mathbf{p}=\mathbf{A} e^{j(\omega t-k x)}
$$


onde A é a constante complexa de amplitude definida pelas condições de contorno, $k$ é o número de onda na direção de propagação e $\omega$ é a frequência angular. A relação entre o número de onda e a frequência angular é dada por:

$$
k=\omega / c_{f}=2 \pi / \lambda
$$

onde $\lambda$ é o comprimento de onda na direção de propagação. Dessa mesma forma, para obter a solução da velocidade de partícula da onda plana deve-se resolver a Equação (2.3) de Euler substituindo $p$ pela solução da Equação (2.4):

$$
p=\rho_{0} c_{f} \nu
$$

ou

$$
\nu=\frac{\mathbf{A}}{\rho_{0} c_{f}} e^{j(\omega t-k x)}
$$

Essa solução introduz o conceito de superfície de fase constante Figura (4). Uma onda plana que se propaga em uma direção arbitrária do plano $x y$ pode ser entendida como frentes de onda com número de onda $\vec{k}=k \hat{n}$, onde $\hat{n}$ representa o vetor unitário na direção de propagação da onda. Nesse caso, a velocidade de partícula e a pressão acústica são comumente expressas em termos de uma função escalar,

$$
\begin{array}{r}
\vec{\nu}=\nabla \Phi \\
p=-\rho_{0} \frac{\partial \Phi}{\partial t}
\end{array}
$$

onde $\Phi$ é o potencial de velocidade. Dessa forma, a Equação 2.4 pode ser reescrita sob a forma da equação de Helmholtz.

$$
\nabla^{2} \Phi+k^{2} \Phi=0
$$

Figura 4 - Superfície de fase constante de um onda plana harmônica no plano $x y$.

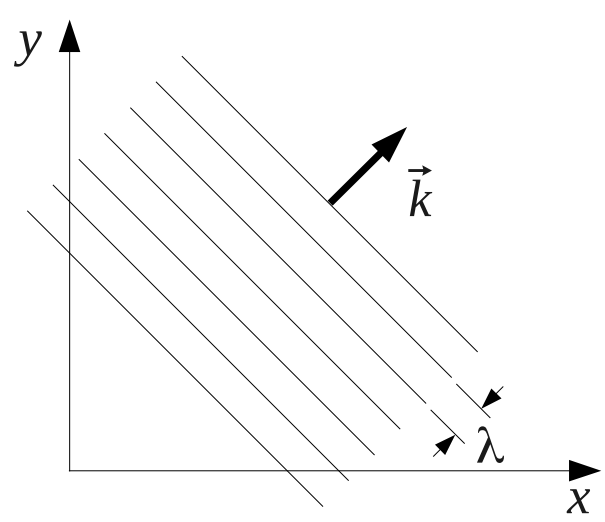




\subsubsection{Energia em fluidos}

A energia transportada por uma onda acústica através de um meio fluido encontra-se na forma de energia potencial e cinética. A variação de energia potencial do fluido, $E_{p f}$ em um elemento fluido devido a uma variação de volume, $V$, é definida por:

$$
E_{p f}=-\int_{V_{0}}^{V} p d V
$$

Essa equação expressa que a variação de volume devido a pressão acústica $p$ positiva realiza trabalho sobre o elemento. Pela conservação de massa temos que,

$$
d V=-(V / \rho) d \rho
$$

Ao considerar que existe uma relação linear entre a variação de pressão e densidade dada por $d p / d \rho=c_{f}^{2}$,

$$
d V=-\left(V / \rho c_{f}^{2}\right) d \rho
$$

Substituindo a Equação 2.15 na Equação 2.13 e integrando na pressão entre 0 e $p$, tem-se

$$
E_{p f}=\frac{p^{2}}{2 \rho_{0} c_{f}^{2}} V_{0}
$$

A densidade de energia potencial do fluido, $\mathcal{U}_{f}$, pode ser expressa pela média temporal da energia potencial dividido pelo volume do elemento $V_{0}$

$$
\mathcal{U}_{f}=\frac{\left\langle p^{2}\right\rangle}{2 \rho_{0} c_{f}^{2}}
$$

onde $\left\langle p^{2}>\right.$ representa a média quadrática da pressão. De forma análoga, a energia cinética, $E_{c}$ é dada por

$$
E_{c}=\int_{V_{0}} \frac{\rho_{0} \nu^{2}}{2} d V
$$

e a densidade de energia cinética, $\mathcal{T}$, por

$$
\mathcal{T}=\frac{\rho_{0}\left\langle\nu^{2}\right\rangle}{2}
$$

onde $\left\langle\nu^{2}\right\rangle$ representa a média quadrática da velocidade e pode ser calculada a partir da seguinte expressão:

$$
\left\langle\nu^{2}\right\rangle=\frac{1}{T} \int_{0}^{T}|\nu|^{2} d t
$$


A densidade de energia total em fluido, $\mathcal{E}_{f}$ pode ser definida como a soma da parcela potencial e cinética

$$
\mathcal{E}_{f}=\mathcal{T}+\mathcal{U}_{f}
$$

Para obter a densidade de energia total de uma onda harmônica plana propagando no plano $x y$, substitui-se a Equação (2.8) na Equação (2.21). Portanto, a densidade de energia total de uma onda plana pode ser expressa por

$$
\mathcal{E}_{f}=\rho_{0}\left\langle\nu^{2}\right\rangle=\left\langle p^{2}\right\rangle / \rho_{0} c_{f}^{2}
$$

Essa expressão de energia é válida para ondas progressivas planas ou também para ondas esféricas ou cilíndricas a uma distância de vários comprimentos de ondas da fonte (KINSLER, 2000).

\subsubsection{Intensidade em fluidos}

A intensidade acústica instantânea $I_{a}(t)\left[\mathrm{W} / \mathrm{m}^{2}\right]$ de uma onda acústica corresponde à taxa instantânea no qual um elemento fluido realiza trabalho em um elemento adjacente por unidade de área

$$
I_{a}(t)=p \nu
$$

A média temporal de $I_{a}(t)$ é definida como intensidade acústica média, $\left\langle I_{a}\right\rangle$. O elemento fluido considerado para uma onda plana possui superfície da secção transversal plana e a intensidade que o atravessa é dada por,

$$
\left\langle I_{a}\right\rangle=P^{2} / 2 \rho_{0} c_{f}
$$

onde $P$ é a amplitude de pressão acústica. A impedância acústica específica, $\mathbf{z}$ é definida como a razão entre a pressão acústica e a velocidade de partícula.

$$
\mathbf{z}=\mathbf{p} / \nu
$$

Para ondas planas essa razão é dada por

$$
\mathbf{z}=r=\rho_{0} c_{f}
$$

onde o produto $\rho_{0} c$ é considerado uma propriedade característica do meio, sendo chamado de impedância acústica característica. Dessa forma, a intensidade de uma onda progressiva plana harmônica pode ser reescrita como

$$
\left\langle I_{a}\right\rangle=P^{2} / 2 r
$$




\subsubsection{Atenuação em fluidos}

A energia acústica transportada pela onda é, em última análise, convertida em energia térmica. Nas situações em que as ondas acústicas se propagam em meios finitos essa conversão pode ser considerada em termos de perdas de energia acústica. Essa dissipação ocorre através de diversos mecanismos de atenuaçã, principalmente por absorção ou espalhamento. Quando há pouca dissipação, é comum analisar cada mecanismo separadamente e considerar a absorção total como sendo a somatória da contribuição de todos os mecanismos.

Como os mecanismos de absorção dependem da frequência, postula-se uma equação dinâmica através de uma velocidade do som complexa $\mathbf{c}_{f}$. O modelo clássico que quantifica essas perdas associa a absorção a um coeficiente de absorção clássico $\alpha$ que pode ser incluído na Equação (2.12).

$$
\nabla^{2} \mathbf{p}+\mathbf{k}^{2} \mathbf{p}=0
$$

onde $\mathrm{k}$ é o número de onda complexo. Define-se $\mathrm{k}$ como tendo uma parte real $k \mathrm{e}$ uma parte imaginária $\alpha$ (KINSLER, 2000). Dessa forma, obtém-se que

$$
\mathbf{k}=k-\jmath \alpha
$$

onde $\alpha$ representa o coeficiente de absorção espacial. A solução da Equação (2.28) para uma onda plana propagando na direção $x$ pode ser expressa da seguinte forma

$$
\mathbf{p}=P \exp ^{-\alpha x} \exp ^{\jmath(\omega t-k x)}
$$

A partir da Equação (2.30, conclui-se que a amplitude decai em função de um fator $\exp ^{-\alpha x}$ que depende da distância percorrida pela onda.

\subsubsection{Ondas em sólidos}

O modelo de propagação de ondas acústicas em sólidos é geralmente mais complexo do que em fluidos. No entanto, primeiramente será definido a equação de onda para a propagação acústica apenas para o caso longitudinal. A solução das equações para este caso possuem a mesmo formato da solução para o caso de propagação de cisalhamento.

Figura 5 - Elemento elástico unidimensional e suas tensões internas em cada face.

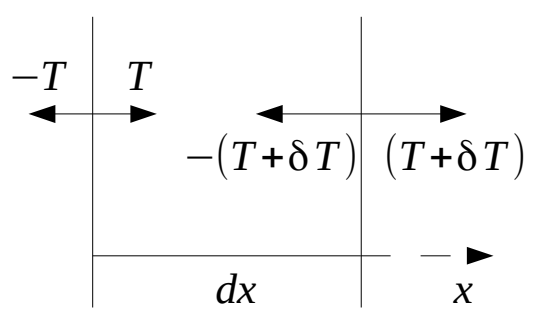


Figura 6 - Orientação das tensôes em um elemento de volume infinitesimal.

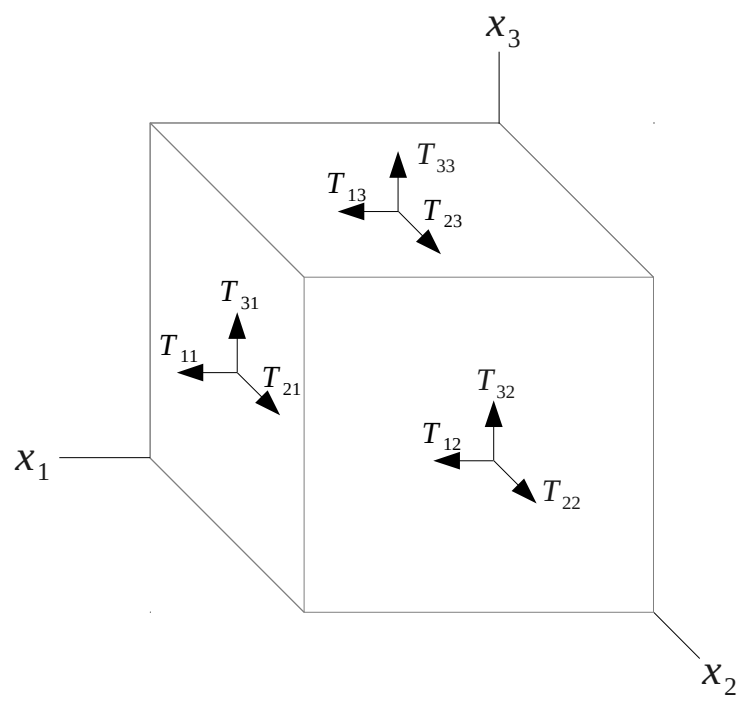

A força por unidade de área aplicada em um sólido é chamado de tensão, $T$ (IEEE, 1996; KINSLER, 2000). Determina-se um elemento elástico unidimensional no qual se define tensões internas na direção $x$. De acordo com a Figura (5), a diferença entre as tensões externas aplicadas em cada lado do elemento é $d x(\delta T / \delta x)$ (KINO, 1987). Portanto, a força aplicada $\delta T / \delta x$, promove um movimento relativo ao centro de massa do elemento.

Apesar de que forças aplicadas em um corpo sólido geram tensões e deformações, tensão não causa necessariamente deformação e vice-versa (ROSENBAUM, 1988). Além disso, tensão e deformação estão relacionadas a partir da Lei de Hooke, que estabelece que para uma tensão suficientemente pequena a quantidade de deformação é proporcional a magnitude da tensão aplicada (NYE, 1985). Para o caso de deformação longitudinal, a tensão é definida como

$$
T=c S
$$

onde $S$ é a deformação definida por $\delta u / \delta x$ e $c$ é a constante elástica do material. Para o caso em que o material é homogêneo, esse mesmo conceito pode ser expandido para todas as direções de propagação, sem perder generalidade.

No caso mais geral, a tensão, deformação e a constante elástica podem ser expressas em termos de tensores (JEFFREYS, 1931). Ao considerar um elemento de volume no sólido ilustrado na Figura (6), os parâmetros $T_{11}, T_{22}$ e $T_{33}$ são componente normais da tensão e os outros termos $T_{12}, T_{21}, T_{13}, T_{31}, T_{23}$ e $T_{32}$ são componentes de cisalhamento.

Considerando um corpo em equilíbrio estático, esse elemento não pode estar em movimento de rotação ou translação. Portanto, as componentes normais e de cisalhamento das tensões em todas as faces não geram momento. Dessa forma, considerando qualquer 
plano $i j$, temos que

$$
T_{i j}=T_{j i}
$$

Além disso, define-se como tensor de deformação como sendo o gradiente do deslocamento $u$, com componentes de deslocamento $u_{i}$ e $u_{j}$ :

$$
S_{i j}=\frac{1}{2}\left(\delta u_{i} / \delta x_{j}+\delta u_{j} / \delta x_{i}\right)
$$

Da mesma forma que na Equação (2.32), o tensor de deformação também é simétrico

$$
S_{i j}=S_{j i}
$$

e a Equação 2.31) pode ser escrita na forma da lei de Hooke generalizada (HODGE, 1970).

$$
T_{i j}=c_{i j k l} S_{k l}
$$

Repetindo a mesma consideração de simetria para o tensor de rigidez elástico,

$$
c_{i j k l}=c_{k l i j}
$$

conclui-se que o tensor de rigidez elástica possui apenas 21 componentes independentes que caracterizam as propriedades de um material sólido anisotrópico.

A equação de onda acústica que se propaga em um sólido anisotrópico pode ser descrita pela equação de movimento a partir da segunda lei de Newton (MORSE, 1981), que é dada por :

$$
\rho \frac{\partial^{2} u_{i}}{\partial t^{2}}=\frac{\partial T_{i j}}{\partial x_{j}}
$$

Substituindo a Equação (2.35) na Equação (2.37), chega-se na equação de onda:

$$
\rho \frac{\partial^{2} u_{i}}{\partial t^{2}}=c_{i j k l} \frac{\partial^{2} u_{l}}{\partial x_{j} \partial x_{k}}
$$

que possui o mesmo formato da Equação (2.4) para fluidos. A solução análoga para a Equação 2.38 sugere a introdução do tensor de Christoffel $\Gamma_{i l}$,

$$
\Gamma_{i l}=c_{i j k l} n_{j} n_{k}
$$

onde, a constante $n_{j}$ e $n_{k}$ são vetores unitários com o mesmo sentido de propagação da onda plana, ou co-seno diretor. A partir desse tensor para uma dada direção, a Equação 2.38 toma a forma de um problema de autovalor e autovetor.

$$
\left|\Gamma_{i l}-\rho c_{s}^{2} \delta_{i l}\right|=0
$$


Portanto, o autovalor e autovetor do tensor de Christoffel determinam a velocidade de propagação da onda em sólidos, $c_{s}$, e a direção de polarização de ondas se propagando na direção $n$ em um cristal de rigidez $c_{i j k l}$.

\subsubsection{Energia em sólido}

A energia total armazenada por unidade de volume em um meio sólido, $\mathcal{E}_{s}$ é dada pela soma de duas componentes: $\mathcal{U}_{e}$ a densidade de energia potencial elástica e $\mathcal{T}$ a densidade de energia cinética.

$$
\mathcal{E}_{s}=\mathcal{T}+\mathcal{U}_{e}
$$

A energia elástica é calculada a partir da tensão aplicada e a deformação sofrida pelo material e pode ser definida como:

$$
\mathcal{U}_{e}=\frac{\langle T S\rangle}{2}
$$

Substituindo as Equações (2.19) e 2.42), a Equação 2.41) pode ser reescrita na forma:

$$
\mathcal{E}_{s}=\frac{1}{2}\left(\rho_{0}\left\langle\nu^{2}\right\rangle+\langle T S\rangle\right)
$$

\subsubsection{Ondas em materiais piezelétricos}

Através teoria linear da piezeletricidade é possível obter as equações constitutivas que relacionam tensão, $T$, e deslocamento elétrico, $D$, com a deformação, $S$, e o campo elétrico, $E$ em um material piezelétrico (TIERSTEN, 1969).

$$
\begin{aligned}
T_{i j} & =c_{i j k l}^{E} S_{k l}-e_{k i j} E_{k} \\
D_{i} & =e_{i k l} S_{k l}+\varepsilon_{i j}^{S} E_{k}
\end{aligned}
$$

onde $e_{k i j}$ denota o tensor piezelétrico, $c_{i j k l}^{E}$ o tensor de rigidez a campo elétrico constante e $\varepsilon_{i j}^{S}$ o tensor de permissividade elétrica a deformação constante. O sobrescrito ${ }^{S}$ denota a deformação constante e o sobrescrito ${ }^{E}$ denota a campo elétrico constante. Além disso, considerando que o campo elétrico seja definido como sendo a derivada do potencial elétrico

$$
E_{i}=-\frac{\partial \varphi}{\partial x_{i}}
$$

e que o deslocamento elétrico, $D$ satisfaz à equação eletrostática para um material dielétrico

$$
\frac{\partial D_{i}}{\partial x_{i}}=0
$$


A partir das Equações (2.33), 2.37), e das Equações 2.44 a (2.47), são extraídas as quatro equações diferenciais (IEEE, 1996; TIERSTEN, 1963),

$$
\begin{aligned}
c_{i j k l} \frac{\partial^{2} u_{k}}{\partial_{i} \partial_{j}}+e_{m l j} \frac{\partial^{2} \varphi}{\partial_{m} \partial_{l}} & =\rho \frac{\partial^{2} u_{j}}{\partial t^{2}}(j=1,2,3) \\
e_{l n k} \frac{\partial^{2} u_{k}}{\partial_{l} \partial_{n}}-\varepsilon_{r s} \frac{\partial^{2} \varphi}{\partial_{r} \partial_{s}} & =0
\end{aligned}
$$

Para o problema unidimensional, a dependência espacial pode ser considerada apenas na direção $z$, de acordo com a Figura (7) e, dessa forma, as equações são simplificadas

Figura 7 - Sistema de coordenadas escolhido para o problema unidimensional.

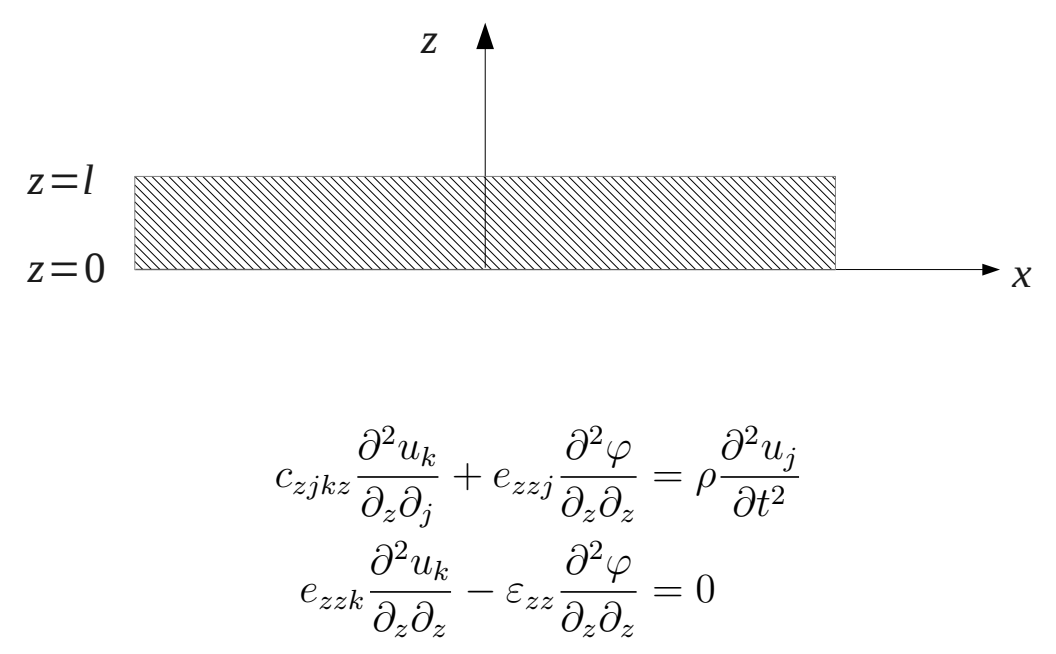

onde $z$ representa o único índice a ser considerado na somatória. Introduzindo duas constantes arbitrárias $\phi_{1}$ e $\phi_{0}$, a Equação (2.51) possui uma solução geral para $\varphi$ :

$$
\varphi=\left(e_{z z k} / \varepsilon_{z z}\right) u_{k}+\phi_{1} z+\phi_{0}
$$

Substituindo a Equação (2.52 na Equação 2.50, obtém-se a seguinte equação para o vetor de deslocamento $u$ :

$$
\left(c_{z j k z}+e_{z z j} e_{z z k} / \varepsilon_{z z}\right) \frac{\partial^{2} u_{k}}{\partial_{i} \partial_{l}}=\rho \frac{\partial^{2} u_{j}}{\partial t^{2}}
$$

Define-se o tensor de rigidez elástica piezelétrica (IEEE, 1996; TIERSTEN, 1963),

$$
\bar{c}_{z j k z}=c_{z j k z}+e_{z z j} e_{z z k} / \varepsilon_{z z}
$$

Para obter a solução geral em regime estacionário da Equação (2.53, supõe-se que

$$
u_{k}(z, t)=u_{k}(z) e^{-j \omega t}
$$

onde

$$
u_{k}(z)=\sum_{n} \beta_{k}^{(n)}\left(A^{(n)} \cos \eta^{(n)} \omega z+B^{(n)} \sin \eta^{(n)} \omega z\right)
$$


onde introduz-se uma constante $\eta^{(n)}$, como sendo o inverso da velocidade de propagação ,

$$
\eta^{(n)}=\sqrt{\rho / \bar{c}^{(n)}}
$$

e $n$ representa cada uma das direções de propagação (uma longitudinal e duas transversais). A diferença entre o número de onda $k$ e a constante $\eta$ está na sua dependência com a velocidade angular $\omega$ e, portanto, $\eta$ não depende da frequência da onda. Nas Equações 2.56 e 2.57, utiliza-se um conjunto de auto-valores $\bar{c}^{(n)}$ e os correspondentes auto-vetores $\beta^{(n)}$. Esse conjunto de auto-valores e auto-vetores é obtido substituindo a constante $\bar{c}_{z j k z}$ da Equação (2.54) na Equação (2.40) de Cristoffel (NOWOTNY; BENES, 1987).

Essa solução geral para $u$ possui seis constantes de integração $A^{(n)}$ e $B^{(n)}(n=1,2,3)$. Juntamente com mais duas constantes, $\phi_{1}$ e $\phi_{0}$, da Equação (2.52) totaliza oito constantes para $\varphi$, que devem ser determinadas das condições de contorno.

Ao introduzir as componentes de tensão $T_{z j}$ e de deslocamento elétrico $D_{z}$ para a direção considerada $z$ e as condições de contorno no plano $z=0$ como sendo os valores $u_{k}(0), T_{z l}(0), \varphi(0)$ e $D_{z}(0)$ é possível calcular as oito constantes de integração da solução geral para as equações diferenciais da Equação (2.45). Para esse propósito, utiliza-se além das Equações 2.52) e 2.56, a Equação 2.44

$$
\begin{aligned}
T_{z j}= & \sum_{n} \beta_{j}^{(n)} \bar{c}^{(n)} \eta^{(n)} \omega\left(-A^{(n)} \sin \eta^{(n)} \omega z\right. \\
& \left.+B^{(n)} \cos \eta^{(n)} \omega z\right)+e_{z z j} \phi_{1} \\
D_{z}= & -\varepsilon_{z z} \phi_{1}
\end{aligned}
$$

Ao resolver as quatro equações lineares, as Equações (2.52), (2.56), (2.58) e (2.59), obtem-se as quatro constantes de integração $A^{(n)}, B^{(n)}, \phi_{0}$ e $\phi_{1}$

$$
\begin{aligned}
A^{(n)} & =\beta_{k}^{(n)} u_{k}(0) \\
B^{(n)} & =\frac{1}{\bar{c}^{(n)} \eta^{(n)} \omega} \beta_{j}^{(n)}\left(T_{z j}(0)+\frac{e_{z z j}}{\varepsilon_{z z}} D_{z}(0)\right) \\
\phi_{0} & =\varphi(0)-\left(e_{z z k} / \varepsilon_{z z}\right) u_{k}(0) \\
\phi_{1} & =-\left(1 / \varepsilon_{z z}\right) D_{z}(0)
\end{aligned}
$$

As constantes de integração da Equação (2.60) são substituídas nas Equações (2.52), (2.56), 2.58) e (2.59) e obtem-se uma solução para a Equação (2.44). Dessa forma, as equações lineares originais pode ser reescritas da seguinte forma. 


$$
\begin{aligned}
u_{k}= & \left(\sum_{n} \beta_{k}^{(n)} \beta_{k}^{(n)} \cos \eta^{(n)} \omega z\right) u_{k}(0)+\left(\sum_{n} \beta_{k}^{(n)} \beta_{j}^{(n)} \frac{\eta^{(n)}}{\rho \omega} \sin \eta^{(n)} \omega z\right) T_{z j}(0) \\
& +\left(\frac{e_{z z j}}{\varepsilon_{z z}} \sum_{n} \beta_{k}^{(n)} \beta_{j}^{(n)} \frac{\eta^{(n)}}{\rho \omega} \sin \eta^{(n)} \omega z\right) D_{z}(0) \\
T_{z j}= & \left(-\sum_{n} \beta_{j}^{(n)} \beta_{k}^{(n)} \frac{\rho \omega}{\eta^{(n)}} \sin \eta^{(n)} \omega z\right) u_{k}(0)+\left(\sum_{n} \beta_{j}^{(n)} \beta_{j}^{(n)} \cos \eta^{(n)} \omega z\right) T_{z j}(0) \\
& +\left(\frac{e_{z z j}}{\varepsilon_{z z}} \sum_{n} \beta_{j}^{(n)} \beta_{k}^{(n)}\left(\cos \eta^{(n)} \omega z-1\right)\right) D_{z}(0) \\
\varphi= & \left.\frac{e_{z z j}}{\varepsilon_{z z}} \sum_{n} \beta_{k}^{(n)} \beta_{k}^{(n)}\left(\cos \eta^{(n)} \omega z-1\right)\right) u_{k}(0) \\
& +\left(\frac{e_{z z j}}{\varepsilon_{z z}} \sum_{n} \beta_{k}^{(n)} \beta_{j}^{(n)} \frac{\eta^{(n)}}{\rho \omega} \sin \eta^{(n)} \omega z\right) T_{z j}(0) \\
& +\varphi(0)+\left(\frac{e_{z z j}}{\varepsilon_{z z}} \sum_{n} \beta_{k}^{(n)} \beta_{j}^{(n)} \frac{\eta^{(n)}}{\rho \omega} \sin \eta^{(n)} \omega z-\frac{z}{\varepsilon_{z z}}\right) D_{z}(0) \\
D_{z}= & D_{z}(0)
\end{aligned}
$$

\subsubsection{Energia em materiais piezelétricos}

A energia potencial total armazenada por unidade de volume em um meio sólido piezelétrico é dada pela soma de duas componentes: $\mathcal{U}_{e}$ referente ao potencial elástico e $\mathcal{U}_{l}$ ao potencial elétrico.

$$
\mathcal{U}_{p}=\mathcal{U}_{e}+\mathcal{U}_{l}
$$

onde $\mathcal{U}_{e}$ é definida pela a Equação (2.42). A densidade de energia potencial elétrica possui contribuição tanto do campo elétrico quanto do deslocamento elétrico e pode ser definia como:

$$
\mathcal{U}_{l}=\frac{\langle E D\rangle}{2}
$$

Substituindo as Equações (2.42) e (2.66), a Equação (2.65) pode ser reescrita na forma:

$$
\mathcal{U}_{p}=\frac{1}{2}(\langle T S\rangle+\langle E D\rangle)
$$

Finalmente, a densidade de energia total em um sólido piezelétrico é dada por:

$$
\mathcal{E}_{p}=\frac{1}{2}\left(\rho_{0}\left\langle\nu^{2}\right\rangle+\langle T S\rangle+\langle E D\rangle\right)
$$




\subsection{TRANSMISSÃO E REFLEXÃO}

Se um meio apresenta uma interface separando-o de um segundo meio, a onda acústica que se propaga entre esses meios sofre reflexão e transmissão, conforme mostra a Figura (8). A relação entres a amplitudes de pressão e suas intensidades das ondas refletidas e transmitidas está ligada às características acústicas como impedância acústica característica, velocidade do som nos dois meios e ao ângulo entre a direção da onda incidente e a direção normal à interface. Pode-se definir o coeficiente de transmissão, $\mathbf{T}_{A}$, e reflexão, $\mathbf{R}_{A}$, de pressão como sendo a razão entre a amplitude de pressão complexa da onda transmitida e refletida respectivamente e da onda incidente.

$$
\begin{aligned}
\mathbf{T}_{A} & =\mathbf{P}_{t} / \mathbf{P}_{i} \\
\mathbf{R}_{A} & =\mathbf{P}_{r} / \mathbf{P}_{i}
\end{aligned}
$$

onde $\mathbf{P}_{i}$ é amplitude de pressão complexa da onda incidente, $\mathbf{P}_{r}$ é amplitude de pressão complexa da onda refletida, $\mathbf{P}_{t}$ é amplitude de pressão complexa da onda transmitida. Esses coeficientes são facilmente calculados para uma situação em que há uma onda plana de incidência normal em uma interface plana entre dois fluidos de impedâncias característica diferentes.

$$
\begin{aligned}
\mathbf{T}_{A} & =\frac{2 r_{2} / r_{1}}{r_{2} / r_{1}+1} \\
\mathbf{R}_{A} & =\frac{r_{2} / r_{1}-1}{r_{2} / r_{1}+1}
\end{aligned}
$$

Considerando a Equação (2.27), define-se os coeficientes de transmissão e reflexão de intensidade como

Figura 8 - Reflexão e transmissão de uma onda plana de incidência normal em uma interface plana entre dois fluidos de impedâncias característica diferentes.

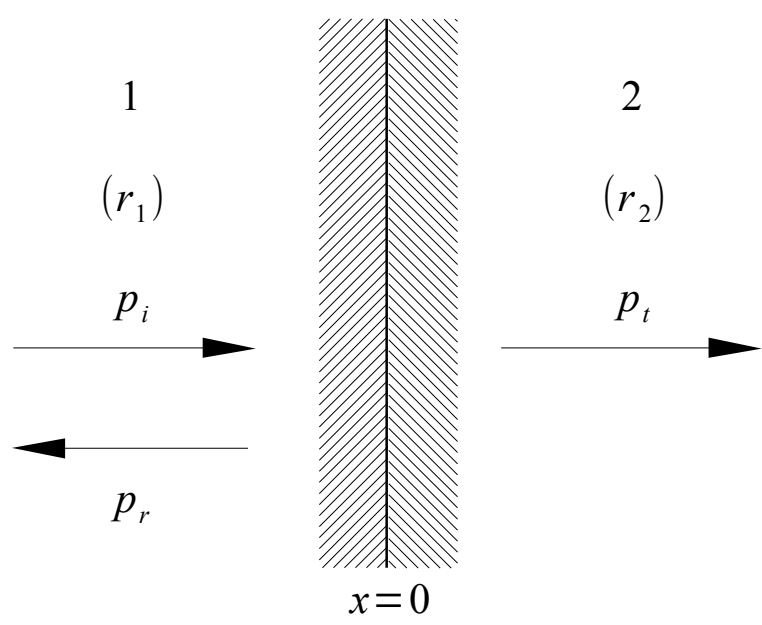




$$
\begin{aligned}
& T_{I}=I_{t} / I_{i}=\left(r_{1} / r_{2}\right)\left|\mathbf{T}_{A}\right|^{2} \\
& R_{I}=R_{t} / R_{i}=\left|\mathbf{R}_{A}\right|^{2}
\end{aligned}
$$

onde $r_{1}$ e $r_{2}$ são as impedâncias característica dos meios 1 e 2 respectivamente. Ao substituir as Equações (2.71) e (2.72) nas Equações (2.73) e (2.74), pode-se reescrever as seguintes relações:

$$
\begin{aligned}
T_{I} & =\frac{4 r_{2} / r_{1}}{\left(r_{2} / r_{1}+1\right)^{2}} \\
R_{I} & =\frac{\left(r_{2} / r_{1}-1\right)^{2}}{\left(r_{2} / r_{1}+1\right)^{2}}
\end{aligned}
$$

Considerando uma camada de fluido de espessura $l$ entre dois outros meios fluidos distintos conforme ilustra a Figura (9), é possível extrair uma expressão para $T_{I}$ entre os dois meios.

$$
T_{I}=\frac{4}{2+\left(r_{3} / r_{1}+\left(r_{1} / r_{3}\right) \cos ^{2} k_{2} l+\left(r_{2}^{2} / r_{1} r_{3}+r_{1} r_{3} / r_{2}^{2}\right) \sin ^{2} k_{2} l\right.}
$$

Para o caso especial em que $k_{2} l \approx\left(n-\frac{1}{2}\right) \pi$, onde $n$ assume qualquer número inteiro positivo, então tem-se que $l \approx(2 n-1) \lambda_{2} / 4 \mathrm{e}$, portanto, $\cos k_{2} l \approx 0$ e $\sin k_{2} l \approx 1$, e Equação 2.77) se torna

$$
T_{I}=\frac{4 r_{1} r_{3}}{\left(r_{2}+r_{1} r_{3} / r_{2}\right)^{2}}
$$

para frequências muito próximas de $f=\left(n-\frac{1}{2}\right) c_{f 2} / 2 l$ a Equação 2.78 assume o valor $T_{I} \approx 1$ quando $r_{2}=\sqrt{r_{1} r_{3}}$. Dessa forma, é possível obter transmissão total da

Figura 9 - Reflexão e transmissão de uma onda plana de incidência normal em uma interface de espessura uniforme.

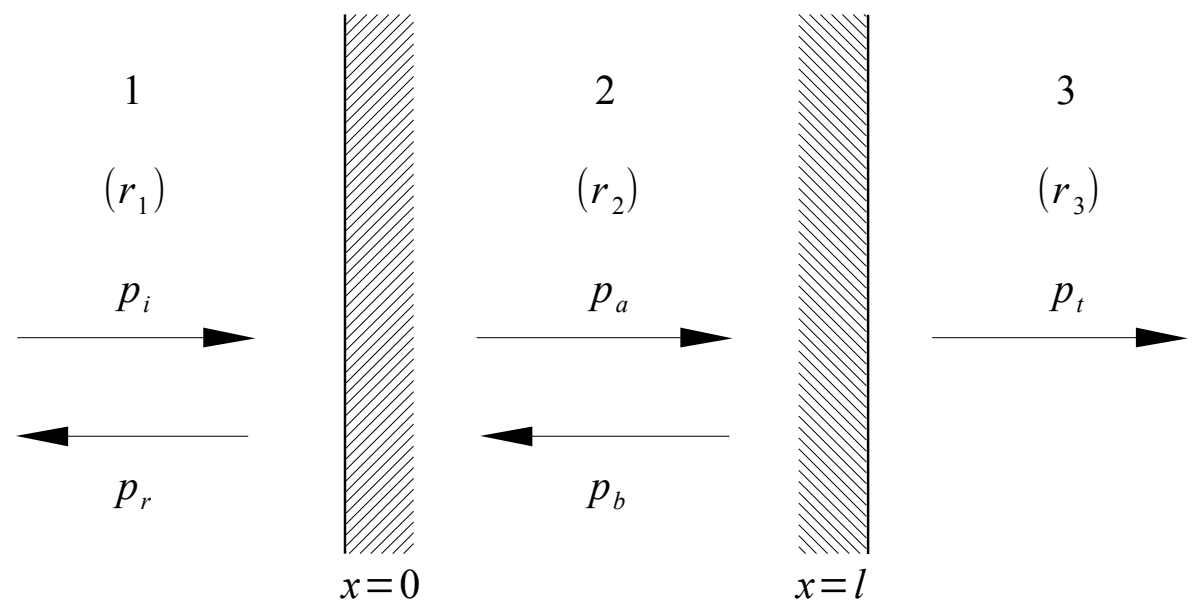


potência acústica de um meio para o outro através de uma camada intermediária cuja impedância característica é a média geométrica das impedâncias dos outros dois meios.

\subsection{FORÇA DE RADIAÇÃO ACÚSTICA}

Os modelos que calculam a pressão de radiação acústica são comumente validados através de modelos experimentais (RUDNICK, 1977). Dado um fluido ideal, é possível obter expressões para o potencial e força acústica aplicada em uma pequena partícula esférica devido a presença de um campo acústico arbitrário (BARMATZ; COLLAS, 1985), tanto progressivo como estacionário. O potencial de velocidade $\Phi$ de um campo acústico pode ser representado através de uma aproximação linear como sendo a soma de um termo incidente, $\Phi_{i n}$, e outro de espalhamento, $\Phi_{s c}$ devido a uma partícula espalhadora,

$$
\Phi=\Phi_{i n}+\Phi_{s c}
$$

O termo referente ao espalhamento pode ser determinado através da solução de um problema de fluxo de fluido incompressível em torno de uma partícula de raio $R<<\lambda$ (LANDAU; LIFSHITS, 1959). O potencial de velocidade da onda espalhada por uma esfera de raio $R$ pode ser definido como

$$
\Phi_{s c}=-\frac{R^{3}}{3 \rho_{s} r} p_{i n} f_{1}-\frac{R^{3}}{2} f_{2} \nabla\left(\nu_{i n} \frac{1}{r}\right)
$$

onde $\rho_{s}$ é a densidade da esfera, $\nu_{i n}$ é a amplitude de velocidade incidente e $r$ é a distância radial entre o centro da esfera e a região do potencial. Os fatores $f_{1}$ e $f_{2}$ são dados por

$$
f_{1}=1-c_{f}^{2} \rho_{f} / \rho_{s} c_{s}^{2}, \quad f_{2}=2\left(\rho_{s}-\rho_{f}\right) /\left(2 \rho_{s}+\rho_{f}\right)
$$

, onde $c_{f}$ e $c_{s}$ são a velocidade de propagação de onda no fluido e na esfera, $\rho_{f}$ e $\rho_{s}$ são a densidade do fluido e da esfera, respectivamente. Dessa forma, Gor'kov (GORKOV, 1962) obteve uma expressão para a média temporal do potencial de radiação acústica $U_{a}$ que atua nessa esfera .

$$
U_{a}=2 \pi R^{3}\left(\frac{\left\langle p^{2}\right\rangle}{3 \rho_{f} c_{f}^{2}} f_{1}-\frac{\left.\rho_{f}<\nu^{2}\right\rangle}{2} f_{2}\right)
$$

Ao substituir as expressões de densidade de energia das Equações (2.17) e 2.19), e considerar $V_{s}=\frac{4 \pi R^{3}}{3}$ o volume da esfera, a Equação 2.82 pode ser reescrita na forma

$$
U_{a}=V_{s}\left(\mathcal{U}_{f} f_{1}-\frac{3}{2} \mathcal{T} f_{2}\right)
$$


As componentes da força acústica $F_{a}$ são determinadas através do potencial usando a expressão

$$
F_{a}=-\nabla U_{a}
$$

substituindo a Equação (2.83) na Equação (2.84), tem-se

$$
F_{a}=V_{s}\left(\frac{3}{2} \nabla \mathcal{T} f_{2}-\nabla \mathcal{U}_{f} f_{1}\right)
$$

Quando se aplica um potencial acústico, da Equação (2.83, em uma partícula, uma força de radiação, da Equação (2.85) atua sobre a partícula no sentido de empurrar para uma região próxima de um mínimo de potencial acústico. Além da força de radiação acústica, outras forças podem atuar sobre essa partícula. Em geral a posição de equilíbrio da partícula não ocorre na região onde a força de radiação é nula. 


\section{MODELO UNIDIMENSIONAL}

\subsection{INTRODUÇÃO}

Um modelo matemático baseado em matriz de transferência é utilizado para simular o comportamento de um ressonador piezelétrico multicamada projetado para gerar um campo ultrassônico estacionário. Nesse ressonador piezelétrico há propagação de ondas harmônicas em fluidos, sólidos e em materiais piezelétricos. Assume-se que todos os parâmetros considerados possuem dependência espacial em apenas uma direção, a de propagação da onda. Além disso, o deslocamento das ondas acústicas são restritas a essa direção. Esse tratamento é justificável porque um transdutor piezelétrico do tipo pistão permite que seja excitado apenas no seu modo de espessura.

\subsection{MATRIZ DE TRANSFERÊNCIA}

Conforme visto na seção 2.2.3 as equações lineares da piezeletricidade podem ser resolvidas para o caso unidimensional. Além disso, é possível simplificar o problema eliminando os parâmetros que consideram a propagação de ondas transversais em sólidos. Um modelo eletromecânico que soluciona as equações de ondas elásticas em diversos meios voltado a propagação de ondas longitudinais é descrito a seguir.

É possivel modelar um transdutor piezelétrico próximo da ressonância no modo de espessura através de modelos de circuito elétrico equivalente (HILL M. ANDSHEN; HAWKES, 2002). Porém, neste trabalho é utilizado o conceito de matriz de transferência que considera um modelo mais geral de piezeletricidade (NOWOTNY et al., 1991). Essas matrizes relacionam as condições de contorno entre duas superfícies de uma camada conforme ilustra a Figura (10).

\subsubsection{Matriz Piezelétrica}

A matriz piezelétrica consiste de um modelo matemático que apresenta a solução da equação de onda em regime estacionário em materiais piezelétricos. Nesse caso, todos os parâmetros em $z$ dependem linearmente da condição de contorno em $z=0$. Portanto, essas relações lineares entre os dois planos da camada podem ser escritas através da seguinte notação matricial.

$$
\left(\begin{array}{c}
u \\
T \\
\varphi \\
D
\end{array}\right)_{z=l}=M_{P}\left(\begin{array}{c}
u \\
T \\
\varphi \\
D
\end{array}\right)_{z=0}
$$


Figura 10 - Condições de contorno consideradas em cada camada.

$$
\left(\begin{array}{c}
u(0) \\
T(0) \\
\phi(0) \\
D(0)
\end{array}\right)=\left(\begin{array}{l}
u(l) \\
T(l) \\
\phi(l) \\
D(l)
\end{array}\right)
$$

onde $l$ denota o espessura da camada e $M_{P}$ apresenta solução das equações para o caso unidimensional e longitudinal no formato de matriz de transferência.

$$
M_{P}=\left(\begin{array}{cccc}
M^{u u} & M^{u T} & 0 & M^{u D} \\
M^{T u} & M^{T T} & 0 & M^{T D} \\
M^{\varphi u} & M^{\varphi T} & 1 & M^{\varphi D} \\
0 & 0 & 0 & 1
\end{array}\right)
$$

para formar a matriz de transferência, da Equação (3.2), as seguintes equações são obtidas a partir de uma simplificação das Equações (2.61) a (2.64) de forma a considerar somente a propagação de ondas longitudinais (ou seja, para $n=1$ ).

$$
\begin{aligned}
M^{u u} & =M^{T T}=\cos \eta l \omega \\
M^{u T} & =\frac{\eta}{\rho \omega} \sin \eta l \omega \\
M^{T u} & =-\frac{\rho \omega}{\eta} \sin \eta l \omega \\
M^{\varphi u}=M^{T D} & =-\sqrt{\frac{l}{\varepsilon_{z z}}} \sqrt{\rho l \omega^{2}} \frac{2 \kappa}{\eta l \omega} \sin ^{2} \frac{\eta l \omega}{2} \\
M^{\varphi T}=M^{u D} & =\sqrt{\frac{l}{\varepsilon_{z z}}} \frac{1}{\sqrt{\rho l \omega^{2}}} \kappa \sin \eta l \omega \\
M^{\varphi D} & =-\frac{l}{\varepsilon_{z z}}\left(1-\kappa^{2} \frac{1}{\eta l \omega} \sin \eta l \omega\right)
\end{aligned}
$$

onde $\kappa$ é definido como fator de acoplamento eletromecânico,

$$
\kappa=e_{z z j} / \sqrt{\bar{c} \varepsilon_{z z}}
$$

\subsubsection{Matriz Não-Piezelétrica}

A mesma relação pode ser estabelecida para obter a matriz de transferência em um material não-piezelétrico. Os termos $M^{u u}, M^{u T}, M^{T T}$ e $M^{T u}$ da matriz $M_{P}$ correspondem 
às relações puramente mecânicas. O termo $M^{\varphi D}$ relaciona os parâmetros puramente elétricos, já os termos mistos $M^{\varphi u}, M^{\varphi T}, M^{u D}$ e $M^{T D}$ correspondem a parte piezelétricas. Para obter a matriz não-piezelétrica $M_{G}$, simplifica-se a Equação (3.2) igualando a zero os termos que não forem puramente mecânicos. Feito isso, obtém-se a seguinte relação,

$$
\left(\begin{array}{c}
u \\
T \\
\varphi \\
D
\end{array}\right)_{z=l}=M_{G}\left(\begin{array}{c}
u \\
T \\
\varphi \\
D
\end{array}\right)_{z=0}
$$

onde

$$
M_{G}=\left(\begin{array}{cccc}
M^{u u} & M^{u T} & 0 & 0 \\
M^{T u} & M^{T T} & 0 & 0 \\
0 & 0 & 1 & 0 \\
0 & 0 & 0 & 1
\end{array}\right)
$$

\subsubsection{Matriz dos eletrodos}

A partir da solução harmônica em regime estacionário, tem-se que o deslocamento elétrico, $D$ em função do tempo é dado por.

$$
D(t)=D e^{-j \omega t}
$$

Das Equações (3.2) e (3.11), pode ser identificado que as condições de contorno de $D$ são idênticas para os dois planos do material piezelétrico. Essa continuidade espacial não ocorre para um eletrodo que seja um condutor perfeito. O valor de $D$ é diferente para

Figura 11 - Possíveis condições de contorno do modelo elétrico.

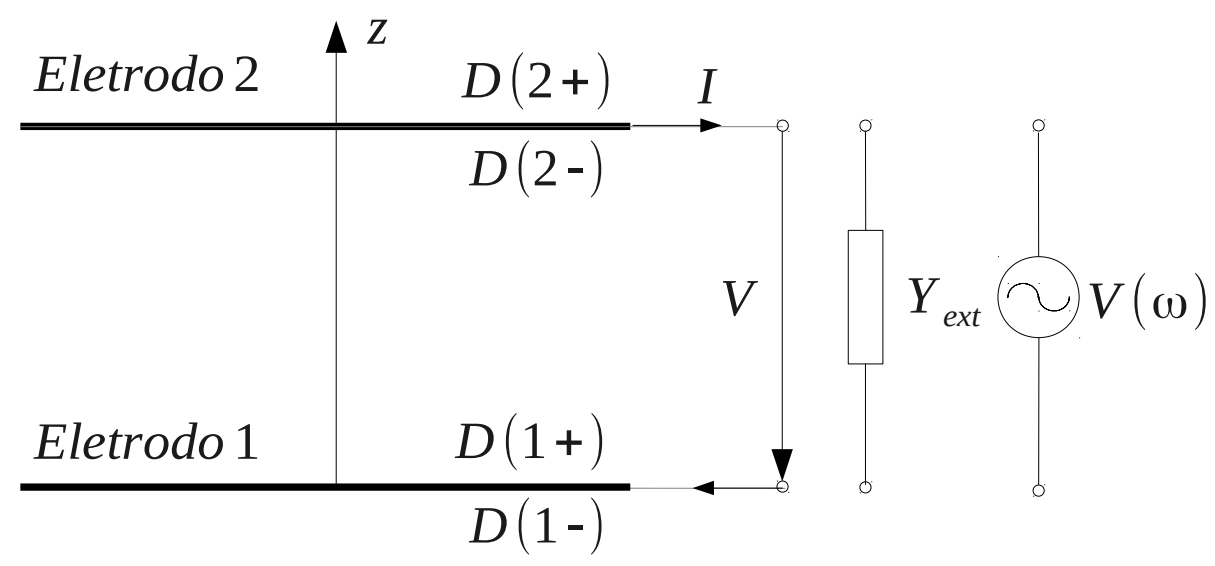


os dois lados do eletrodo 1 , sendo definido como $D\left(1^{+}\right)$e $D\left(1^{-}\right)$, respectivamente. A Figura (11) indica essa notação que também é utilizada para o eletrodo 2.

A diferença $D\left(1^{+}\right)-D\left(1^{-}\right)$no eletrodo 1 está relacionada com a densidade de carga elétrica, $\sigma_{f}$ por unidade de área dos eletrodos

$$
D\left(1^{+}\right)-D\left(1^{-}\right)=\sigma_{f}
$$

Como a carga é distribuída uniformemente no eletrodo, tem-se que

$$
Q=\sigma_{f} A=\left[D\left(1^{+}\right)-D\left(1^{-}\right)\right] A .
$$

onde $A$ é a área do eletrodo. A conservação de carga elétrica é expressa pela equação da continuidade obtida pelas equações de Maxwell

$$
I=\frac{d Q}{d t}
$$

Substituindo a Equação (3.12) na Equação (3.14) e resolvendo a Equação 3.15 da continuidade, a corrente elétrica $I_{1}$ que passa pelo eletrodo 1 é expressa por

$$
I_{1}=\jmath \omega A\left[D\left(1^{+}\right)-D\left(1^{-}\right)\right]
$$

A Equação 3.16 mostra que a condição de contorno $D$ é dependente do fluxo de corrente elétrica. Como são considerados apenas dois eletrodos, a corrente $I=I_{1}=-I_{2}$ está relacionada exclusivamente com a tensao elétrica $V=\varphi_{1}-\varphi_{2}$ entre os eletrodos pela relação

$$
I=V Y
$$

ou

$$
V=Z I
$$

onde $Y$ denota a admitância e $Z$ a impedância elétrica do circuito. Descrevendo uma conexão externa do dois eletrodos por uma admitância $Y_{e x t}=-Y$ ou por uma fonte de tensão elétrica externa $V(\omega)$, conforme a Figura (11). Considerando a referência do potencial $\varphi_{2}=0$, a tensão elétrica entre os eletrodos fica $V=\varphi_{1}$ e a Equação (3.16, obtem-se a relação

$$
D\left(1^{+}\right)=D\left(1^{-}\right)+\frac{Y}{\jmath \omega A} \varphi_{1}
$$


Dessa forma, para um eletrodo ideal na posição $z$, é possível escrever de forma análoga a Equação (3.1) a relação,

$$
\left(\begin{array}{c}
u \\
T \\
\varphi \\
D
\end{array}\right)_{z=z^{+}}=M_{E}\left(\begin{array}{c}
u \\
T \\
\varphi \\
D
\end{array}\right)_{z=z^{-}}
$$

onde

$$
M_{E}=\left(\begin{array}{cccc}
1 & 0 & 0 & 0 \\
0 & 1 & 0 & 0 \\
0 & 0 & 1 & 0 \\
0 & 0 & \frac{Y}{j \omega A} & 1
\end{array}\right)
$$

Para um eletrodo de espessura considerável, deve-se incluir a parte mecânica na matriz de transferência conforme as Equações (3.3) a (3.5):

$$
M_{E m e c}=\left(\begin{array}{cccc}
M_{E m e c}^{u u} & M_{E m e c}^{u T} & 0 & 0 \\
M_{E m e c}^{T u} & M_{E m e c}^{T T} & 0 & 0 \\
0 & 0 & 1 & 0 \\
0 & 0 & 0 & 1
\end{array}\right)
$$

Portanto, a matriz para todo eletrodo pode ser escrito como

$$
M_{E t o t}=M_{E} \cdot M_{E m e c}=M_{E m e c} \cdot M_{E}
$$

\subsection{MULTICAMADAS}

Em um problema de propagação de ondas acústicas em multicamadas, a solução do sistema completo é tal que cada material satisfaz sua própria equação diferencial. Existe uma continuidade em cada interface e as condições de contorno das superfícies externas do sistema multicamada são satisfeitas adequadamente (ADLER, 1990)

Ao considerar uma camada piezelétrica, $P$, entre dois eletrodos, $E$ e outras camadas não piezelétricas, $G_{i}$, no lado externo dos eletrodos, conforme a Figura (12), a relação entre os parâmetros $u, T, \varphi$ e $D$ em cada uma das superfícies livres 1 e 2 da montagem é dada pela matriz de transferência $M_{G E Q E}$

$$
\begin{aligned}
M_{G E Q E} & =M_{G} \cdot M_{E} \cdot M_{Q} \cdot M_{E} \\
M_{G} & =M_{G_{N}} \cdot \ldots \cdot M_{G_{2}} \cdot M_{G_{1}}
\end{aligned}
$$


Figura 12 - Divisão estrutural de uma organização de camadas arbitrárias

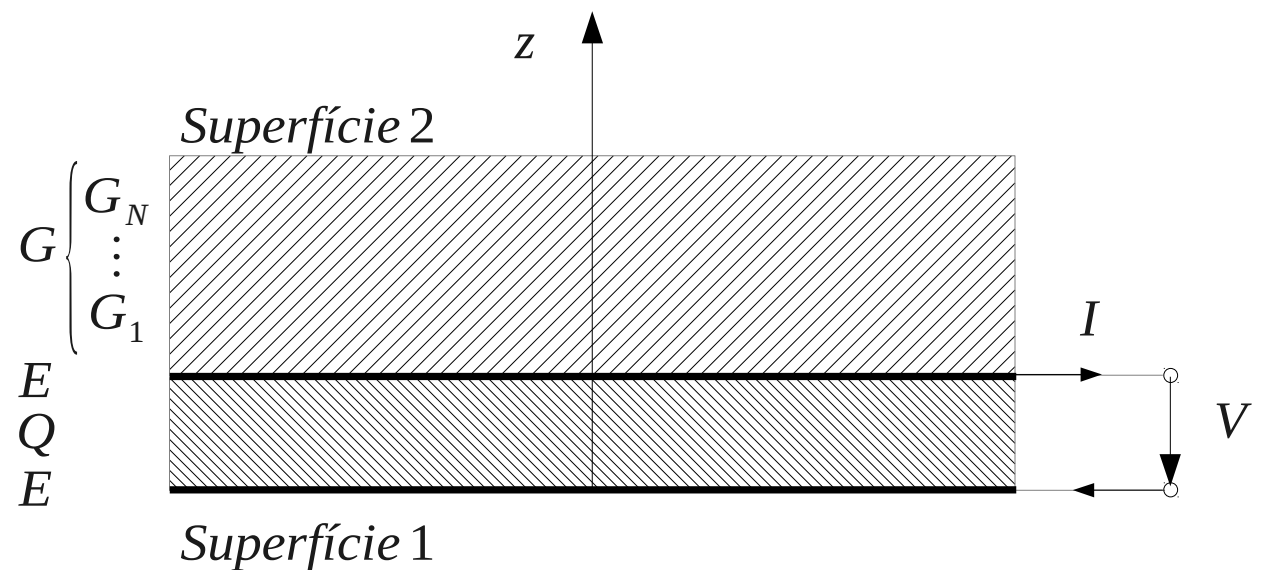

representando as camadas de $G_{1}$ a $G_{N}$ a medida que se afasta da origem do sistema de coordenadas. Analogamente a Equação (3.11), de forma que $M_{G}$ é dada por,

$$
M_{G}=\left(\begin{array}{cccc}
M_{G}^{u u} & M_{G}^{u T} & 0 & 0 \\
M_{G}^{T u} & M_{G}^{T T} & 0 & 0 \\
0 & 0 & 1 & M_{G}^{\varphi D} \\
0 & 0 & 0 & 1
\end{array}\right)
$$

Nesse caso, se for necessário considerar uma parte mecânica nas matrizes dos eletrodos, a matriz $M_{E m e c}$ pode ser incluída tanto na matriz $M_{G}$, como na $M_{Q}$ (NOWOTNY; BENES, 1987). O resultado da multiplicação dessas matrizes em $M_{G E Q E}$ leva uma forma mais geral, dada pela expressão,

$$
M_{G E Q E}=\left(\begin{array}{llll}
M^{u u} & M^{u T} & M^{u \varphi} & M^{u D} \\
M^{T u} & M^{T T} & M^{T \varphi} & M^{T D} \\
M^{\varphi u} & M^{\varphi T} & M^{\varphi \varphi} & M^{\varphi D} \\
M^{D u} & M^{D T} & M^{D \varphi} & M^{D D}
\end{array}\right) .
$$

Considerando as condições de contorno nas superfícies livres do arranjo, tem-se que as tensões e deslocamentos elétricos são nulos. $\mathrm{E}$ se for denotado por $u_{1}, \varphi_{1} \mathrm{e} u_{2}, \varphi_{2}$ as outras condições de contorno nas superfícies 1 e 2 , respectivamente, a relação entre os extremos da montagem fica,

$$
\left(\begin{array}{c}
u_{2} \\
0 \\
\varphi_{2} \\
0
\end{array}\right)=M_{G E Q E}\left(\begin{array}{c}
u_{1} \\
0 \\
\varphi_{1} \\
0
\end{array}\right)
$$

Utilizando a forma geral $M_{G E Q E}$ da Equação (3.27), a solução para $u_{1}$ fica: 


$$
\begin{aligned}
u_{1} & =-\left[M^{T u}\right]^{-1} \cdot M^{T \varphi} \varphi_{1} \\
0 & =-M^{D u} \cdot\left[M^{T u}\right]^{-1} \cdot M^{T \varphi} \varphi_{1}+M^{D \varphi} \varphi_{1}
\end{aligned}
$$

Para que haja solução não-trivial $\varphi_{1} \neq 0$, é necessário que a seguinte relação

$$
M^{D \varphi}=M^{D u} \cdot\left[M^{T u}\right]^{-1} \cdot M^{T \varphi}
$$

seja válida. Como a matriz de transferência $M$ contém a admitância $Y$ e a frequência angular $\omega$, a Equação 3.31 estabelece a relação entre $Y$ e $\omega$. A admitância $Y(\omega)$ pode ser calculada ao isolar os termos $M_{G E Q E}^{D \varphi}, M_{G E Q E}^{D u}, M_{G E Q E}^{T \varphi}$ e $M_{G Q}^{T u}$ da Equação (3.24), de forma a obter as expressões:

$$
\begin{aligned}
M_{G E Q E}^{D \varphi} & =(Y / \jmath \omega A)\left[2+(Y / \jmath \omega A) M_{Q}^{\varphi D}\right] \\
M_{G E Q E}^{D u} & =(Y / \jmath \omega A) M_{Q}^{\varphi u} \\
M_{G E Q E}^{T \varphi} & =(Y / \jmath \omega A)\left[M_{G}^{T u} \cdot M_{Q}^{u D}+M_{G}^{T T} \cdot M_{Q}^{T D}\right] \\
M_{G Q}^{T u} & =M_{G}^{T u} \cdot M_{Q}^{u u}+M_{G}^{T T} \cdot M_{Q}^{T u}
\end{aligned}
$$

Da Equação (3.31), obtém-se a relação explícita para a equação da adimitância:

$$
\begin{aligned}
2 \jmath \omega A / Y= & -M_{Q}^{\varphi D}+M_{Q}^{\varphi u} \cdot\left[M_{G}^{T u} \cdot M_{Q}^{u u}+M_{G}^{T T} \cdot M_{Q}^{T u}\right]^{-1} \\
& \cdot\left(M_{G}^{T u} \cdot M_{Q}^{u D}+M_{G}^{T T} \cdot M_{Q}^{T D}\right)
\end{aligned}
$$

\subsubsection{Ressonador multicamadas}

Um ressonador que gera campo de ultrassom estacionário tipicamente consiste em 4 camadas, um transdutor piezelétrico $(P)$, uma camada de acoplamento $(A)$ que isola as cerâmicas do líquido, uma camada de amostra líquida (L) e um refletor (R) (GROSCHL, 1998a). A Figura (13) apresenta cada camada indicando seu comprimento e o eixo das coordenadas $z$ no qual a onda se propaga.

Além disso, o método da matriz permite o cálculo dos parâmetros consideradas ao longo de cada camada. Esse cálculo é realizado para uma freqüência $\omega$ fixa. No primeiro passo, é calculada a admitância elétrica $Y(\omega)$ do conjunto a partir da Equação (3.33. Em seguida, a matriz de transferência dos eletrodos, $M_{E}$, é calculada a partir da Equação 3.21 .

Subsequentemente, os parâmetros do campo acústico são calculados para qualquer posição $z=z^{\prime}$, avaliando-se ponto a ponto a matriz de transferência $M_{n}$ da camada cor- 
Figura 13 - Modelo unidimensional do ressonador multicamadas.

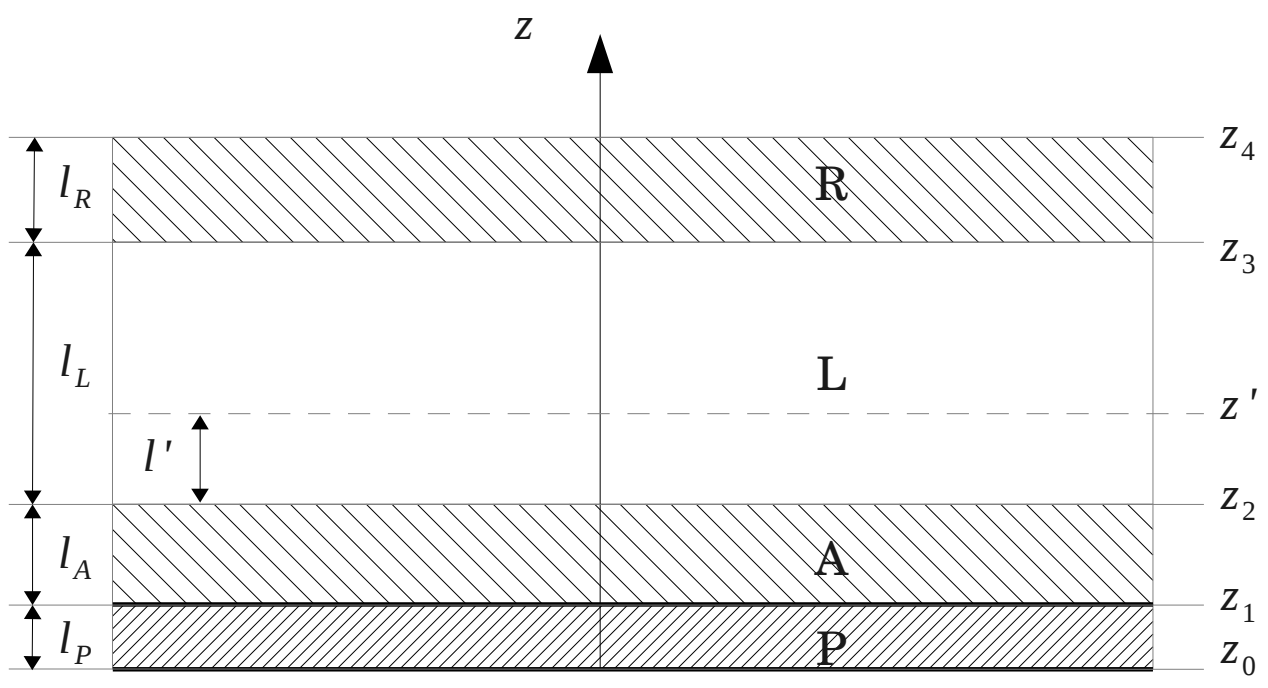

respondente. Nessa matriz, a espessura da camada de $l$ é substituída pela espessura variável $l^{\prime}=z^{\prime}-z_{n-l}$ da sub-camada como mostra a Figura (13):

$$
\left(\begin{array}{c}
u \\
T \\
\varphi \\
D
\end{array}\right)_{z=z^{\prime}}=M_{n}\left(x^{\prime}-x_{n-1}\right)\left(\begin{array}{c}
u \\
T \\
\varphi \\
D
\end{array}\right)_{z=z_{n-1}}
$$

As camadas de eletrodo não influenciam o progresso do deslocamento $u$ e da tensão $T$, pois são muito finos e podem ser considerados sem inércia de massa. As matrizes de transferência das camadas piezelétrica e dos eletrodos podem ser combinadas com uma matriz de transferência total $M_{1}$ da camada ativa, onde $M_{1}=M_{E} M_{P} M_{E}$. Os valores iniciais de superfície livre $1\left(z=z_{0}\right)$ são:

$$
\begin{aligned}
u_{0}, & T_{0}=0, \\
\varphi_{0}=V_{a p}, & D_{0}=0
\end{aligned}
$$

onde $V_{a p}$ denota a amplitude de tensão applicada entre os eletrodos. O valor inicial para a amplitude de deslocamento $u_{0}$ é calculada a partir da Equação (3.29). Utilizando a Equação (3.34) e os valores iniciais da Equação (3.35), calcula-se a distribuição espacial dos parâmetros $u(z), T(z), \varphi(z)$ e $D(z)$.

\subsection{MODELO DE PERDAS}

Até aqui foi considerada uma vibração unidimensional ideal, no entanto esse modelo necessita que seja estabelecido perdas. Uma das formas de fazer isso é incluir amorte- 
cimento viscoelástico, $\mu$, adicionando um termo que contenha uma derivada temporal à Equação (2.31) (AULD; AULD, 1973).

$$
T=c S+\mu \frac{\partial S}{\partial t}
$$

Para o caso de dependência harmônica $e^{j \omega t}$ do campo acústico, a Equação 3.36 pode ser escrita em uma notação complexa como,

$$
\tilde{T}=c \tilde{S}+j \omega \mu \tilde{S}=\tilde{c} \tilde{S}
$$

onde é introduzido a constante elástica de rigidez complexa

$$
\tilde{c}=c+j \omega \mu .
$$

Um meio que possui amortecimento pode ser caracterizado pelo seu fator de qualidade acústica, $\mathcal{Q}$, definido como:

$$
\mathcal{Q}=\frac{c}{\omega \mu}
$$

Substituindo a Equação (3.39) na Equação 3.38, temos:

$$
\tilde{c}=\frac{c}{\left(1+\jmath \frac{1}{\mathcal{Q}}\right)} .
$$

De acordo com a relação entre o inverso da velocidade do som e a constante elástica de rigidez, seguindo a notação complexa para o valor de $\mathcal{Q} \gg 1$, a Equação (2.57), fica:

$$
\tilde{\eta}=\frac{\eta}{\left(1+\jmath \frac{1}{2 \mathcal{Q}}\right)}
$$

Além disso, o amortecimento devido a perdas no dielétrico pode ser considerada incluindo uma parte imaginária à constante dielétrica (HOLLAND, 1967)

$$
\tilde{\varepsilon}=\varepsilon+\frac{\gamma}{\jmath \omega}
$$

onde $\gamma$ é a condutividade elétrica. Para camadas largas de espessura constante, $\gamma$ pode ser expresso como $\gamma=\omega \epsilon \tan \vartheta$. Portanto, a Equação (3.42), fica:

$$
\tilde{\varepsilon}=\varepsilon(1-\jmath \tan \vartheta)
$$

O conceito de constantes complexas permite que os cálculos seja feitos exatamente da mesma forma que no caso ideal. 


\subsection{FLUXO DE ENERGIA}

A energia transportada por uma onda estacionária parcial através de um meio pode ser entendida através do fluxo de energia. O vetor de Poynting representa a densidade direcional do fluxo de energia transferida por unidade de área. Dessa forma, é possível definir a densidade de energia armazenada em campos harmônicos tanto acústicos como eletromagnéticos. O valor médio do vetor de Poynting representa a energia total armazenada por unidade de volume.

Nas definições anteriores de energia, segundo um modelo elástico não-piezelétrico, não foi feita distinção quanto a direção de propagação da onda. No entanto, a energia armazenada em materiais piezelétricos tem sido estudada em termos do vetor de poynting (HAVLICE et al., 1970), (HOLLAND, 1967). Nesse caso, é importante definir o sistema de coordenadas ao longo do qual há fluxo de energia.

De acordo com o teorema de Poyting para material piezelétrico, em um caso unidimensional o vetor de Poyting, $\tilde{\Pi}(z)$, em notação complexa é dado por

$$
\tilde{\Pi}(z)=\frac{1}{2}\left[(-\jmath \omega \tilde{u}(z))^{*} \tilde{T}(z)+\tilde{\varphi}(z)(\jmath \omega \tilde{D}(z))^{*}\right]
$$

onde * denota o complexo conjugado. Nesse momento, é interessante estabelecer que $\nu$ representa a amplitude de velocidade sendo calculada através da equação

$$
\tilde{\nu}(z)=\jmath \omega \tilde{u}(z)
$$

A Equação (3.44) pode ser derivada diretamente das equações de Maxwell (AULD; AULD, 1973). Sua parte real, $\Re\{\tilde{\Pi}(z)\}$, representa densidade real de fluxo de energia $\left(\mathrm{W} / \mathrm{m}^{2}\right)$ e, portanto, é representado pelo seu valor médio. Um valor positivo do vetor de Poynting significa que a energia flui no sentido positivo de $z$.

A potência elétrica de entrada deve ser igual ao fluxo de potência total que atravessa a superfície livre do ressonador em $z=z_{0}$ e pode ser obtida através do vetor de Poynting:

$$
\begin{aligned}
P_{e l}^{r e a l} & =A \cdot \Re\left\{\tilde{\Pi}\left(z_{0}\right)\right\}, \\
P_{e l}^{a p p} & =A\left|\tilde{\Pi}\left(z_{0}\right)\right| .
\end{aligned}
$$

onde $P_{e l}^{r e a l}$ e $P_{e l}^{a p p}$ denotam a potência elétrica real e aparente, respectivamente. Isso ocorre pois não há potência mecânica fornecida por outra fonte e os potenciais elétricos entre eletrodos são $\Re\left\{\tilde{\varphi}_{1}\right\}=V_{a p}$ e $\tilde{\varphi}_{2}=0$. Em termos de tensão aplicada no eletrodo, $V_{a p}$ e admitância do ressonador, $\tilde{Y}$, as Equações 3.46 e 3.47) podem então serem reescritas da seguinte forma. 


$$
\begin{aligned}
P_{e l}^{r e a l} & =\frac{1}{2} V_{a p}^{2} \Re\{\tilde{Y}\}, \\
P_{e l}^{a p p} & =\frac{1}{2} V_{a p}^{2}|\tilde{Y}|,
\end{aligned}
$$

A densidade de energia total média armazenada $\left(\mathrm{J} / \mathrm{m}^{3}\right)$ ao longo do eixo $z$ do ressonador é calculada considerando as Equações 2.43) e 2.68. A partir da definição do valor médio, $\mathcal{E}_{p}$ pode ser expressa na forma complexa

$$
\tilde{\mathcal{E}}_{p}(z)=\frac{1}{4}\left[\rho \tilde{\nu}(z) \tilde{\nu}^{*}(z)+\Re\left\{\tilde{T}(z) \tilde{S}^{*}(z)+\tilde{E}(z) \tilde{D}^{*}(z)\right\}\right]
$$

onde $\tilde{S}(z)$ e $\tilde{E}(z)$ podem ser obtidos das equações constitutivas 2.44 e 2.45. Dessa forma, a Equação 3.50 pode ser reescrita somente em termos das variáveis conhecidas $\tilde{\nu}(z), \tilde{T}(z)$ e $\tilde{D}(z)$

$$
\tilde{\mathcal{E}}_{p}(z)=\frac{1}{4}\left[\rho \tilde{\nu}(z) \tilde{\nu}^{*}(z)+\frac{\eta^{2}}{\rho} \tilde{T}(z) \tilde{T}^{*}(z)+\left(\frac{1-\kappa^{2}}{\varepsilon}\right) \tilde{D}(z) \tilde{D}^{*}(z)\right]
$$

De forma análoga, densidade de energia total média em materiais puramente mecânicos pode ser reescrita da seguinte forma

$$
\tilde{\mathcal{E}}_{s}(z)=\frac{1}{4}\left[\rho \tilde{\nu}(z) \tilde{\nu}^{*}(z)+\frac{1}{c^{2}} \tilde{T}(z) \tilde{T}^{*}(z)\right]
$$




\section{MODELO BIDIMENSIONAL}

\subsection{INTRODUÇÃO}

Outros modelos matemáticos podem ser utilizados para simular campos acústicos, potencial de radiação acústica, além de impedância elétrica de transdutores piezoelétricos em sistemas de coordenadas bidimensionais.

Um modelo que considera apenas parâmetros mecânicos é utilizado para prever o comportamento de câmaras acústicas de geometria retangular. Esse modelo utiliza soluções analíticas de campo acústico estacionário em câmaras regulares para obter o potencial de radiação acústica além da força resultante.

Outro modelo eletromecânico utiliza o método dos elementos finitos (MEF) para extrair tanto o campo acústico como a impedância elétrica de transdutores. Nesse caso, são fornecidos diversos parâmetros incluindo propriedades dos materiais envolvidos para resolver as equações diferenciais da seção (2.2) através de uma formulação integral.

\subsection{MODOS EM CÂMARAS RETANGULARES}

Uma das formas preliminares de prever o comportamento de câmaras acústicas estacionárias é através de uma solução analítica simplifacada (BARMATZ; COLLAS, 1985). Nesta seção, é apresentado um modelo que considera apenas as dimensões das câmaras em um sistema bidimensional de coordenadas retangulares e parâmetros de propagação de ondas planas para obter o campo adimensional de pressão acústica e de velocidades de partícula. Esse modelo também considera as propriedades de densidade do meio de propagação e supõe que uma partícula esférica de interesse sofre ação da força de radiação para calcular o potencial de radiação na câmara.

Para modelar uma onda estacionária em uma câmara retangular será considerado que suas paredes são completamente rígidas. Para simplificar, as dimensões da câmara serão consideradas $l_{z} \mathrm{e} l_{y}$. As condições de contorno rígidas são tais que a velocidade do fluido nas paredes e perpedicular à parede é nula. A equação de onda nas coordenadas retangulares é

$$
\frac{\partial^{2} p}{\partial z^{2}}+\frac{\partial^{2} p}{\partial y^{2}}=\frac{1}{c_{f}^{2}} \frac{\partial^{2} p}{\partial t^{2}}
$$

Se a origem do sistema de coordenadas for escolhido no canto da câmara, a solução da pressão no seu interior para a Equação (4.1) é

$$
\begin{aligned}
p & =\cos k_{x} x \cos k_{y} y e^{-\jmath \omega t} \\
\omega & =\sqrt{\omega_{z}^{2}+\omega_{y}^{2}}
\end{aligned}
$$


Nesse caso a velocidade de partícula na direção $z$ é

$$
\nu_{z}=\frac{\omega_{z}}{\jmath \omega \rho c_{f}}-\sin k_{z} z \cos k_{y} y e^{-\jmath \omega t}
$$

Analogamente, na direção y é

$$
\nu_{y}=\frac{\omega_{y}}{\jmath \omega \rho c_{f}}-\sin k_{y} y \cos k_{z} z e^{-\jmath \omega t}
$$

Para que as condições de contorno sejam satisfeitas os seguintes valores de $k$ são possíveis.

$$
\begin{aligned}
& k_{z}=n_{z} \frac{\pi}{l_{z}}, k_{y}=n_{y} \frac{\pi}{l_{y}} \\
& k=\pi\left[\left(\frac{n_{z}}{l_{z}}\right)^{2}+\left(\frac{n_{y}}{l_{y}}\right)^{2}\right]^{\frac{1}{2}}
\end{aligned}
$$

onde $n_{z}$ e $n_{y}$ são dados por valores inteiros positivos. A velocidade de partícula $\nu$ possui componentes na direção $z$ e $y$ e o seu valor absoluto dado por

$$
\begin{aligned}
|\nu| & =\left[\left(k_{z} / k\right)^{2} \sin ^{2} k_{z} z \cos ^{2} k_{y} y\right. \\
& \left.+\left(k_{y} / k\right)^{2} \cos ^{2} k_{z} z \sin ^{2} k_{y} y\right]^{1 / 2} \sin \omega t .
\end{aligned}
$$

Dessa forma, o potencial de velocidade para um campo estacionário em uma câmara retangular de dimensões fica

$$
\Phi_{i n}=-\left(\nu_{0} / k\right) \cos k_{z} z \cos k_{y} y \sin \omega t,
$$

A média quadrática da pressão fica

$$
\begin{aligned}
\left\langle p^{2}\right\rangle & =\cos ^{2} k_{z} z \cos ^{2} k_{y} y \\
\left\langle\nu^{2}\right\rangle & =\left(k_{z} / k\right)^{2} \sin ^{2} k_{z} z \cos ^{2} k_{y} y \\
& +\left(k_{y} / k\right)^{2} \cos ^{2} k_{z} z \sin ^{2} k_{y} y
\end{aligned}
$$

Substituindo as Equações (4.9) e (4.10) na Equação (2.83), obtém-se o potencial de radiação acústica no interior da câmara retangular dado por

$$
\begin{aligned}
\mathcal{U}_{a}=\left(\pi R^{3} \rho \nu_{0}^{2}\right)\left[\left(f_{1} / 3\right) \cos ^{2} k_{z} z \cos ^{2} k_{y} y\right. \\
-\left(f_{2} / 2\right)\left\{\left(k_{z} / k\right)^{2} \sin ^{2} k_{z} z \cos ^{2} k_{y} y\right. \\
\left.\left.+\left(k_{y} / k\right)^{2} \cos ^{2} k_{z} z \sin ^{2} k_{y} y\right\}\right]
\end{aligned}
$$


Para simplificar as Equações (2.83) e (2.85), desconsiderando o raio do objeto, $R$, a sua densidade, $\rho$, a velocidade de propagação no fluido, $c_{f}$ e a velocidade máxima de partícula $\nu_{0}$, obtém-se os parâmetros adimensionais do campo de pressão $\tilde{p}$, potencial de radiação $\tilde{\mathcal{U}}_{a}$ e velocidade de partícula, conforme a seguinte definição

$$
\begin{aligned}
\tilde{p} & =p_{i n} / \rho c_{f} \nu_{0}, \\
\tilde{\nu} & =\nu_{i n} / \nu_{0}, \\
\tilde{\mathcal{U}}_{a} & =\mathcal{U}_{a} /\left(\pi R^{3} \rho \nu_{0}^{2}\right)
\end{aligned}
$$

Subistituindo a Equação 4.11 na Equação 4.12, obtém-se o potencial adimensional em uma câmara retangular:

$$
\begin{aligned}
\tilde{\mathcal{U}}_{a}= & \left(f_{1} / 3\right) \cos ^{2} k_{z} z \cos ^{2} k_{y} y \\
- & \left(f_{2} / 2\right)\left[\left(k_{z} / k\right)^{2} \sin ^{2} k_{z} z \cos ^{2} k_{y} y\right. \\
& \left.+\left(k_{y} / k\right)^{2} \cos ^{2} k_{z} z \sin ^{2} k_{y} y\right] .
\end{aligned}
$$

\subsection{MÉTODO DE ELEMENTOS FINITOS}

O método bidimensional descrito na seção (4.2 obtem a solução analítica das equações diferenciais que governam o comportamento do fluido em uma região de geometria simplificada. Esse método supõe que a solução do conjunto de equações seja igual a sobreposição de ondas planas estacionárias. No entanto, a aplicação real de ondas estacionárias no interior de uma câmara ressonante é feita através da excitação elétrica de transdutores piezelétricos com geometrias mais complexas.

Outros fenômenos piezelétricos que ocorrem nessa aplicação não são previstos pelos modelos analíticos devido a complexidade das condições de contorno. Parte desses fenômenos são verificados a partir de modelos numéricos baseados em uma formulação integral do problema original. O cálculo variacional é um método analítico que trata funções variáveis como sendo incógnitas do problema. Essas funções são utilizadas para solucionar essas equações em domínios simplificados e genéricos.

O MEF consiste em dividir o domínio do problema em diversos subdomínios nos quais o cálculo variacional é capaz de solucionar. Dessa forma, esse método numérico aproxima o conjunto de soluções analíticas através do cálculo diferencial por um conjunto numérico de soluções através do cálculo variacional. Nesse caso, as funções variáveis são chamadas de funções de forma e os subdomínios de elementos finitos. 


\subsubsection{Princípio variacional}

O princípio variacional é utilizado no cálculo variacional para determinar a relação entre as variáveis de um problema discreto e suas condições de contorno. O problema variacional é equivalente ao problema onde as equações diferenciais regem o sistema. O princípio de Hamilton afirma que a dinâmica de um sistema é determinada pelo princípio variacional aplicado à função Lagrangeana. Esse princípio determina que as variáveis do sistema evoluem com o tempo de maneira que a seguinte equação seja satisfeita (TIERSTEN, 1967)

$$
\delta \int_{t_{1}}^{t_{2}} \mathcal{L} d t+\int_{t_{1}}^{t_{2}} \delta \mathcal{W} d t=0
$$

onde $\mathcal{L}$ é a função Lagrangeana, $\mathcal{W}$ é o trabalho virtual dos carregamentos externos e $t_{1}$ e $t_{2}$ são os limites que definem o intervalo de tempo. A função Lagrangeana é dada por:

$$
\mathcal{L}=\int_{V}(\mathcal{T}-\mathcal{E}) d V
$$

onde $\mathcal{E}$ assume o valor de entalpia elétrica $\mathcal{H}$ para o caso piezelétrico, ou de energia potencial elástica $\mathcal{U}_{e}$ para o caso não-piezelétrico. Por brevidade, o princípio de Hamilton é desenvolvido somente para o primeiro caso. A entalpia elétrica $\mathcal{H}$ é dada por (IEEE, 1996)

$$
\mathcal{H}=\mathbf{U}_{p}-\mathbf{E}^{t} \mathbf{D}
$$

onde $\mathbf{U}_{p}$ representa $\mathcal{U}_{p}$ no formato vetorial. Dessa forma, a Equação 4.15 assume a forma

$$
\mathcal{L}=\int_{V}(\mathcal{T}-\mathcal{H}) d V=\int_{V} \frac{1}{2}\left[\rho \dot{\mathbf{u}}^{t} \dot{\mathbf{u}}-\mathbf{S}^{t} \mathbf{T}+\mathbf{E}^{t} \mathbf{D}\right] d V
$$

onde $\dot{\mathbf{u}}$ representa o campo de velocidades. Integrando por partes o variacional do termo de energia cinética $\rho \delta \dot{\mathbf{u}}^{t} \dot{\mathbf{u}}$ no intervalo entre $t_{1}$ e $t_{2}$, tem-se que

$$
\int_{t_{1}}^{t_{2}} \rho \delta \dot{\mathbf{u}}^{t} \dot{\mathbf{u}} d t=\left[\rho \delta \mathbf{u}^{t} \dot{\mathbf{u}}\right]_{t_{1}}^{t_{2}}-\int_{t_{1}}^{t_{2}} \rho \delta \mathbf{u}^{t} \ddot{\mathbf{u}} d t=-\int_{t_{1}}^{t_{2}} \rho \delta \mathbf{u}^{t} \ddot{\mathbf{u}} d t
$$

Dessa forma, aplicando o operador variacional na Equação 4.17), obtém-se:

$$
\delta \int_{t_{1}}^{t_{2}} \mathcal{L} d t=\int_{t_{1}}^{t_{2}} \int_{V} \frac{1}{2}\left[\rho \delta \mathbf{u}^{t} \ddot{\mathbf{u}}-\delta \mathbf{S}^{t} \mathbf{T}+\delta \mathbf{E}^{t} \mathbf{D}\right] d V d t
$$

A segunda parcela da Equação (4.14 refere-se ao trabalho externo realizado pelas forças mecânicas e elétricas e para carregamentos pontuais é dada por:

$$
\int_{t_{1}}^{t_{2}} \delta \mathcal{W} d t=\int_{t_{1}}^{t_{2}}\left(\delta \mathbf{u}^{t} \mathbf{F}_{P}-\delta \varphi^{t} \mathbf{Q}\right) d t
$$


onde $\mathbf{F}_{P}$ denota a força pontual e $\mathbf{Q}$ denota a carga elétrica. Substituindo as equações constitutivas encontradas nas Equações (2.44) e (2.45) na Equação 4.19) e a Equação (4.20) na Equação 4.14, obtém-se as equações de equilibrio expressas por

$$
\int_{V}\left(-\rho \delta \mathbf{u}^{t} \ddot{\mathbf{u}}-\delta \mathbf{S}^{t}\left(c^{E} \mathbf{S}-\mathbf{e}^{t} \mathbf{E}\right)+\delta \mathbf{E}^{t}\left(\mathbf{e}^{t} \mathbf{S}+\varepsilon^{S} \mathbf{E}\right)\right) d V=-\delta \mathbf{u}^{t} \mathbf{F}_{P}+\delta \varphi^{t} \mathbf{Q}
$$

Separando os termos que multiplicam $\delta \mathbf{u}^{t}$ e $\delta \mathbf{S}^{t}$ dos que multiplicam $\delta \mathbf{E}^{t}$ e $\delta \varphi^{t}$, tem-se que

$$
\begin{cases}\int_{V}\left(\rho \delta \mathbf{u}^{t} \ddot{\mathbf{u}}+\delta \mathbf{S}^{t}\left(c^{E} \mathbf{S}-\mathbf{e}^{t} \mathbf{E}\right)\right) d V & =\delta \mathbf{u}^{t} \mathbf{F}_{P} \\ \int_{V}\left(\delta \mathbf{E}^{t}\left(\mathbf{e}^{t} \mathbf{S}+\varepsilon^{S} \mathbf{E}\right)\right) d V & =\delta \varphi^{t} \mathbf{Q}\end{cases}
$$

\subsubsection{Elementos finitos plano}

Neste trabalho, o problema de elementos será resolvido para o estado plano de deformações. Dessa forma, as componetes da deformação, do deslocamento e do campo elétrico que possuem termos na direção $y$ são nulos:

$$
S_{z y}=S_{y y}=S_{x y}=u_{y}=D_{y}=0
$$

Para solucionar a equação de equilíbrio visto na Equação 4.22 através do MEF, o domínio do problema é dividido em vários elementos finitos. Nesse caso, as variáveis contínuas de deslocamento mecânico $\mathbf{u}_{e}$ e do potencial elétrico $\varphi_{e}$ no elemento estão relacionados com os seus valores nodais $\{\mathbf{U}\}_{e}$ e $\{\boldsymbol{\varphi}\}_{e}$ a partir das funções de forma $\left[\mathbf{N}_{u}\right]$ $\mathrm{e}\left[\mathbf{N}_{\varphi}\right]$

$$
\begin{aligned}
\mathbf{u}_{e} & =\left[\mathbf{N}_{u}\right]\{\mathbf{U}\}_{e} \\
\varphi_{e} & =\left[\mathbf{N}_{\varphi}\right]\{\varphi\}_{e}
\end{aligned}
$$

Utilizando as Equações 2.33 e 2.46 que definem a deformação mecânica e o campo elétrico, é possível obter os respectivos vetores $\mathrm{S}$ e $\mathbf{E}$ na forma:

$$
\begin{aligned}
\mathbf{S}_{e} & =\left[\begin{array}{ccc}
0 & \frac{\partial}{\partial z} & \frac{\partial}{\partial x} \\
\frac{\partial}{\partial x} & 0 & \frac{\partial}{\partial z}
\end{array}\right]^{t} \mathbf{u}_{e}=\left[\mathbf{B}_{u}\right]\{\mathbf{U}\}_{e} \\
\mathbf{E}_{e} & =-\left[\begin{array}{cc}
\frac{\partial}{\partial x} & \frac{\partial}{\partial z}
\end{array}\right]^{t} \varphi_{e}=-\left[\mathbf{B}_{\varphi}\right]\{\varphi\}_{e}
\end{aligned}
$$


Logo, a equação de equilíbrio 4.22 pode ser reescrita utilizando as Equações 4.24 à (4.27)

$$
\left\{\begin{array}{c}
\{\delta \mathbf{U}\}_{e}^{t} \int_{V_{e}}\left(\begin{array}{c}
\rho\left[\mathbf{N}_{u}\right]^{t}\left[\mathbf{N}_{u}\right]\{\ddot{\mathbf{U}}\}_{e}+ \\
+\left[\mathbf{B}_{u}\right]^{t}\left[\mathbf{c}^{E}\right]\left[\mathbf{B}_{u}\right]\{\mathbf{U}\}_{e}+ \\
+\left[\mathbf{B}_{u}\right]^{t}[\mathbf{e}]^{t}\left[\mathbf{B}_{\varphi}\right]\{\boldsymbol{\varphi}\}_{e}
\end{array}\right) d V_{e}=\{\delta \mathbf{U}\}_{e}^{t}\left[\mathbf{N}_{u}\right]^{t}\left\{\mathbf{F}_{P}\right\}_{e} \\
\{\delta \boldsymbol{\varphi}\}_{e}^{t} \int_{V_{e}}\left(\begin{array}{c}
-\left[\mathbf{B}_{\varphi}\right]^{t}[\mathbf{e}]\left[\mathbf{B}_{u}\right]\{\mathbf{U}\}_{e}+ \\
+\left[\mathbf{B}_{\varphi}\right]^{t}\left[\varepsilon^{S}\right]\left[\mathbf{B}_{\varphi}\right]\{\boldsymbol{\varphi}\}_{e}
\end{array}\right) d V_{e}=\{\delta \boldsymbol{\varphi}\}_{e}^{t}\left[\mathbf{N}_{\varphi}\right]^{t}\{\mathbf{Q}\}_{e}
\end{array}\right.
$$

Esse novo sistema de equações deve ser válido para qualquer variação arbitrária de deslocamento $\{\mathbf{U}\}_{e}$ e potencial elétrico $\{\boldsymbol{\varphi}\}_{e}$. Dessa forma, para cada elemento a Equação 4.28 pode ser escrita na forma

$$
\begin{array}{r}
{[\mathcal{M}]\{\ddot{\mathbf{U}}\}_{e}+\left[\mathcal{K}_{u u}\right]\{\mathbf{U}\}_{e}+\left[\mathcal{K}_{u \varphi}\right]\{\boldsymbol{\varphi}\}_{e}=\{\mathbf{f}\}_{e}} \\
{\left[\mathcal{K}_{\varphi u}\right]\{\mathbf{U}\}_{e}+\left[\mathcal{K}_{\varphi \varphi}\right]\{\boldsymbol{\varphi}\}_{e}=\{\mathbf{q}\}_{e}}
\end{array}
$$

onde

$$
\begin{aligned}
{[\mathcal{M}] } & =\int_{V_{e}} \rho\left[\mathbf{N}_{u}\right]^{t}\left[\mathbf{N}_{u}\right] d V \\
{\left[\mathcal{K}_{u u}\right] } & =\int_{V_{e}}\left[\mathbf{B}_{u}\right]^{t}\left[\mathbf{c}^{E}\right]\left[\mathbf{B}_{u}\right] d V \\
{\left[\mathcal{K}_{u \varphi}\right] } & =\int_{V_{e}}\left[\mathbf{B}_{u}\right]^{t}[\mathbf{e}]^{t}\left[\mathbf{B}_{\varphi}\right] d V \\
{\left[\mathcal{K}_{\varphi u}\right] } & =\int_{V_{e}}\left[\mathbf{B}_{\varphi}\right]^{t}[\mathbf{e}]\left[\mathbf{B}_{u}\right] d V \\
{\left[\mathcal{K}_{\varphi \varphi}\right] } & =-\int_{V_{e}}\left[\mathbf{B}_{\varphi}\right]^{t}\left[\varepsilon^{S}\right]\left[\mathbf{B}_{\varphi}\right] d V \\
\{\mathbf{f}\}_{e} & =\left[\mathbf{N}_{u}\right]^{t}\left\{\mathbf{F}_{P}\right\}_{e} \\
\{\mathbf{q}\}_{e} & =-\left[\mathbf{N}_{\varphi}\right]^{t}\{\mathbf{Q}\}_{e}
\end{aligned}
$$

O amortecimento no MEF é determinado por uma matriz de amortecimento $\left[\mathcal{C}_{u u}\right]$ que multiplica o vetor de velocidade nodal $\{\dot{\mathrm{U}}\}_{e}$. Esse termo é adicionado à Equação 4.29 podendo ser reescrita na forma:

$$
[\mathcal{M}]\{\ddot{\mathbf{U}}\}_{e}+\left[\mathcal{C}_{u u}\right]\{\dot{\mathbf{U}}\}_{e}+\left[\mathcal{K}_{u u}\right]\{\mathbf{U}\}_{e}+\left[\mathcal{K}_{u \varphi}\right]\{\boldsymbol{\varphi}\}_{e}=\{\mathbf{f}\}_{e}
$$

Na prática, é conveniente aproximar o comportamento do amortecimento por (LERCH, 1990):

$$
\left[\mathcal{C}_{u u}\right]=\alpha^{e}[\mathcal{M}]+\beta^{e}\left[\mathcal{K}_{u u}\right]
$$


A partir da Equação (4.39), quatro tipos de amortecimento pode ser modelado de acordo com os valores dos coeficientes de amortecimento $\alpha^{e}$ e $\beta^{e}$ que dependem das característica de dissipação da estrutura. Quando uma estrutura está sujeita a uma excitação harmônica, o seu amortecimento pode ser considerado viscoso $\left(\alpha^{e}=0 ; \beta^{e}>0\right)$. Dessa forma, a Equação 4.39) é simplificada para amortecimentos viscosos com coeficiente $\beta^{e}$ em função do fator de qualidade mecânica $\mathcal{Q}$ :

$$
\beta^{e}=\frac{1}{\omega \mathcal{Q}}
$$

\subsubsection{Modelagem por elementos finitos}

A modelagem por elementos finitos de um ressonador piezelétrico é feita utilizando diversos tipos de elementos planos. O comportamento do fluido no interior da câmara é modelado através de um elemento de fluido acústico. Para o refletor e a camada de acoplamento são utilizados os elementos sólidos isotrópicos. A implementação do modelo dos materiais piezelétricos é feita através de elemento sólido anisotrópico. Um elemento de superfície com acomplamento fluido-estrutura é utilizado para acoplar os graus de liberdade de deslocamento das faces da câmara com os graus de liberdade de pressão do fluido no seu interior.

Todos os elementos utilizado são definidos para resolver o problema simplificado de estado plano de deformação. Por esse motivo, modelo de MEF prevê o comportamento do ressonador somente em um plano de secção transversal. Os valores do parâmetros como impedância elétrica e potencial acústico não são calculados de maneira absoluta nesse modelo. No entanto, o comportamento relativo desses parâmetro como a diferença de fase da impedância e o potencial acústico adimensional podem ser analisados através dessa aproximação.

Os resultados obtidos pelo MEF de acordo com os graus de liberdade analisados não são diretamente relacionadas aos parâmetros de interesse. No entanto, eles são calculados através dos parâmetros de amplitude de carga $Q_{0}$ e o campo de pressão do fluido.

A impedância elétrica é calculada a partir das Equações 3.15 e 3.18 de forma que

$$
Z=\frac{V}{I}=\frac{V}{\jmath \omega Q_{0}}
$$

O potencial acústico é calculado a partir das Equações 2.3 e 2.82 de forma que

$$
\mathcal{U}_{a}=2 \pi R^{3}\left(\frac{\left\langle p^{2}\right\rangle}{3 \rho_{f} c_{f}^{2}} f_{1}-\frac{\left\langle\nabla p^{2}\right\rangle}{2 \omega^{2} \rho_{f}} f_{2}\right)
$$




\section{ANÁLISE DE GERAÇÃO DE ONDAS}

\subsection{INTRODUÇÃO}

Este capítulo descreve os resultados obtidos através da simulação computacional e dos testes experimentais. O modelo unidimensional é utilizado para projetar os ressonadores multicamadas através dos parâmetros elétricos e acústicos. Através do modelo bidimensional, são apresentados os resultados do potencial de radiação acústica por meio da formulação de Gor'kov.

Em seguida, descreve-se o procedimento utilizado para a montagem e teste das células desenvolvidas, fazendo uma comparação com os resultados simulados para avaliar o seu funcionamento. Foram frabricadas três células diferentes para frequências de $0.8,1.0 \mathrm{e}$ $1.5 \mathrm{MHz}$. São apresentados os materiais utilizados nas células, sendo que uma ênfase maior é dada nas características que comprometem a semelhança da montagem com o modelo de simulação, bem como as ferramentas utilizadas para sua montagem. Os testes foram realizados com a intenção de validar os modelos através da medição direta das características elétricas por um analizador de impedância elétrica e acústicas através da visualização do potencial de radiação.

\subsection{PROJETO UNIDIMENSIONAL}

Esta seção apresenta o projeto das células através do modelo analítico unidimensional. As diretrizes são baseadas no projeto de dispositivos de separação de partículas suspensas em fluidos (GROSCHL, 1998b). Um ressonador típico de 4 camadas, visto na seção (3.3), deve ser projetado através da selecão dos materias e do cálculo das dimensões de cada camada. Deve-se levar em consideração intensidades acústicas e eficiência de transmissão máximas.

Para a camada ativa, são utilizadas cerâmicas piezelétricas de titanato zirconato de chumbo (PZT) pois possuem altas intensidades acústicas devido ao seu alto fator de acoplamento eletromecânico. A sua frequência de operação, $f_{o}$ é escolhida próxima da frequência de ressonância do modo de espessura (a fundamental ou múltiplo ímpar), que corresponde a maiores amplitudes de vibração mecâncias.

O conjunto cerâmica e camada de acoplamento é denominado transdutor e deve vibrar em sua frequência de ressonância. Para que isso ocorra, a dimensão da camada de acoplamento deve ser próxima de um múltiplo ímpar de um quarto de onda na frequência de operação, de acordo com a seção (2.2.1). As perdas por atenução nessa camada devem ser mínimas e, portanto, o menor valor possível de sua espessura é escolhido. $O$ material escolhido da camada de acoplamento foi o alumínio pois trata-se de um material de fácil usinagem. As mesma considerações referentes à camada de acoplamento são feitas com relação à camada do refletor. 
A espessura da camada da câmara é limitada devido a atenuação da onda acúsitica. Quanto maior for a atenuação para uma determinada frequência de operação menor será sua dimensão máxima na qual ainda há formação de onda estacionária. Para frequências de operação em torno de $1 \mathrm{MHz}$ essa dimensão é limitada a poucos centímetros. Embora, na prática a escolha da frequência de operação dependa bastante do ângulo de fase da impedância elétrica, não há necessidade que a dimensão dessa camada leve em consideração o comprimento de onda (GROSCHL, 1998b).

\subsubsection{Análise da impedância elétrica}

A análise da impedância elétrica pode ser feita em 4 etapas pois o comportamento total do conjunto das camadas resulta na sobreposição do comportamento de cada camada separada. Dessa forma, são identificadas as características principais da impedância elétrica para cada etapa da análise. As dimensões utilizadas para a simulação dos modelos de três células diferentes são mostradas na Tabela (2), as propriedades dos materiais são mostrados nas Tabelas $3 \mathrm{e} 4$. As propriedades do PZT8 foram obtidas utilizando um método de caracterização experimental de Pérez et al. (2010) e através das equações apresentadas na seção (3.2). As propriedades do PZT4 foram obtidas do fabricante.

Nesta seção, somente a célula modelo A é analisada e os outro modelos na seção (5.5). A característica da cerâmica piezelétrica é analisada através do cálculo de sua impedância elétrica. A Figura (14) ilustra o módulo da impedância elétrica através de uma linha contínua na escala logarítmica e sua fase através de uma linha tracejada na escala normal.

Nota-se duas regiões características, o primeiro pico de mínima impedância absoluta próximo de $1 \mathrm{MHz}$ e o segundo pico da máxima impedância absoluta próximo de 1.1 $M H z$. A frequência em que ocorre esses picos são chamadas de frequência de ressonância (ou ressonância em série) e de anti-ressonância (ou ressonância em paralelo), respectivamente. Observa-se também que essas frequências características não ocorrem

Tabela 2 - Dimensões das camadas dos ressonadores

\begin{tabular}{lccccc}
\hline Ressonador & \multicolumn{3}{c}{ Espessura $l[\mathrm{~mm}]$} & & Área $A$ \\
& Piezelétrico & Acoplamento & Liquido & Refletor & {$\left[\mathrm{mm}^{2}\right]$} \\
\hline modelo A & 2.13 & 2.85 & 17.45 & 9.53 & 2704 \\
modelo B1 & 2.54 & 3.78 & 16.55 & 9.53 & 3675 \\
modelo B2 & 1.45 & 2.15 & 16.55 & 9.53 & 3675 \\
\hline
\end{tabular}

Tabela 3 - Propriedades dos materiais do modelo unidimensional do ressonador

\begin{tabular}{lccc}
\hline Propriedades & Epóxi & Alumínio & Água \\
\hline Densidade $\left[\mathrm{g} / \mathrm{cm}^{3}\right.$ ] & 3890 & 2654 & 998 \\
Velocidade de propagação $[\mathrm{m} / \mathrm{s}]$ & 4326 & 6437 & 1490 \\
Constante elástica $c[\mathrm{GPa}]$ & 72.8 & 110 & 2.2 \\
Fator de qualidade $Q_{\text {eff }}$ & 10 & 100 & 500 \\
\hline
\end{tabular}


Tabela 4 - Propriedades dos materiais piezelétricos do modelo unidimensional do ressonador

\begin{tabular}{lcc}
\hline Propriedades & PZT8 & PZT4 \\
\hline Densidade $\left[\mathrm{g} / \mathrm{cm}^{3}\right]$ & 7514 & 7500 \\
Velocidade de propagação $[\mathrm{m} / \mathrm{s}]$ & 4722 & 4171 \\
Constante elástica $c[\mathrm{GPa}]$ & 163 & 130 \\
Fator de qualidade acústica efetiva $Q_{\text {eff }}$ & 1700 & 500 \\
Fator de acoplamento eletromecânico $\kappa$ & 0.4863 & 0.3898 \\
Permissividade elétrica $\varepsilon 10^{-9}[\mathrm{As} / \mathrm{Vm}]$ & 6.15 & 11.51 \\
Perda elétrica tan $\theta$ & 0.0014 & 0.004 \\
Constate piezelétrica $e[\mathrm{~N} / \mathrm{Vm}]$ & 15.6 & 13.9 \\
\hline
\end{tabular}

estritamente onde a curva da fase passa pela origem devido as perdas no material. Ou seja, a frequência de ressonância e anti-ressonância não correspondem à frequência de fase nula.

Em seguida, analisa-se a impedância elétrica do conjuto transdutor. A Figura (15) apresenta o resultado da simulação do conjunto correspondente à cerâmica piezelétrica e a camada de acoplamento. Uma fina camada de epóxi de $100 \mu \mathrm{m}$ entre as duas camadas também foi considerada no modelo. Ao comparar a Figura (14) com a Figura (15), nota-se a influência dessa nova camada nas frequências de ressonância do transdutor aproximandoas uma da outra. Em geral, a adição de inércia de massa no modelo resulta em um sistema com menor acoplamento eletromecânico.

Incluindo a camada do fluido, diversos picos de máximos e mínimos de impedância aparecem na Figura (16). Essas ressonâncias adicionais correspondem às ressonâncias do fluido que se repetem segundo um intervalo de frequência menor de aproximadamente $40 \mathrm{kHz}$. Isso se deve ao fato de que ao longo da espessura da câmara existem vários

Figura 14 - Resultado analítico do espectro de impedância elétrica da cerâmica piezeletrica.

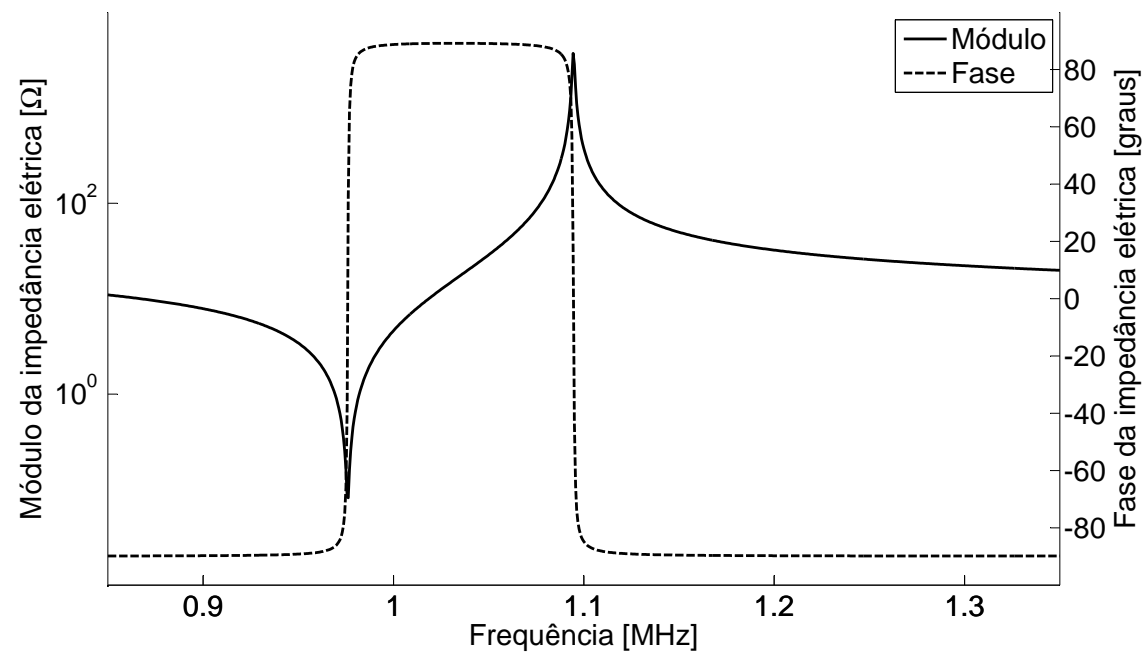


Figura 15 - Resultado analítico do espectro de impedância elétrica da conjunto transdutor.

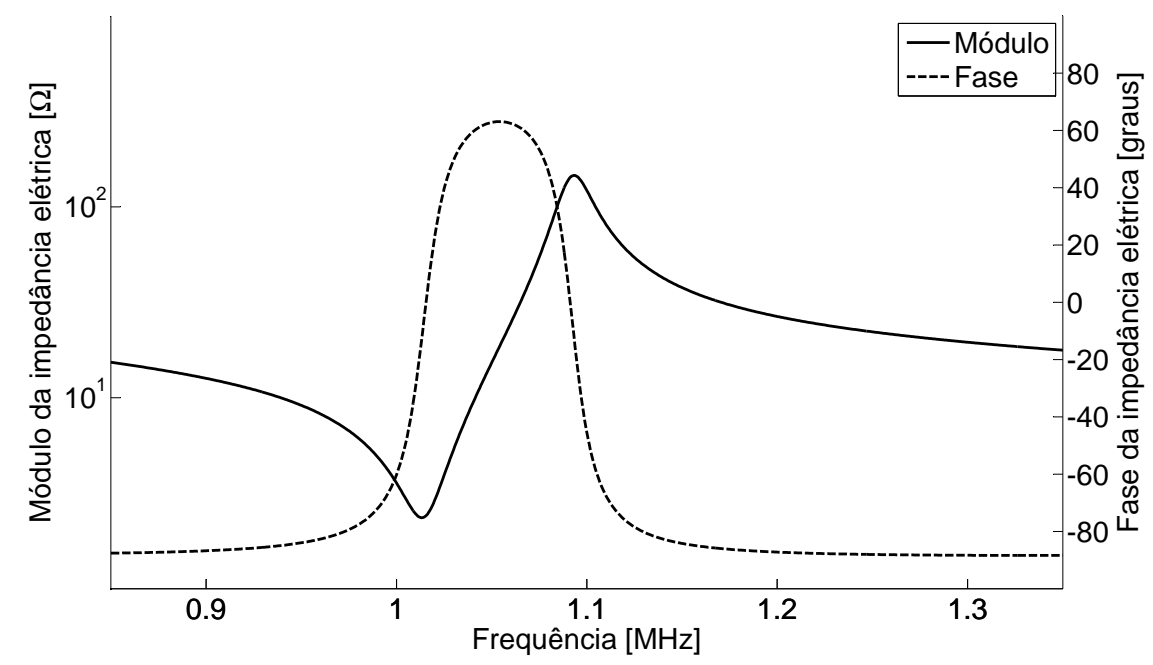

comprimentos de onda. Pode-se notar também que o modelo insere novas passagens por zero na curva de fase onde são identificadas como sendo frequências de máxima transmissão de energia real de acordo com a Equação (3.48).

A Figura (17) mostra a etapa final da análise corresponde ao modelo completo incluindo a camada do refletor. Nessa etapa é possível reparar que o refletor exerce pequena influência no comportamento elétrico final do ressonador. Muito embora o refletor seja uma peça importante na montagem, as propriedades elétricas do ressonador são fortemente influenciadas pelas propriedades do fluido no intervalo de frequência entre ressonâncias e pelas propriedades do transdutor nas regiões próximas às ressonâncias (GROSCHL, 1998a).

Figura 16 - Resultado analítico do espectro de impedância elétrica da conjunto transdutor mais a camada de fluido.

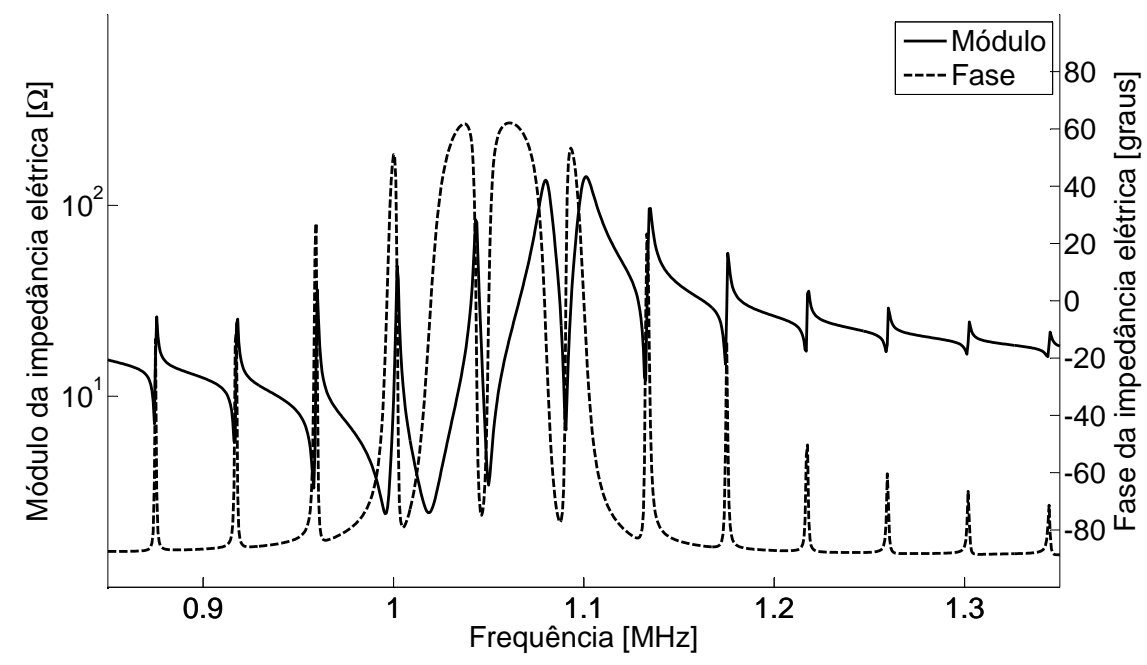


Figura 17 - Resultado analítico do espectro de impedância elétrica do ressonador completo.

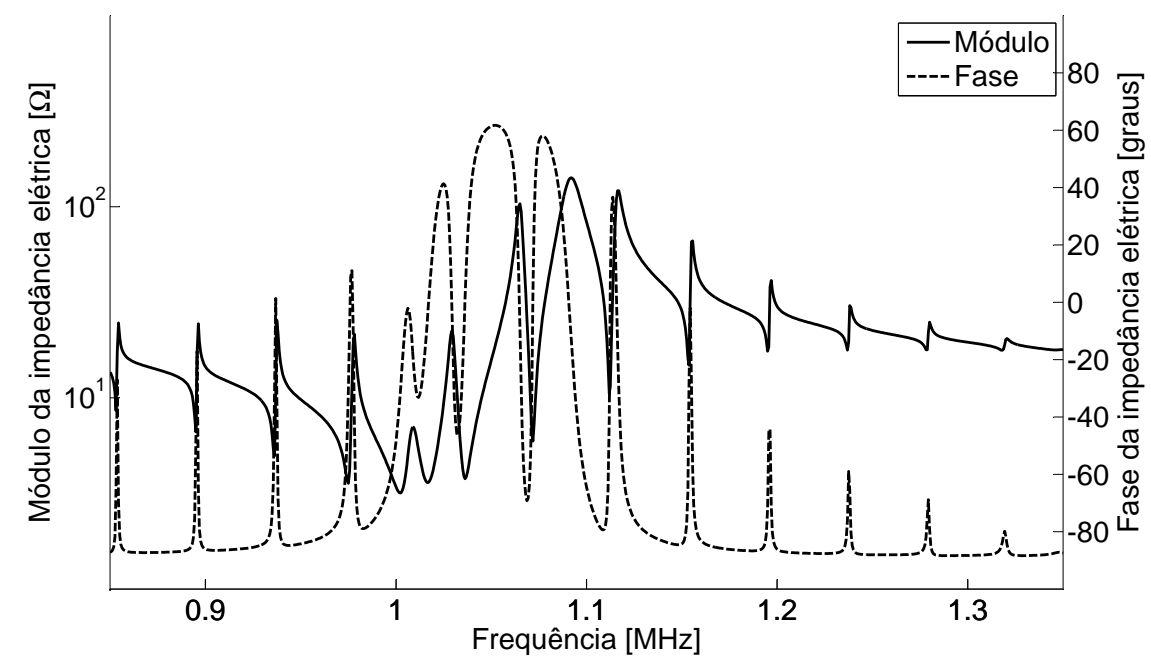

\subsubsection{Análise do fluxo de energia}

A energia total que flui ao longo das camadas do ressonador é considerado essencial no projeto de células eficientes. Por um lado, o modelo pode ser aplicado na análise de um dado ressonador em particular para a determinação da banda ótima de frequência de operação. Por outro, para uma banda desejada de frequência de operação, o modelo permite a otimização do projeto com relação à geometria do ressonador e a seleção de materiais para obter máxima eficiência (GROSCHL, 1998b).

A análise do fluxo de energia é feita para o primeiro caso de otimização. A partir do modelo desenvolvido na seção (5.2.1), são comparadas duas regiões de operação próximas das frequências de ressonância da célula. Ambas as frequências são localizadas em regiões de mínimo de impedância correspondentes à frequências de ressonância em série da camada do fluido. De acordo com a Figura (17), as frequências analisadas correspondem a 1.02 e $1.12 \mathrm{MHz}$. Para essas frequências, a Figura 18 mostra a distribuição espacial da velocidade de partícula, o fluxo de energia e a densidade de energia total.

A amplitude da velocidade de partícula é obtida através do cálculo do valor absoluto da velocidade de acordo com a Equação (3.45). O fluxo de energia total real é calculado pela parte real da Equação (3.44) multiplicada pela área da secção tranversal $A$ do ressonador. A densidade de energia total armazenada é dada pela Equação (3.51 multiplicada por $A$. Assume-se que a potência elétrica aparente de entrada seja $60 \mathrm{VA}$ para os cálculos de energia.

A partir da Figura (18) é possivel notar que a distribuição de amplitude de velocidade em qualquer frequência não possui as características de uma onda estacionária pura. É notável que os locais de mínima amplitude ocorrem em amplitudes não nulas de velocidade. Devido a atenuação, há formação de uma onda estacionária parcial no interior do 
Figura 18 - Distribuição espacial da amplitude de velocidade, fluxo de energia e densidades de energia no ressonador modelo A preenchida com água.
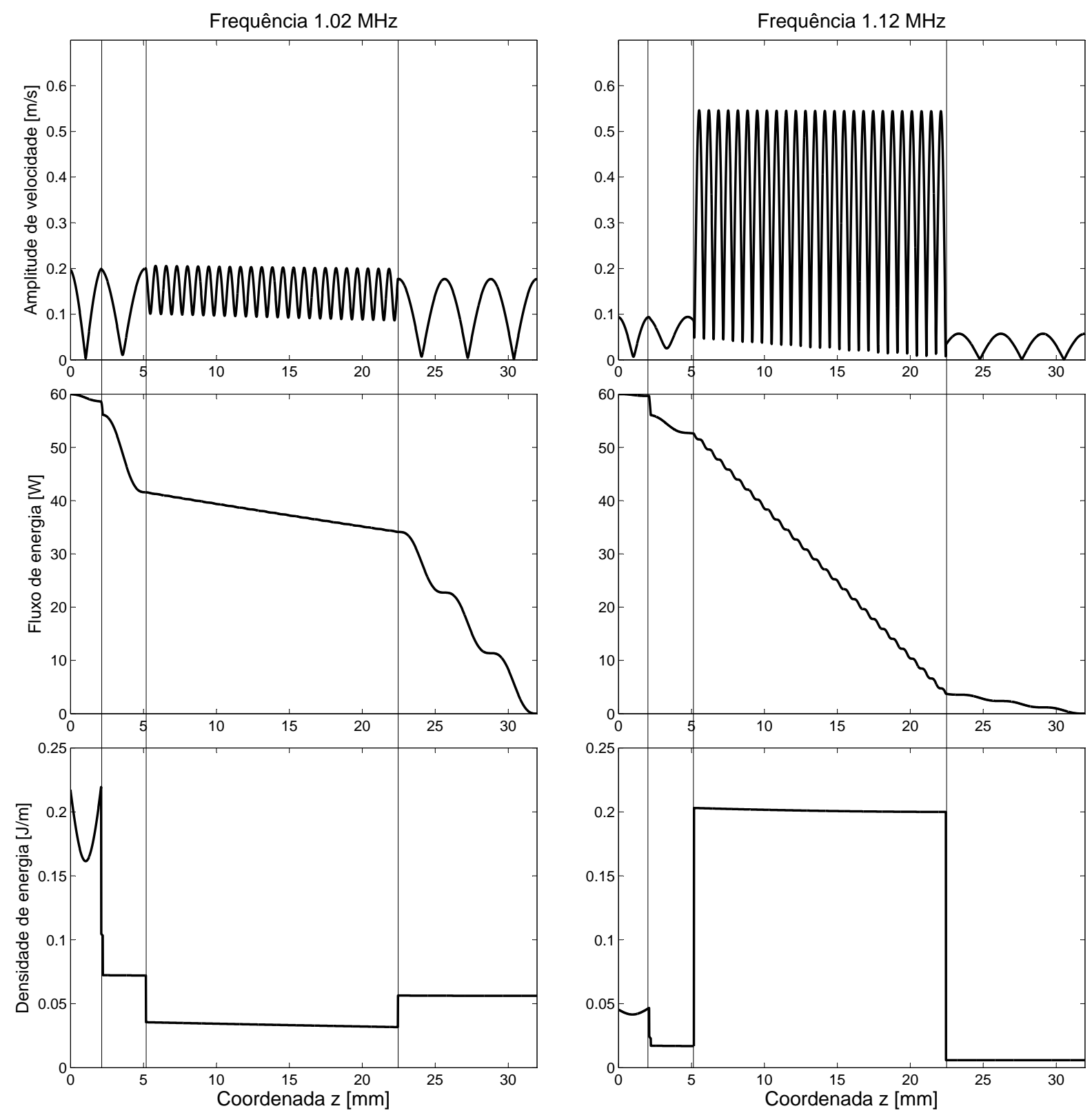

ressonador (GROSCHL, 1998a). Além disso, a onda refletida a cada mudança de interface não possui a mesma amplitude que a onda incidente, pois parte dessa onda é transmitida para a próxima camada. Nessas condições, há uma sobreposição de uma onda estacionária pura cuja energia é redistribuída e uma onda progressiva atenuada cuja energia é dissipada ao longo das camadas.

Na frequência de operação de $1.12 \mathrm{MHz}$ existe um aumento significativo na amplitude de velocidade, assim como na densidade de energia na camada de fluido comparado a camada do transdutor e do refletor. Diferente da frequência $1.02 \mathrm{MHz}$, que mostra a mesma situação na frequência de operação correspondente a ressonância em série. Nesse caso, a amplitude de velocidade em todas as camadas são praticamente iguais. A densidade 
de energia é baixa na camada de fluido e alta nas camadas do transdutor. Com a mesma potência elétrica fornecida, a densidade de energia no fluido é muito maior no caso de 1.12 $M H z$ do que no caso de $1.02 \mathrm{MHz}$.

\subsection{PROJETO BIDIMENSIONAL}

Para simular o comportamento do potencial acústico adimensional para um câmara retangular foi utilizada a Equação 4.13 do modelo analítico bidimensional e a Equação 4.42 do modelo numérico por MEF. Os modelos consideram uma secção transversal dos ressonadores no plano zy. O diagrama esquemático do modelo é ilustrado na Figura (19) cuja geometria é justificada pelos aspectos construtivos da célula apresentados a seguir na seção (5.4). Esse diagrama apresenta as dimensões da câmara ressonante e o posicionamento das cerâmicas do transdutor.

A análise desse modelo tem por objetivo verificar o comportamento real de uma câmara retangular ressonante. Através do modelo bidimensional é possível considerar variação de amplitude não somente na direção de propagação de onda como também em uma direção lateral prevista em geometrias reais de campo (GROSCHL, 1998a).

Figura 19 - Secção transversal do ressonador utilizado no modelo bidimensional plano analítico e numérico.

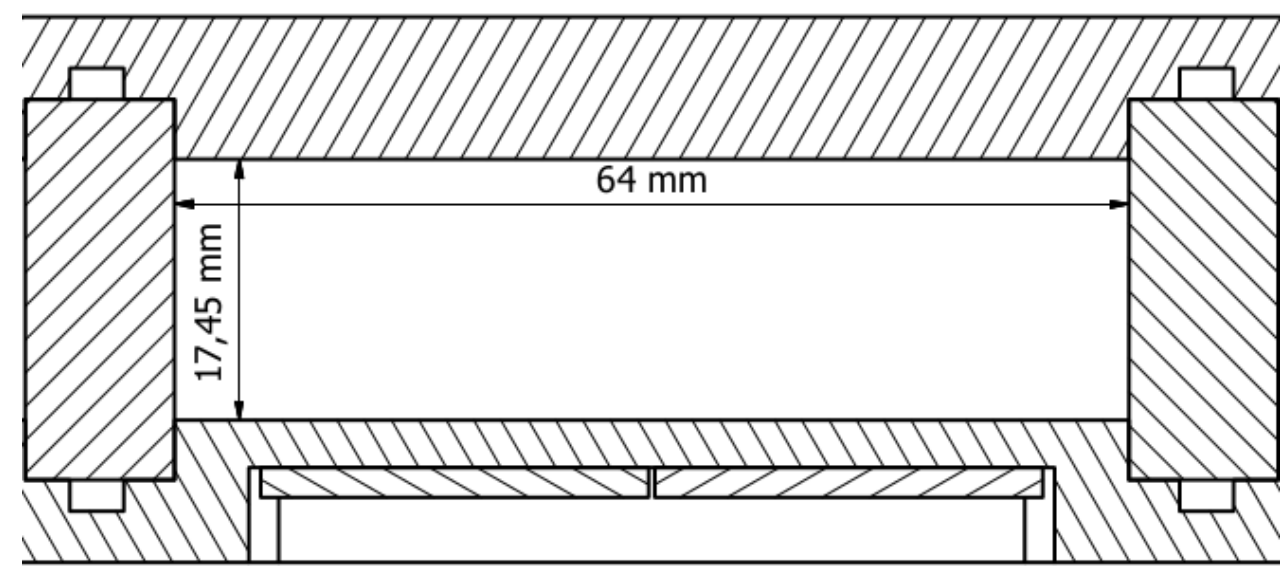

\subsubsection{Modelagem analítica}

Inicialmente é considerada apenas a propagação de ondas planas no interior da câmara com dimensões indicadas na Figura (19). Considerando as propriedades dos materiais listados na Tabela (5), o valor do número de onda na direção $z$ deve ser $k_{z} \approx 4321$ para a frequência $f=1.02 \mathrm{MHz}$ e $k_{z} \approx 4681$ para a frequência $f=1.12 \mathrm{MHz}$.

Para que haja variação de amplitude lateral o valor de número de onda na direção $y$ deve assumir um valor arbitrário que dependa do padrão de vibração da superfície da fonte. Supondo dois casos de propagação de ondas, o primeiro no qual o transdutor vibre em um padrão de deslocamento constante para cada cerâmica $\left(n_{y}=2\right)$ e o segundo no qual há 
Tabela 5 - Propriedades dos materiais utilizados no modelo analítico bidimensional.

\begin{tabular}{lcc}
\hline Material & $\begin{array}{c}\text { Velocidade } \\
(\mathrm{m} / \mathrm{s})\end{array}$ & $\begin{array}{c}\text { Densidade } \\
\left(\mathrm{kg} / \mathrm{m}^{3}\right)\end{array}$ \\
\hline Água & 1491 & 998 \\
Esfera de vidro & 5578 & 2500 \\
\hline
\end{tabular}

Figura 20 - Potencial de radiação acústica obtido pelo modelo analítico da célula modelo A nas frequência $1.02 \mathrm{MHz}$ (acima) e $1.12 \mathrm{MHz}$ (abaixo).

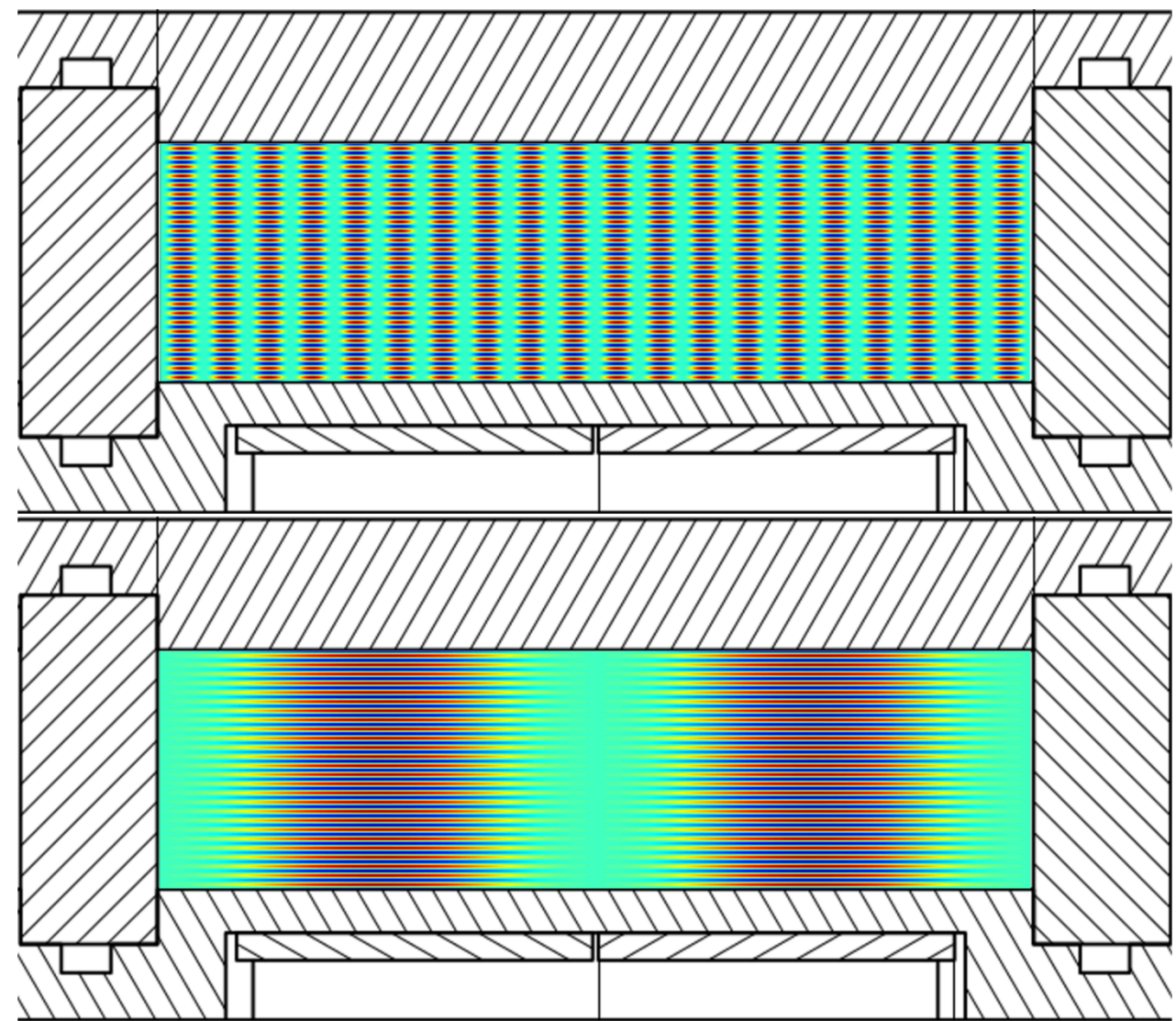

propagação ondas de superfície $\left(n_{y}=20\right)$. Dessa forma, os valores de número de onda segundo o modelo de Barmatz e Collas (1985) são calculados e mostrados na Tabela (6).

Para o cálculo de potencial acústico são considerados água como meio fluido e esferas de vidro como as partículas que sofrem a ação das forças de radiação. De acordo com as propriedades indicadas na Tabela (5), são calculados os fatores do potencial de radiação $f_{1}=0.97$ e $f_{2}=0.50$. Dessa forma, o potencial adimensional é calculado para os dois casos de propagação de onda.

A Figura (20) apresenta o potencial acústico adimensional através do gráfico onde as regiões de máximo aparecem em vermelho e de mínimo em azul. Como o modelo considera os contornos rígidos e um meio sem perdas, o seu resultado corresponde a um campo acústico puramente estacionário. Um padrão de franjas ocorre em $1.02 \mathrm{MHz}$ ao longo do eixo y que resulta da suposição feita de que há propagação de ondas superficiais na face do transdutor. Outro padrão ocorre em $1.12 \mathrm{MHz}$ menos frequente no eixo lateral 
Tabela 6 - Número de onda segundo o modelo de Barmatz e Collas (1985).

\begin{tabular}{cccc}
\hline Caso & $k_{z}$ & $k_{y}$ & $k$ \\
\hline $1^{\circ}$ & 4321 & 9812 & 4431 \\
$2^{\circ}$ & 4681 & 98.12 & 4682 \\
\hline
\end{tabular}

de acordo com a suposição de que o campo sofre influência somente na área coberta pelo transdutor.

\subsubsection{Modelagem por elementos finitos}

O modelo da secção transversal completa da célula é feito utilizando o MEF. Esse modelo além de incluir dimensões laterais como apresentado na seção (5.3), também considera uma geometria mais complexa para a camada de acoplamento e paredes laterais com dimensões finitas e propriedades realistas. As propriedades dos materiais utilizados e da cerâmicas piezelétricas conforme a formulação de estado plano de deformações estão descritas no Anexo A. Nesse anexo, o parâmetro $E$ corresponde ao módulo de Young, $\nu$ ao coeficiente de Poisson e $\mathcal{Q}$ à qualidade mecânica e as propriedades das cerâmicas estão representadas segundo a notação reduzida proposta por Nye (1985). No modelo de elementos finitos implementado não é possível incluir o fator de qualidade nas propriedades da água pois o elemento utilizado não possui graus de liberdade de estrutura.

A modelagem por elementos finitos é feita no software comercial ANSYS 10. Foram

Figura 21 - Discretização em elementos finitos, tipo de elementos utilizados e condições de contorno do modelo do ressonador.

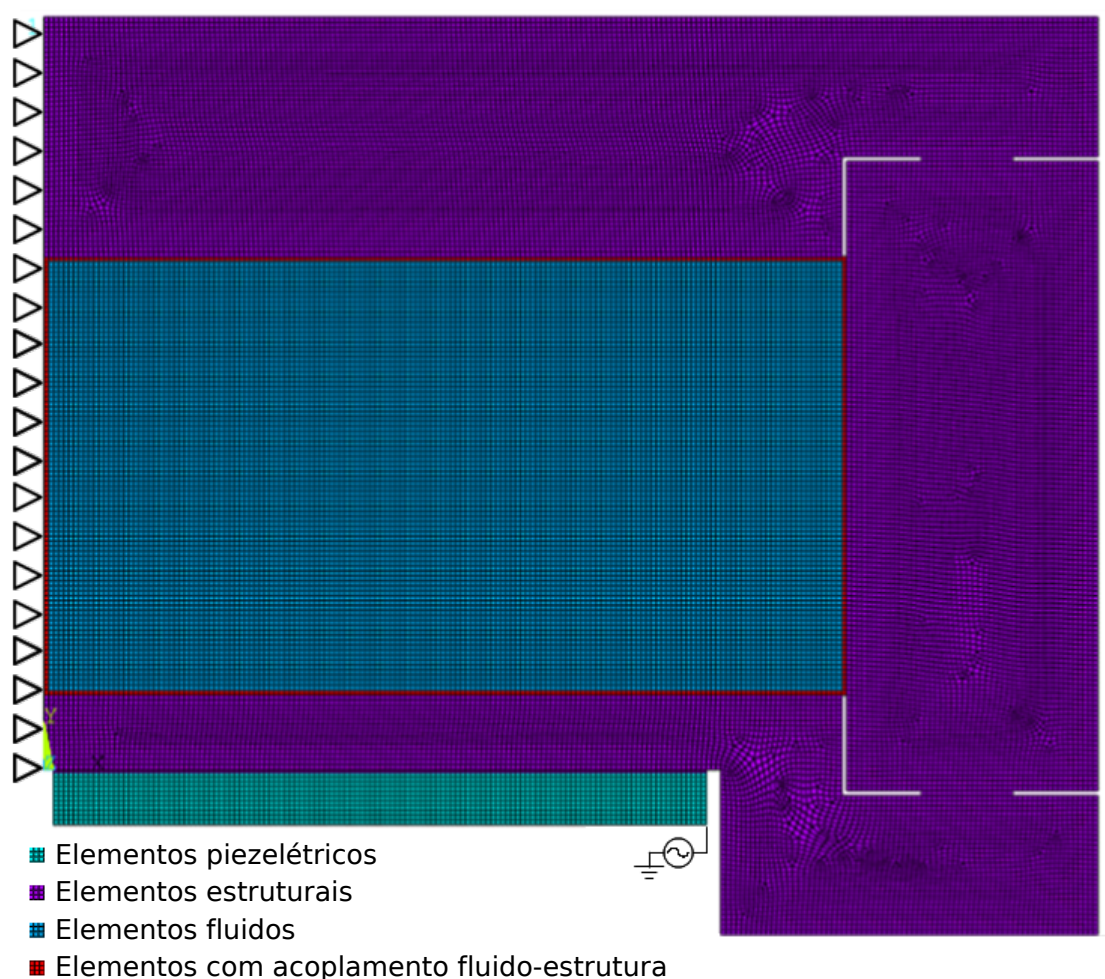


Figura 22 - Espectro de impedância elétrica do ressonador obtido por MEF.

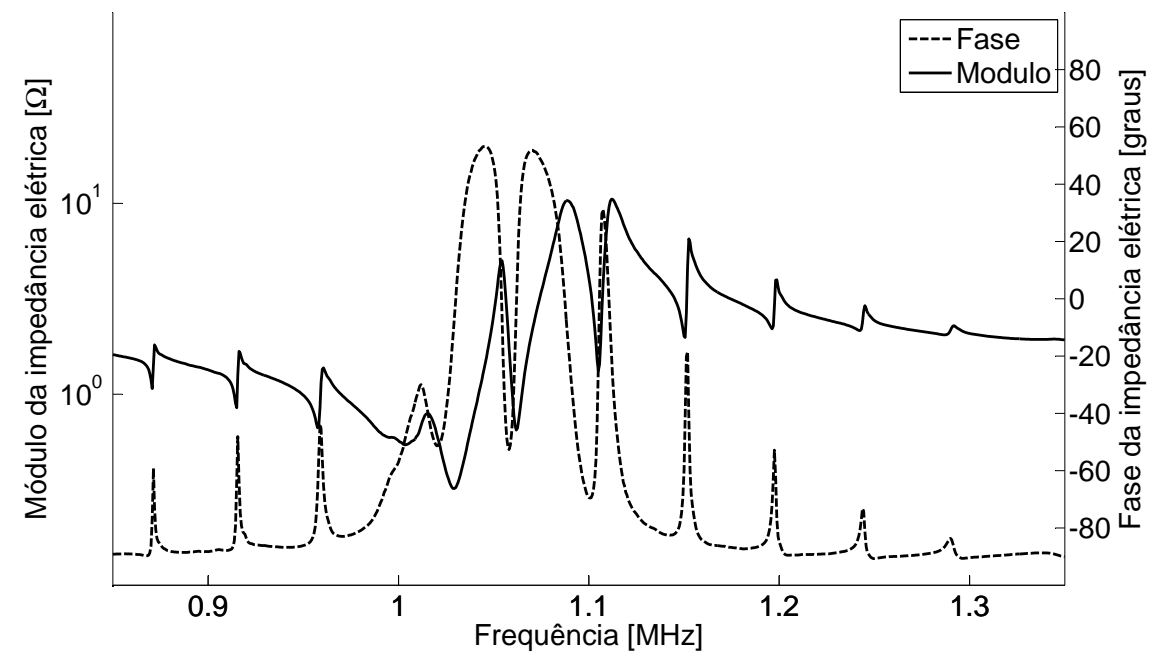

utilizados os elementros PLANE42 para modelar o material da camada de acoplamento , do refletor e das paredes laterais. O modelo da camada de fluido foi feito usando o elemento FLUID29 e o PLANE13 para simular o material piezelétrico. Por último, o elemento FSI foi utilizado para simular o acoplamento fluido-estrutura.

O modelo de elementos finitos utilizado está ilustrado na Figura 21) apresentando a distribuição dos elementos e das condições de contornos. Como a célula possui simetria retangular, o modelo de elementos finitos é feito somente de um dos lados com somente uma cerâmica. As condições de contorno utilizadas consideram que os nós localizados no eixo de simetria não possuem deslocamento na direção do eixo. Além disso, é aplicado uma diferença de potencial de $1 \mathrm{~V}$ entre os terminais da cerâmica.

A solução é obtida a partir da análise harmônica realizada no intervalo de frequência entre 0.85 e $1.35 \mathrm{MHz}$. Em seguida, são apresentados os resultados da impedância elétrica e do potencial de radiação acústica. A Figura 22 mostra o resultado do espectro de impedância elétrica. Pode-se notar que o módulo da impedância elétrica não possui a mesma magnitude daquela obtida através do modelo analítico unidimensional. No entanto, a fase da impedância elétrica obtida pelos dois modelos são comparáveis.

A Figura (23) mostra os resultados do potencial de radiação acústica para as frequências de 1.03 e $1.10 \mathrm{MHz}$. Essas frequências foram obtidas a partir da mesma análise segundo o modelo unidimensional, mas utilizando o espectro de impedância obtido pelo modelo de elementos finitos. O potencial acústico resultante nessas frequências apresenta os padrões previstos pelo modelo bidimensional analítico. No entanto, o resultado a $1.03 \mathrm{MHz}$ mostra que os padrões de franjas não são uniformes e apresentam influência da reflexão das bordas da câmara. Já o potencial a $1.10 \mathrm{MHz}$ corresponde a um resultado muito próximo do modelo ideal e é considerado esperado para os protótipos experimentais. 
Figura 23 - Potencial de radiação acústica obtido pelo MEF da célula modelo $A$ nas frequências $1.03 \mathrm{MHz}$ (acima) e $1.10 \mathrm{MHz}$ (abaixo).

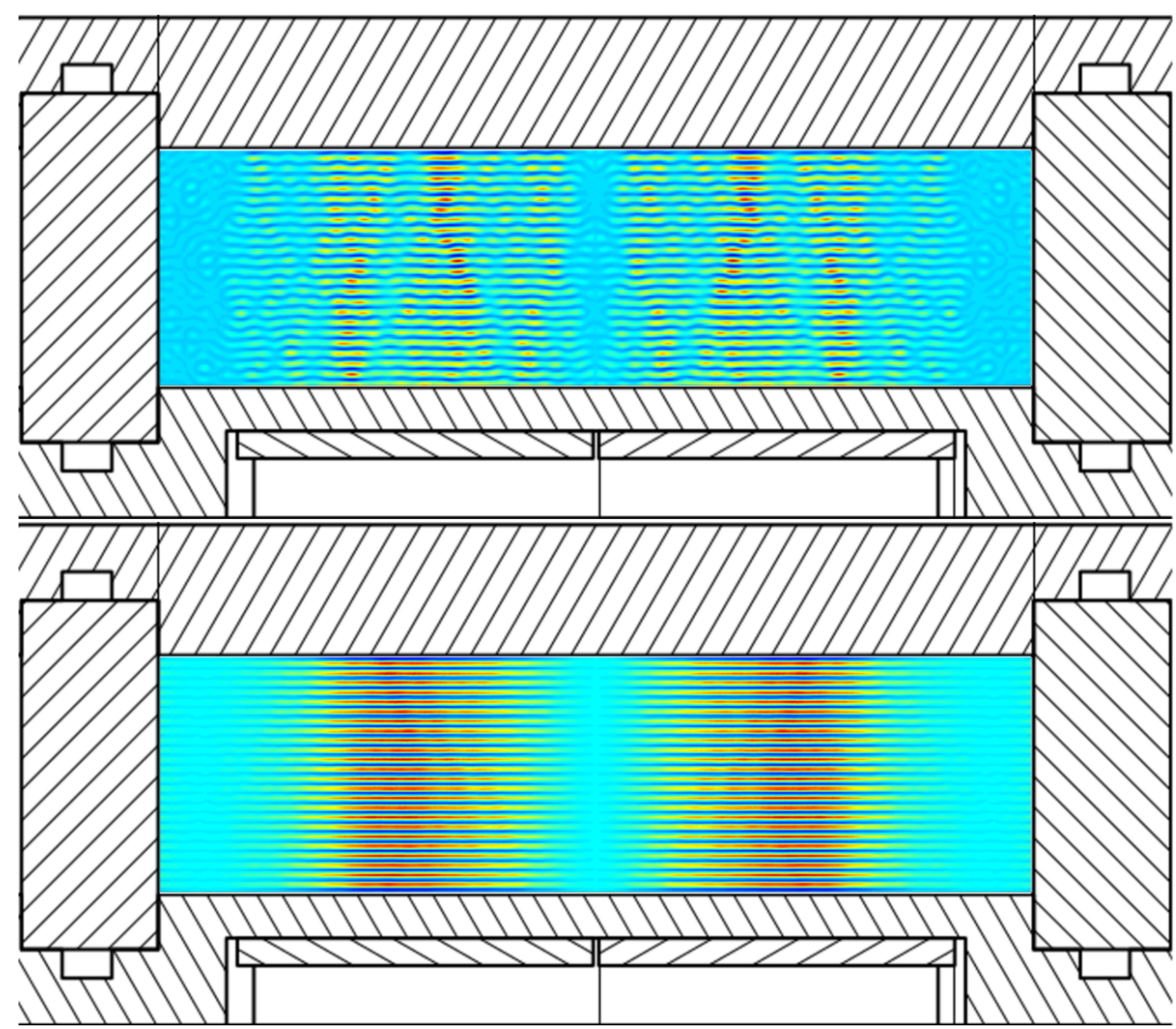

\subsection{MONTAGEM DOS PROTÓTIPOS}

Esta seção descreve todos os procedimentos adotados para realizar a montagem das células de separação desenvolvidas. São fabricadas três células distintas a partir de dois modelos ( $A$ e $B$ ) de célula projetados com características diferentes. As cerâmicas piezelétricas utilizadas nas células foram obtidas a partir de discos de cerâmica PZT.

Os discos foram submetidos a um procedimento de corte no formato de um quadrado em dispositivo de precisão IsoMet ${ }^{\circledR} 5000$ Precision Saw. A Tabela (7) indica as características das cerâmicas utilizadas para cada modelo de célula. Para obter a cerâmica do modelo B2, foi utilizado um disco de PZT8 de espessura de $2.54 \mathrm{~mm}$ lapidado no equipamento modelo PM5 (Logitech) e os eletrodo foram refeitos usando tinta condutiva de prata. A sequência de usinagem e montagem é ilustrada na Figura (24). Em seguida, foi apli-

Tabela 7 - Características das cerâmicas utilizadas nos projetos das células.

\begin{tabular}{cccccc}
\hline Modelo & Material & $\begin{array}{c}\text { Frequência } \\
f[\mathrm{MHz}]\end{array}$ & $\begin{array}{c}\text { Diâmetro } \\
{[\mathrm{mm}]}\end{array}$ & $\begin{array}{c}\text { Lateral } \\
{[\mathrm{mm}]}\end{array}$ & $\begin{array}{c}\text { Espessura } \\
{[\mathrm{mm}]}\end{array}$ \\
\hline A & PZT 8 & 1.0 & 38.1 & 26 & 2.05 \\
B1 & PZT 4 & 0.8 & 51.0 & 35 & 2.54 \\
B2 & PZT 4 & 1.5 & 51.0 & 35 & 1.45 \\
\hline
\end{tabular}


Figura 24 - Desenho esquemático de usinagem e montagem do conjunto de cerâmicas para as células modelo $A$ e $B$.

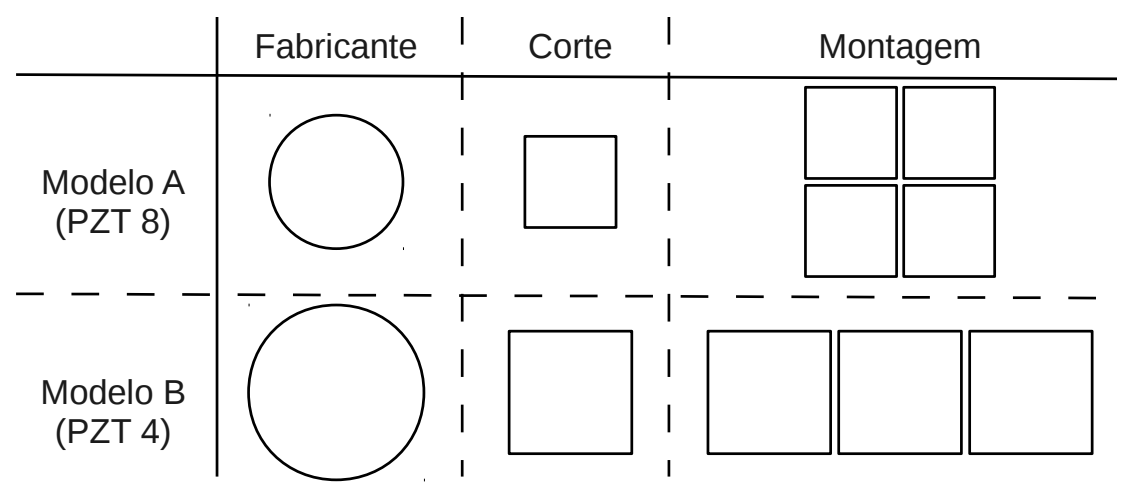

cado um isolante nas laterais das cerâmicas para cobrir as faces cortadas anteriormente. Utilizou-se uma fina camada de polyamida DuPont ${ }^{\mathrm{TM}}$ Kapton ${ }^{\circledR}$ nas faces cortadas para isolar eletricamente cada cerâmica do conjunto. O modelo A possui 4 cerâmicas com 676 $\mathrm{mm}^{2}$ de área de eletrodo e o seu conjunto possui $2704 \mathrm{~mm}^{2}$ de área. O modelo $\mathrm{B}$ possui 3 cerâmicas com $1225 \mathrm{~mm}^{2}$ de área de eletrodo e o seu conjunto possui $3675 \mathrm{~mm}^{2}$ de área. As células possuem volume de câmara de aproximadamente $120 \mathrm{ml}$.

Foi utilizado um adesivo epóxi condutivo CW2400 da All-Pec Industries ${ }^{\circledR}$ para fixar as cerâmicas nas camadas de acoplamento em material de alumínio. O eletrodo com polarização positiva da cerâmica ficou em contato com o alumínio e o de polarização negativa ficou livre. Juntamente com o efeito adesivo, o material permite condutividade entre o eletrodo de prata existente na superfície cerâmicas piezelétrica e o alumínio da camada de acomplamento. Foi feito um teste de condutividade após aquecimento em estufa a $60{ }^{\circ} \mathrm{C}$ durante 1 hora. A cura máxima do epóxi é obtida após 24 horas. Em cada cerâmica foi soldado um fio de cobre ao terminal do eletrodo a qual foi fixado o conector de sinal positivo da fonte de potência. A carcaça de alumínio das células serviu de terra físico comum à todas as cerâmicas.

A montagem de todos os componentes em cada modelo de célula é mostrada nas Figura (25), incluindo as câmaras de amostra, placas de acrílico para visualização e os parafusos para fixação. Um anel de borracha de secção cilíndrica foi utilizado para vedar os espaços de encaixe entre as peças de alumínio e de acrílico no modelo A. Para fixar as peças da célula modelo $B$ foi utilizado um selante elástico da marca Sikaflex ${ }^{\circledR}$. A montagem final dos dois modelos de célula está representada na Figura (26).

\subsection{COMPARAÇÃO DOS RESULTADOS}

Esta seção apresenta a comparação dos resultados de simulação de impedância elétrica através dos dois modelos com os resultados experimentais. Além disso, apresenta os resultados do potencial de radiação acústica através da visualização dos resultados de dois tipos de ensaio diferentes, um com esferas de vidro e outro com amido de milho. 
Figura 25 - Vista explodida da montagem da célula modelo A (acima) e B (abaixo).
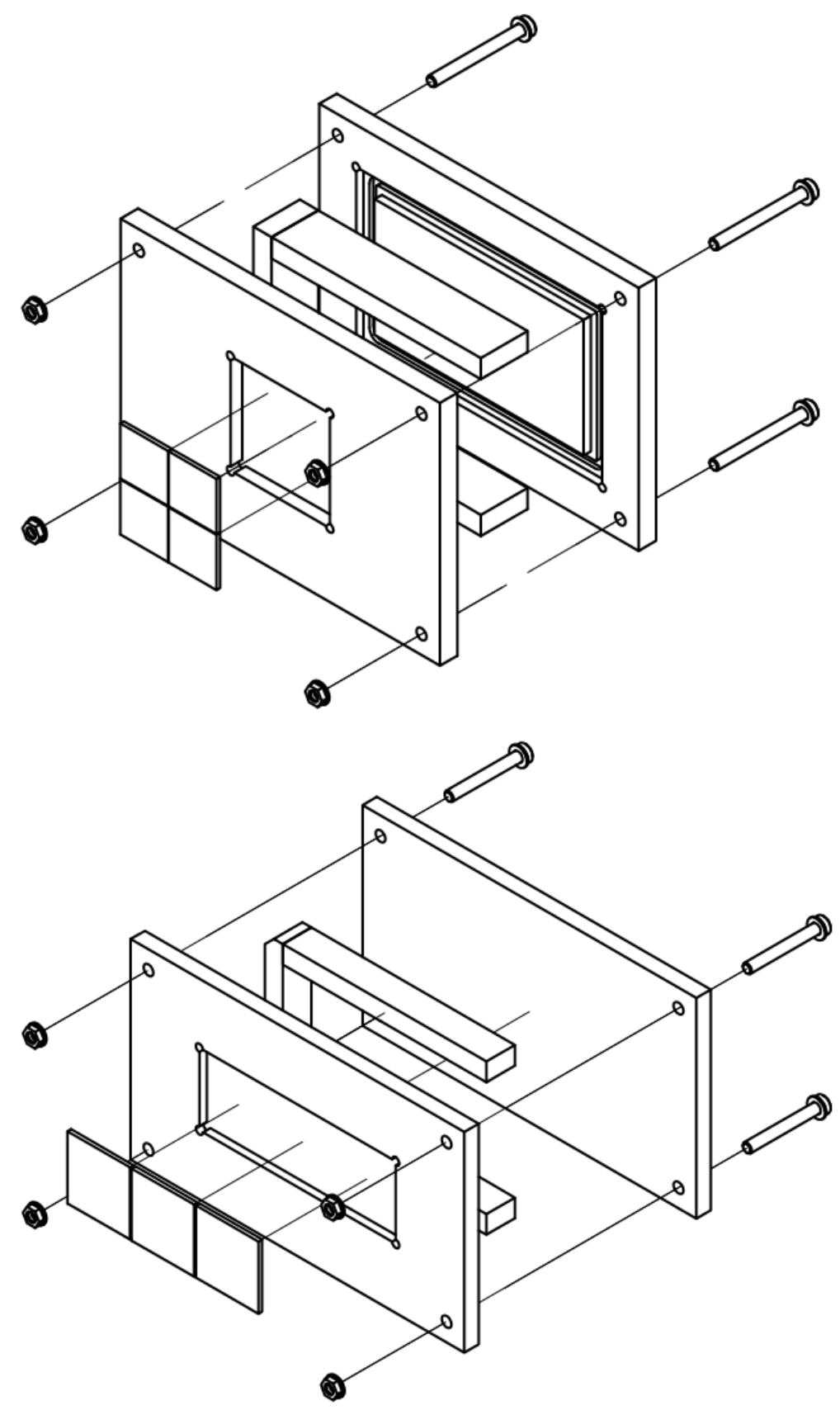

\subsubsection{Análise da impedância elétrica}

Foram extraídos os espectros de impedância elétrica experimental em uma série de 801 pontos utilizando um analizador de impedância modelo 4294A (Agilent Technologies). A faixa de frequência varia dependendo da célula analisada, mas todos os resultados são apresentados com um intervalo de $500 \mathrm{kHz}$. As Figuras (27), 28) e (29) mostram a comparação entre os resultados dos modelos unidimensional e bidimensional e os experimentias. 
Figura 26 - Fotos das células modelo A (esquerda) e modelo B (direita).

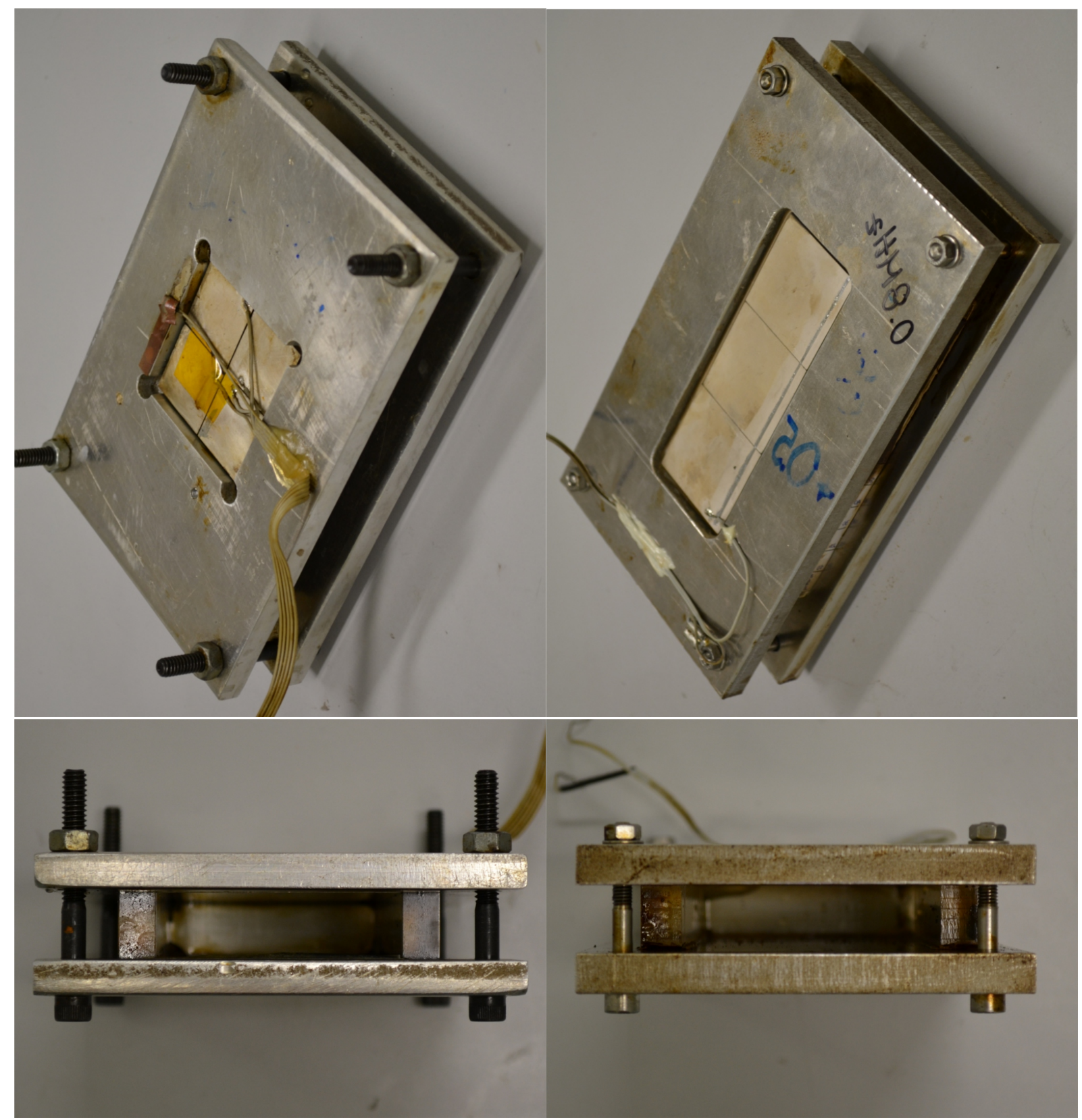


Figura 27 - Comparação do espectro de impedância elétrica da célula de $1.0 \mathrm{MHz}$.

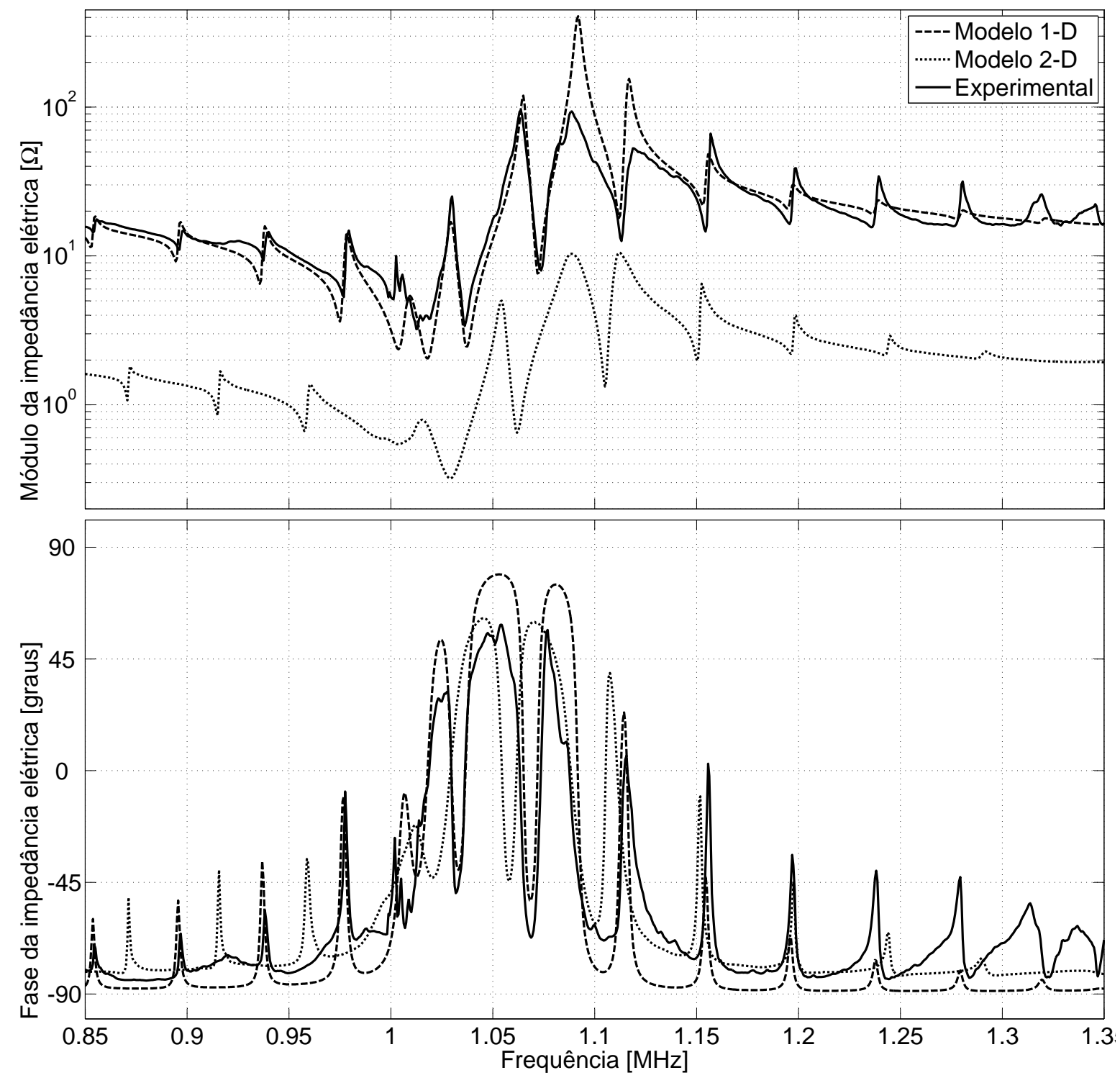


Figura 28 - Comparação do espectro de impedância elétrica da célula de $0.8 \mathrm{MHz}$.

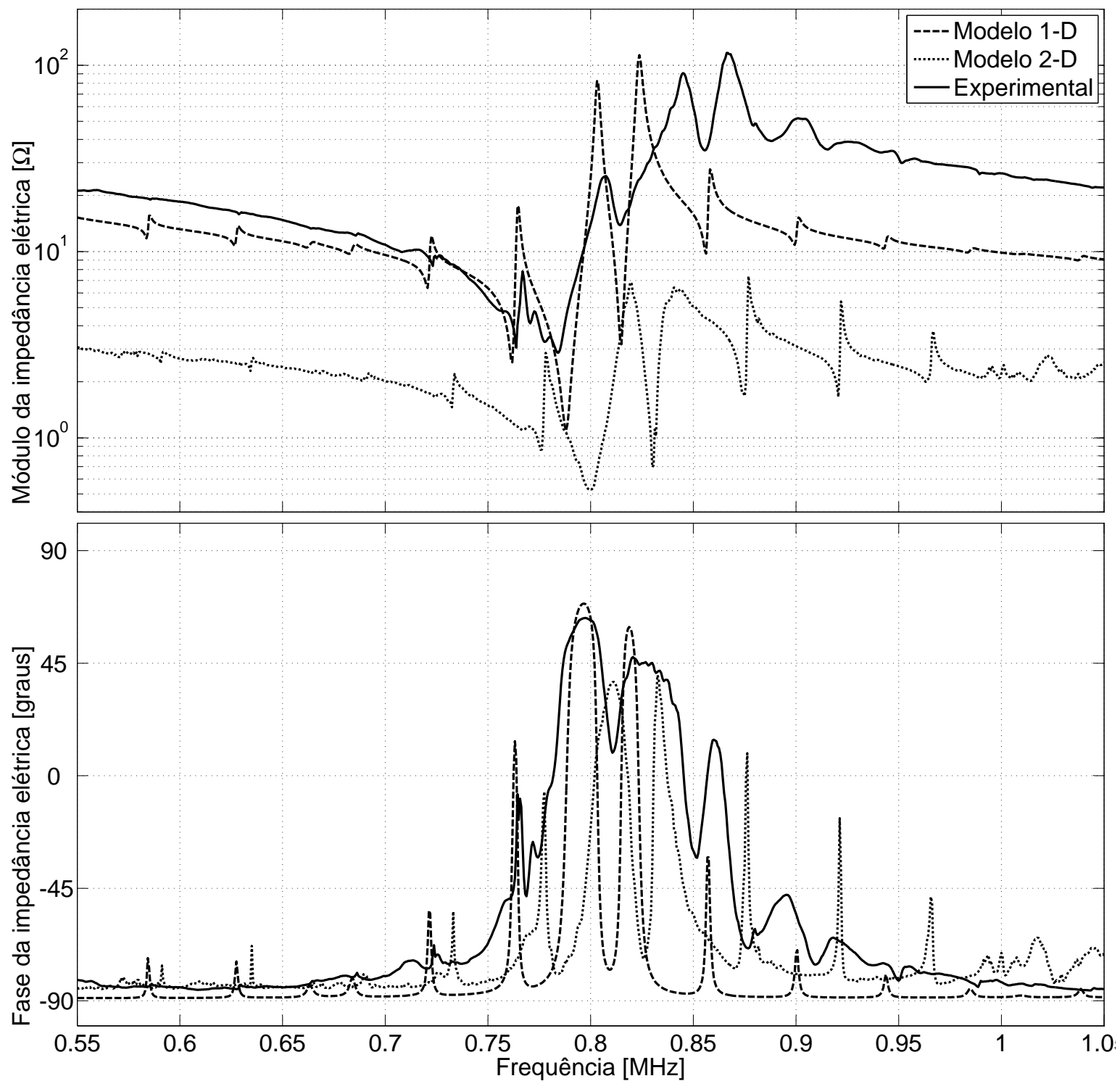


Figura 29 - Comparação do espectro de impedância elétrica da célula de $1.5 \mathrm{MHz}$.

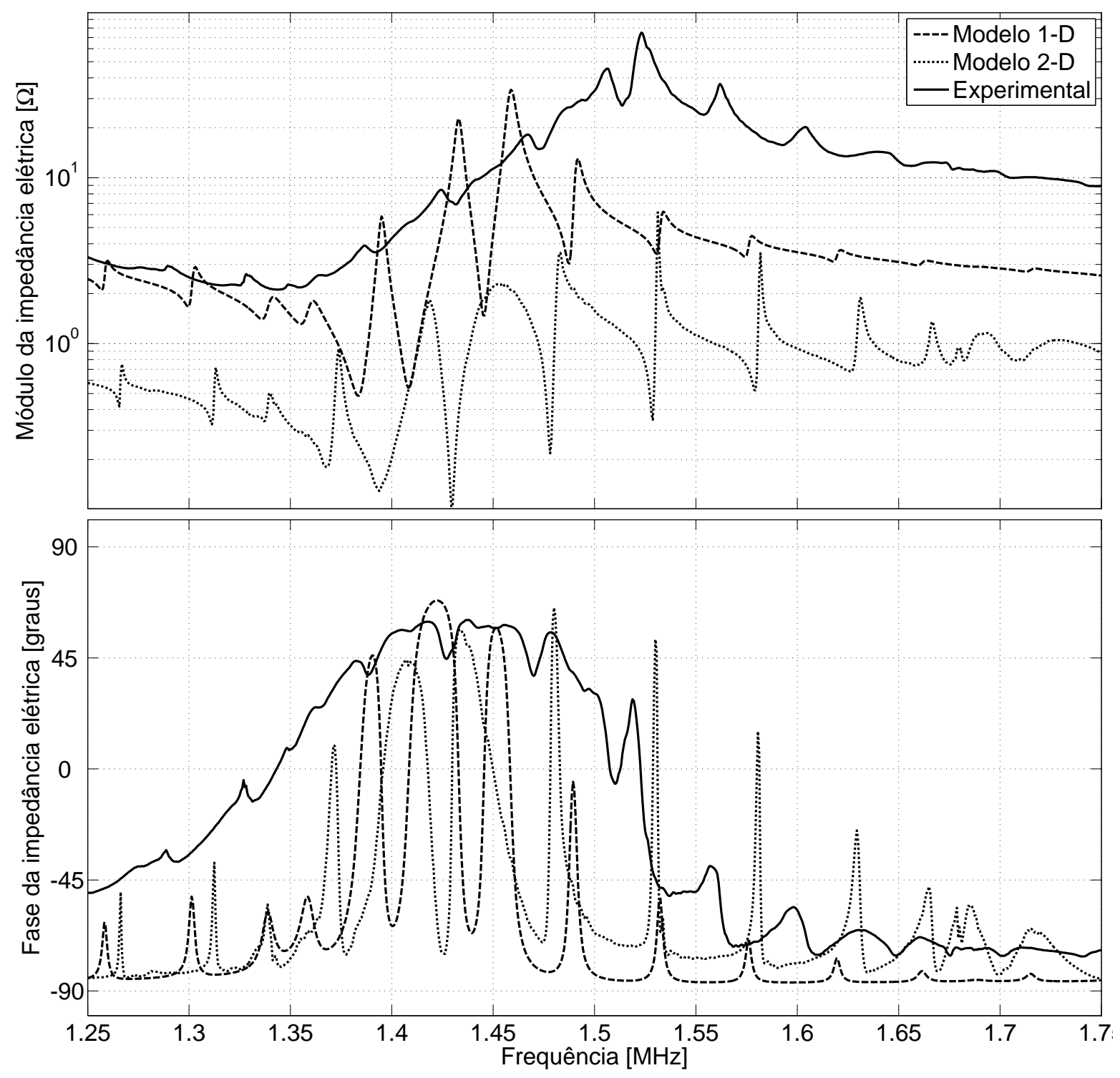




\subsubsection{Análise do potencial de radiação}

Para visualizar o potencial de radiação resultante foi feita uma montagem utilizando um conjunto de eletrônica de potência ligado às células. A eletrônica consiste de um amplificador de potência modelo 800A3A (AR RF/Microwave Instrumentation) e um gerador de função modelo 33220A (Agilent).

Na Figura (30) é mostrada uma foto ilustrando os efeitos do fenômeno da força de radiação acústica através da suspensão de partículas esféricas de vidro. Para isso, foram preparadas amostras de testes adicionando microesferas de vidro de aproximadamente $50 \mu \mathrm{m}$ de diâmetro à célula preenchida com água destilada. A foto foi tirada na mesma posição das imagens inferiores da Figura (26). Esse experimento foi realizado aplicandose uma tensão alternada de baixa potência $(\approx 20 \mathrm{~W})$ nos terminais dos eletrodos da célula. O resultado desse experimento revela que a onda estacionária gerada na câmara da célula possui as características previstas pelo modelo bidimensional. As partículas de vidro aparecem aprisionadas seguindo um padrão de franjas não uniformes.

Em seguida foi realizado um experimento com amido de milho misturado em água. Uma amostra foi preparada com teor de amido de milho de $15 \%$ em massa, formando uma suspensão relativamente estável. Essa amostra foi submetida a aplicação de ultrassom e a visualização foi feita através da parede lateral de acrílico. Uma fonte de luz foi posicionada atrás da célula para aumentar o contraste da imagem. Com a aplicação de ultrassom as partículas de amido de milho são empurradas para as regiões de mínimo potencial de radiação, onde se aglomeram e decantam por efeito da gravidade. Com o tempo a suspensão fica menos turva devido a diminuição do teor de amido de milho em água na região visualizada. Na Figura (31), a parte (a) mostra a suspensão em repouso e a parte (b) mostra o fenômeno de separação gravitacional auxiliado por ultrassom.

O processo continua até que a resultante das forças aplicadas nas partículas seja in-

Figura 30 - Foto da célula modelo A operando a uma frequência de $1.04 \mathrm{MHz}$ no ensaio com esferas de vidro.

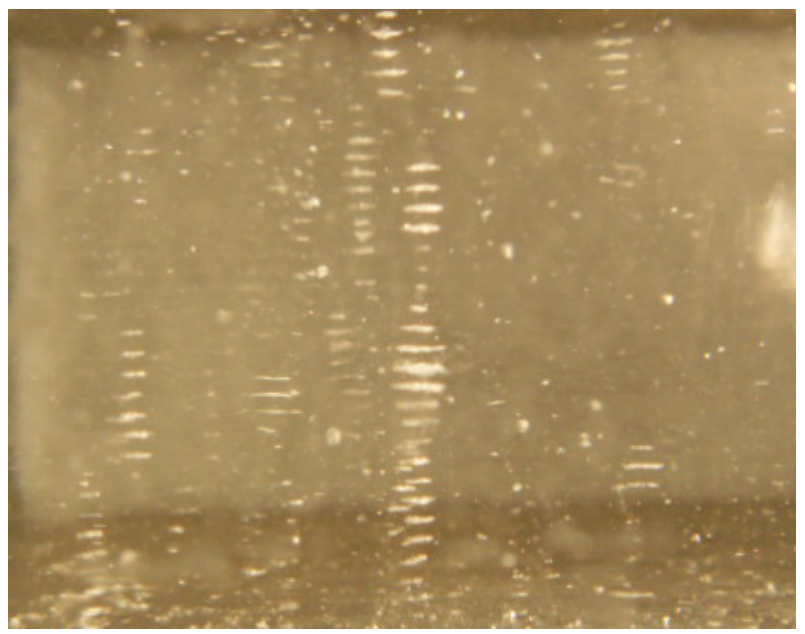


Figura 31 - Sequência de imagens do ensaios com amido de milho ilustrando o fenômeno de separação.

(a)

(b)

suficiente para provocar o arraste das partículas para o fundo da célula devido a pequena quantidade de amido de milho presente nas regiões de mínimo potencial. Algumas partículas entram em equilíbrio de forças ocasionando o aprisionamento delas. Em seguida, esse processo de aprisionamento é cessado ao desligar a aplicação de ultrassom. As partículas aprisionadas são liberadas retornando ao processo de decantação. A Figura (32) ilustra o fenômeno de aprisionamento na parte (c) e o comportamento das partículas logo após desligar o ultrassom na parte (d).

Por último, o ultrassom foi ligado novamente para recomeçar o experimento a partir de um estado de menor teor de amido de milho na parte superior da célula. Com isso, o padrão de franjas reaparece e a decantação ocorre com menor intensidade. No entanto, com o aumento da temperatura e a mudança das propriedades do fluido, a aplicação de onda estacionária apresenta uma instabilidade. Essa instabilidade provoca o escoamento do fluido na direção de propagação gerando vórtices indesejáveis no interior da câmara. $A$ Figura (33) ilustra o reinício da aplicação de ultrassom em (e) e o fenômeno de correnteza

Figura 32 - Sequência de imagens do ensaios com amido de milho ilustrando o fenômeno de aprisionamento.

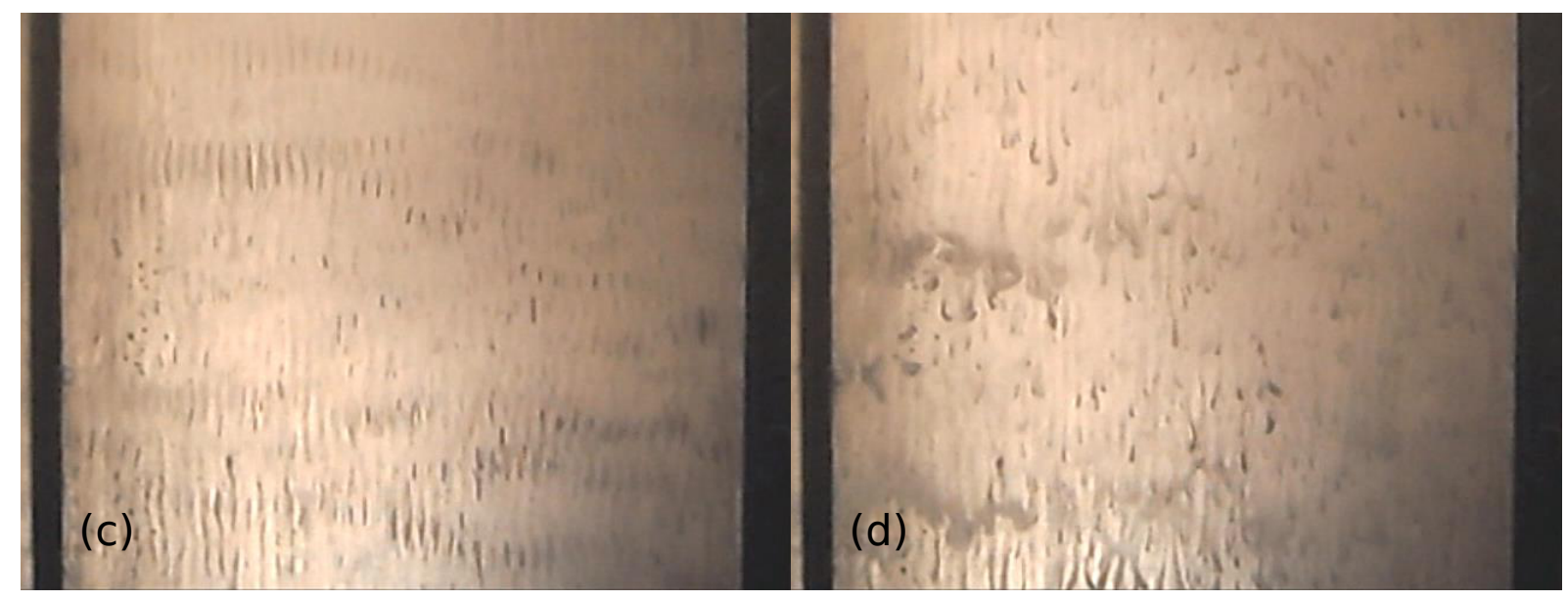


Figura 33 - Sequência de imagens do ensaios com amido de milho ilustrando o fenômeno de correnteza acústica.

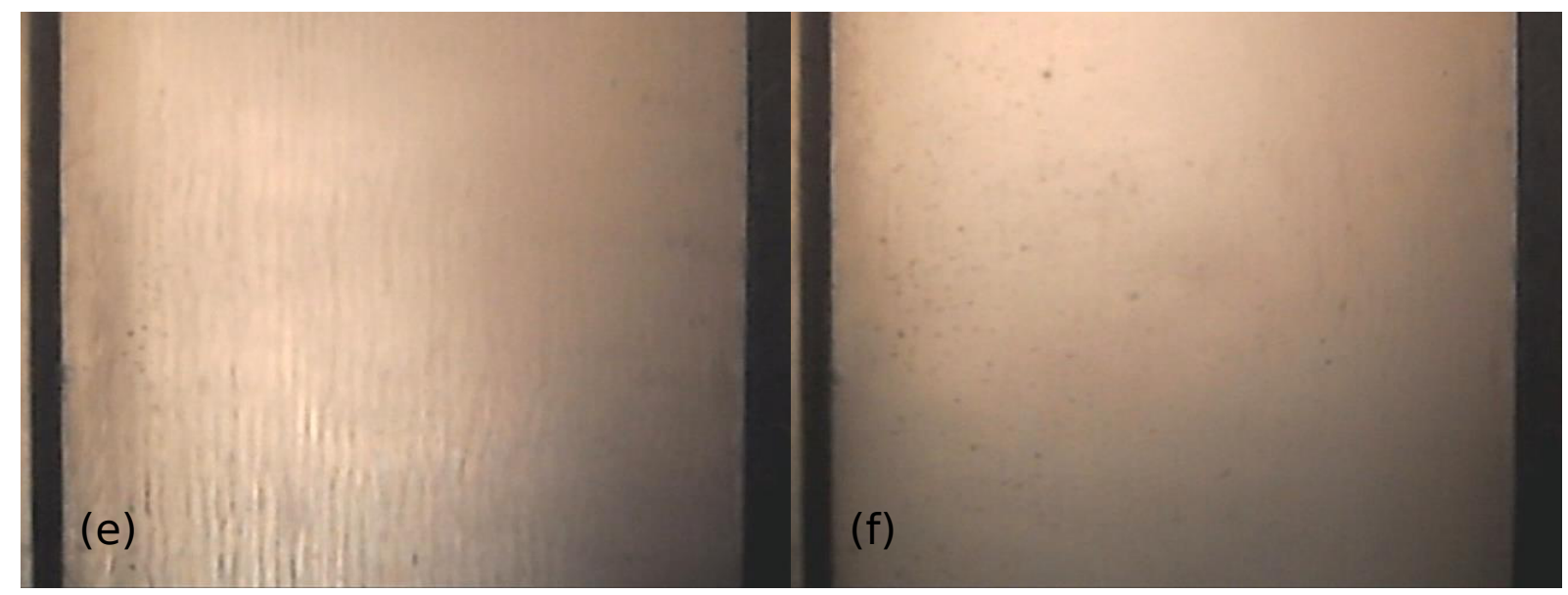

acústica em (f).

\subsection{DISCUSSÃO DOS RESULTADOS}

A comparação dos resultados revela que os modelos possuem vantagens e desvantagens. O modelo unidimensional prevê com pouca margem de erro as características de impedância elétrica das células. Isso significa que o comportamento médio da célula no plano perpendicular ao eixo são satisfeitas pelas equações desse modelo unidimensional. Portanto, é razoável concluir que os parâmetros energéticos calculados analiticamente (fluxo de energia e energia total média) também satisfaçam na média o comportamento real da célula.

Porém, a análise feita no plano de secção transversal da célula mostra que o campo acústico não possui comportamento plano. Os resultados do modelo bidimensional mostram que há formação de onda estacionária na direção perpendicular ao eixo do modelo unidimensional. Isso se deve principalmente à relação entre as dimensões da câmara e o comprimento de onda. No entanto, os resultados numéricos não prevêm de forma absoluta a impedância elétrica, que se trata de uma parâmetro importante na aplicação das células.

Os resultados experimentais de impedância elétrica mostram que a caracterização dos materiais envolvidos, principalmente das cerâmicas piezelétricas, implica na formulação de um modelo mais próximo da realidade. Verificou-se que os modelos das células modelo $B$ não representaram os resultados experimentais de forma razoável devido à falta de caracterização das propriedades das cerâmicas PZT4. Além disso, os modelos de elementos finitos não está completamente ajustado com as condições reais de contorno. Com excessão da célula modelo $A$ cujo espectro de impedância simulado possui boa concordância com o resultado experimental.

A análise do potencial de radiação feita através do experimento com esferas de vidro confirma as diferenças entre os modelos. A formação de franjas observada através dos 
resultados experimentais condiz com a análise feita pelo MEF. O problema de distribuição não uniforme da superfície do transdutor pode ser solucionada através do uso de um material piezelétrico compósito proposto por Andrade (2006). Esses materiais possuem seus modos laterias atenuados através do acréscimo de materiais poliméricos junto à estrutura da cerâmica.

Por fim, o ensaio com a suspensão de amido de milho revela diversos fenômenos decorrentes da aplicação da técnica. As forças de radiação acústica intensificam a separação gravitacional e aprisionam as partículas sólidos nas regiões de mínimo potencial de radiação. Porém, o fenômeno de instabilidade verificado no final do ensaio deve ser melhor estudado para evitar que ocorra escoamento de fluido. Esse fenômeno não é explicado neste trabalho, mas pode ser entendida como sendo correnteza acústica e decorre principalmente devido a grandes amplitudes de deslocamento da onda propagante em um meio atenuante(ANDRADE, 2010). 


\section{APLICAÇÃO DAS CÉLULAS}

\subsection{INTRODUÇÃO}

Este capítulo apresenta os procedimentos utilizados nos ensaios com emulsão de petróleo. Descreve como é feita a síntese de emulsão e analisa sua influência na impedância elétrica e no fluxo de energia da célula modelo $A$. Apresenta a montagem dos equipamentos necessários para a realização dos ensaios de aplicação das células. Por último, apresenta os resultados comparando diferentes ensaios variando a potência aplicada, frequência de operação e quantidade de desemulsificante.

\subsection{SÍNTESE E ANÁLISE DE EMULSÕES}

Nesta seção os materiais e métodos para síntese de emulsão de petróleo são apresentados. É feita uma análise dos resultados de impedância elétrica e de fluxo de energia seguindo os mesmo métodos apresentados na seção (5.2) e utilizando os resultados da caracterização das propriedades da emulsão apresentados no Apêndice (A]).

Foram preparadas emulsões de petróleo do tipo água em óleo contendo o teor de água de $33 \%(v / v)$ à temperatura ambiente de aproximadamente $23^{\circ} \mathrm{C}$. Foi ultilizada uma solução salina de $50 \mathrm{~g} / L$ de NaCl (salmoura) como fase dispersa.

Inicialmente são medidos analiticamente $200 \mathrm{ml}$ de petróleo e $100 \mathrm{ml}$ de salmoura. As duas fases são transferidas para o interior de um recipiente de vidro para agitação. Esse recipiente e os fluidos são submetidos à agitação na velocidade de $100 \mathrm{bpm}$, durante um minuto. Posteriormente, a emulsão é cisalhada utilizando o homogeneizador UltraTurrax T25, na rotação de $8000 \mathrm{rpm}$, durante um minuto e quinze segundos.

Em sequência, um produto químico desemulsificante é adicionado à emulsão seguida de sua homogeneização por um minuto. O desemulsificante DISSOLVAN 961 é diluído à 3, 4.5 e 6\% $(v / v)$ em álcool etílico e uma dosagem de produto químico de 10, 15 e 20 ppm é utilizada através de uma micropipeta de $100 \mu L$.

\subsubsection{Análise de impedância elétrica}

Após a síntese da emulsão, foi feita uma verificação experimental da influência das propriedades da amostra na impedância elétrica da célula. Foi utilizado o mesmo procedimento descrito na seção (5.5) para comparar os resultados experimentais com o modelo unidimensional. Para obter as propriedades da emulsão, foi feita uma caracterização utilizando uma ensaio não destrutivo por ultrassom. A técnica de transmissão e recepção bem como os resultados obtidos estão descritos no Apêndice (A).

A partir do valores de densidade, velocidade de propagação da emulsão e da Equação (A.8), foi estimado o valor da qualidade acústica effetiva da câmara com emulsão. $O$ 
Figura 34 - Comparação do espectro de impedância elétrica do ressonador utilizando emulsão de petróleo para análise da carga.

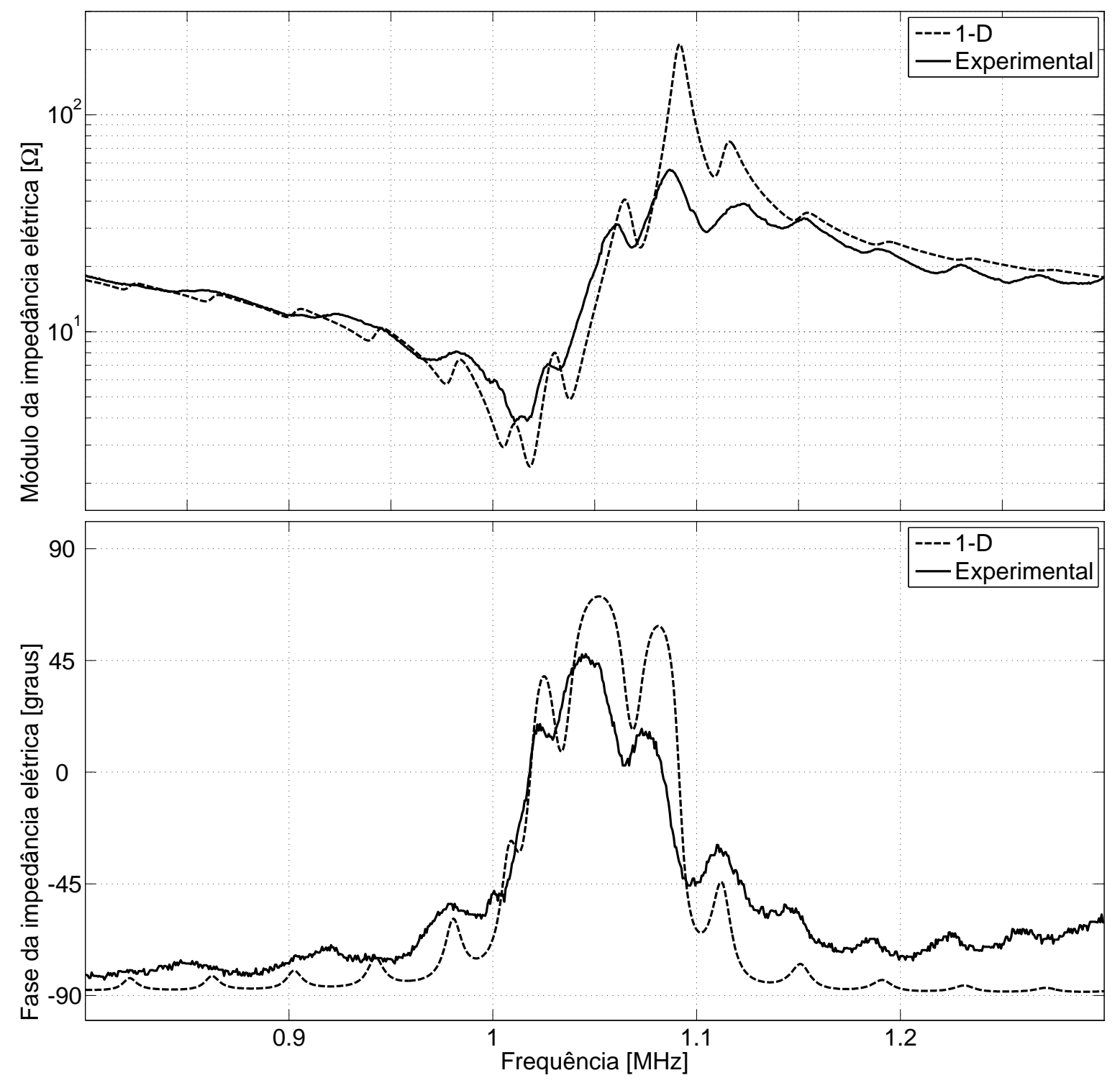

valor encontrado, $\mathcal{Q}_{\text {eff }}=100$, resulta da ação do coeficiente de atenuação efetivo levando em consideração perda por absorção e perdas adicionais. A Figura (34) apresenta o resultado da comparação do espectro de impedância elétrica experimental com o simulado.

O resultado de impedância elétrica implica que os modos de ressonância da câmara, antes evidentes no espectro da célula com água, aparecem com menor intensidade sendo atenuados pela gotículas de água da emulsão. Dessa forma, uma análise energética é feita novamente para comparar a eficiência considerando as novas regiões de frequência de máxima transmissão de energia real. De acordo com a Figura (34), as frequências de 1.02 e $1.09 \mathrm{MHz}$ foram escolhidas. 
Figura 35 - Distribuição espacial da amplitude de velocidade, fluxo de energia e densidades de energia no ressonador modelo A preenchida com emulsão.
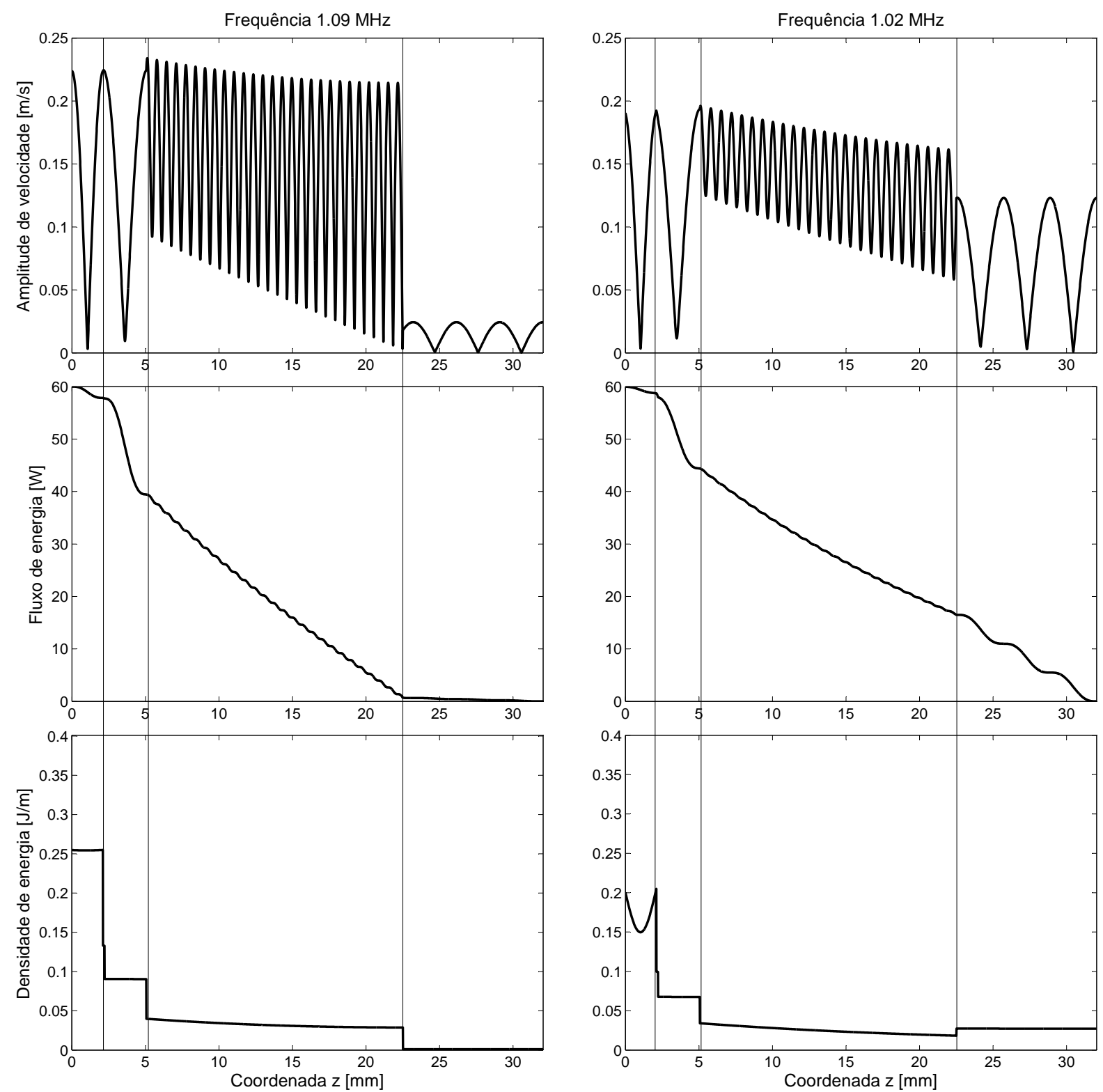

\subsubsection{Análise do fluxo de energia}

A Figura (35) apresenta a análise do fluxo de energia para as frequência onde há maior transferência de energia real. O gráfico de distribuição de amplitude de velocidade revela que há uma grande diferença entre a onda propagante presente no início e no final das camadas. De acordo com a distribuição de fluxo de energia e de densidade de energia, nota-se que a maior parte da energia transmitida é perdida devido a forte atenuação na camada da emulsão.

Apesar das características comuns ao dois pontos de operação, observa-se que a amplitude de velocidade na câmara é maior na frequência de $1.09 \mathrm{MHz}$. Porém, isso não significa que há maior densidade de energia na câmara operando a $1.09 \mathrm{MHz}$. 


\subsection{ENSAIOS DE COALESCÊNCIA DE EMULSÕES}

O procedimento utilizado no preparo das emulsões dos petróleos baseia-se na metodologia empregada para a avaliação do desempenho de desemulsificantes em petróleos em laboratório. Nesse ensaio, comparou-se o desempenho da desemulsificação de petróleos segundo o mecanismo da separação gravitacional, mediante aplicação de ondas estacionárias de ultrassom. A cinética de separação foi monitorada através da fração de água livre no interior das células de separação.

Transferiram-se alíquotas de $120 \mathrm{~mL}$ de emulsão sintética para as duas células de separação para avaliação da desemulsificação. A primeira célula (chamada de teste branco) foi deixada por 20 min em análise do mecanismo de separação gravitacional através da quantificação da separação de água em função do tempo. A outra célula foi submetida a tratamento com ultrassom. O procedimento utilizado neste ensaio por ultrassom foi 0 mesmo realizado no teste com aquecimento convencional.

Um procedimento de ensaio similar é descrito no Apêndice (C), no qual é realizado banho de ultrassom com frequência mais baixa (35 KHz) em emulsões de óleos lubrificantes. Nesse método alternativo apresentado por Antes (2011), diversos ensaios com emulsão de petróleo são realizados e servem de comparação com os resultados deste trabalho.

\subsubsection{Conceito de instrumentação}

Para realizar os ensaios, foi utilizado uma instrumentação que inclui controlador de frequência (PC), células de ultrassom, eletrônica de potência, sensores de corrente e tensão, sensores de temperatura e aquecedor controlado como ilustrado na Figura (36).

Os sensores de temperatura e o aquecedor foram montados para funcionar em maIha aberta com controle manual de temperatura. Porém, o aquecedor controlado não foi

Figura 36 - Esquema geral da instrumentação para os ensaios.

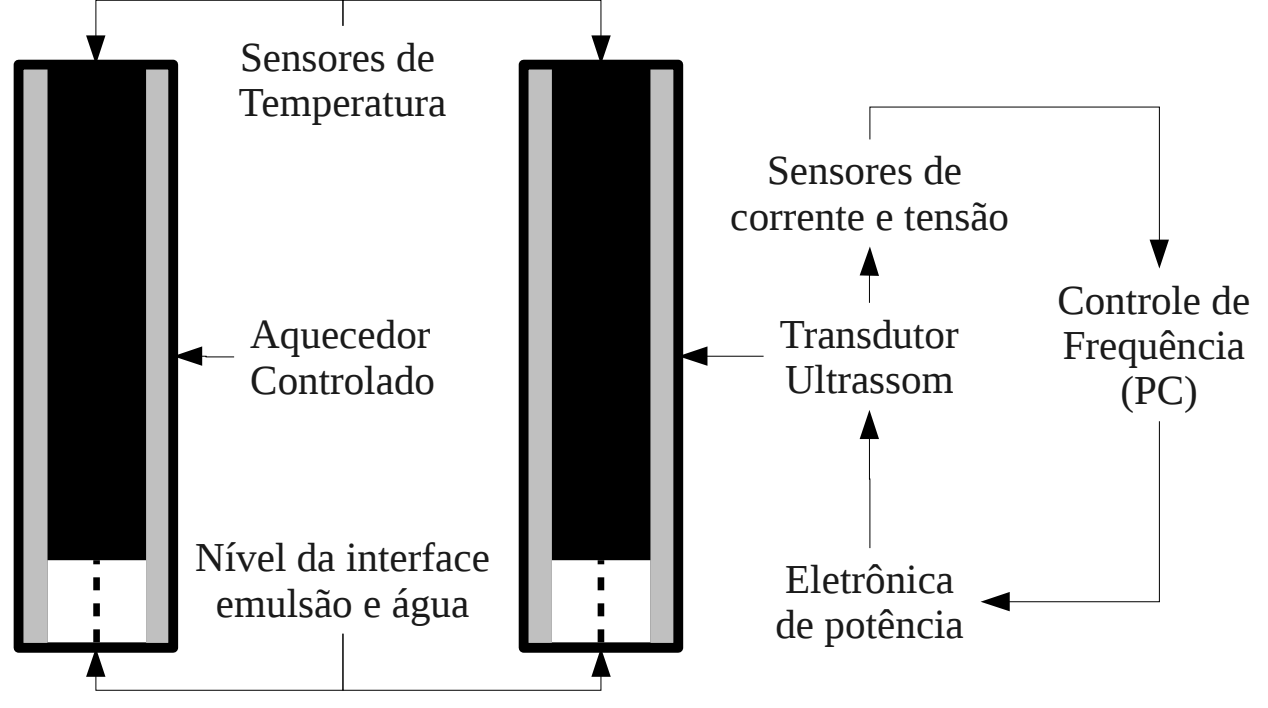


utilizado para os resultados finais pois a diferença entre a inércia térmica das células dificultava o controle preciso da temperatura dos ensaios. Já os sensores de corrente e tensão foram utilizados em malha fechada com controle automático de frequência através do PC e a eletrônica de potência. A instrumentação utilizada no controle também faz o cálculo da potência aplicada em tempo real e seu ajuste é realizado manualmente através da variação do ganho na saída do amplificador de potência.

A malha de controle de frequência monitora a corrente e tensão aplicadas na célula e atua no gerador de sinal variando a frequência de excitação e maximizando a potência aplicada. O osciloscópio captura através dos sensores a diferença de fase entre corrente e tensão. O PC aquisita o seu valor médio a uma taxa de amostragem de $1 \mathrm{~Hz}$, atuando como controle no sentido de minimizar o erro entre o valor médio e o de referência.

Um comando é enviado para que o gerador de sinal aplique o sinal na frequência atual até que receba o próximo valor. Os parâmetros do controlador PID foram ajustados para obter uma resposta em regime sem erro. Mantendo uma diferença de fase nula entre a corrente e tensão o controle minimiza a perda de potência real aplicada durante o ensaio. Maiores detalhes do sistema de controle são encontrados no Apêndice (B).

\subsubsection{Aparato experimental}

$\mathrm{Na}$ etapa de preparação de emulsão foram preparados diluissões de desemulsificante utilizando uma micropipeta de volume fixo $(100 \mu L)$ e outra pipeta graduada de $10 \mathrm{~mL}$. Em seguida foram armazenados para serem utilizados posteriormente nos ensaios. Acreditase que parte do erro quanto a cinética de desemulsificação pode ser atribuída a volatilidade dessa diluição. A Figura (37) mostra o equipamento utilizado para cisalhar a emulsão logo antes de ser misturada ao desemulsificante.

Para realizar o monitoramento da desemulsificação, foram utilizadas escalas calibradas

Figura 37 - Foto em detalhe do preparo de emulsões: UltraTurrax (esq.), micropipeta (cen.), desemulsificante diluído (dir.).

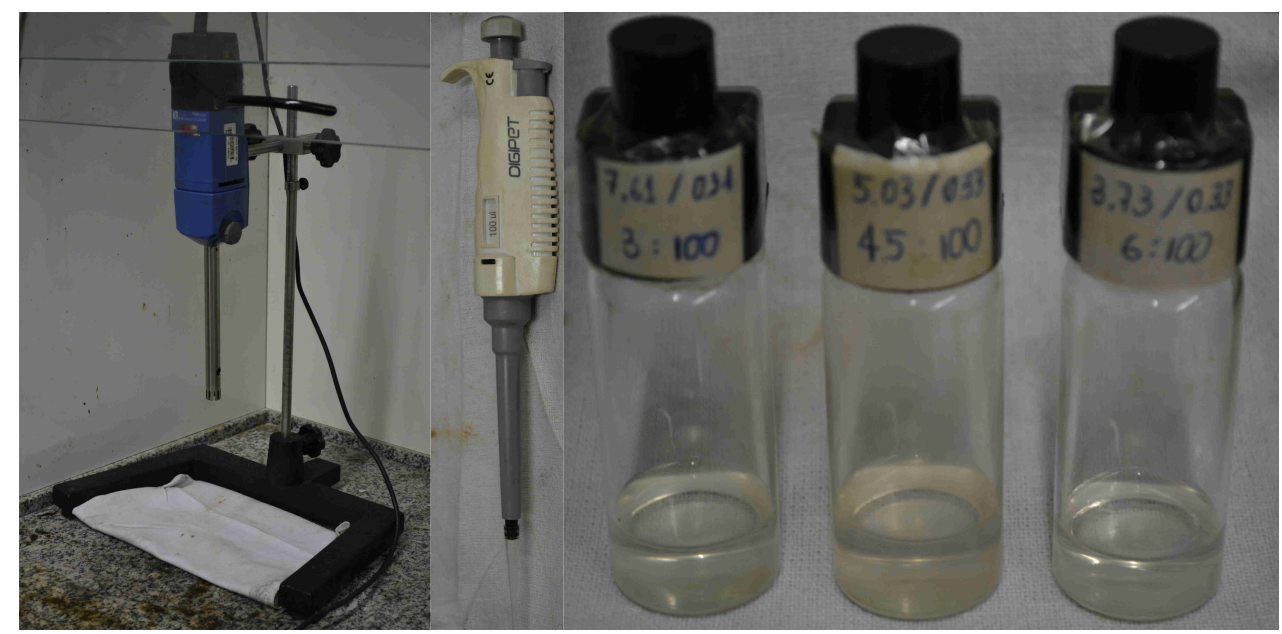


Figura 38 - Foto em detalhe da visualização da interface óleo-água (esq.) e do sensor de temperatura (dir.).

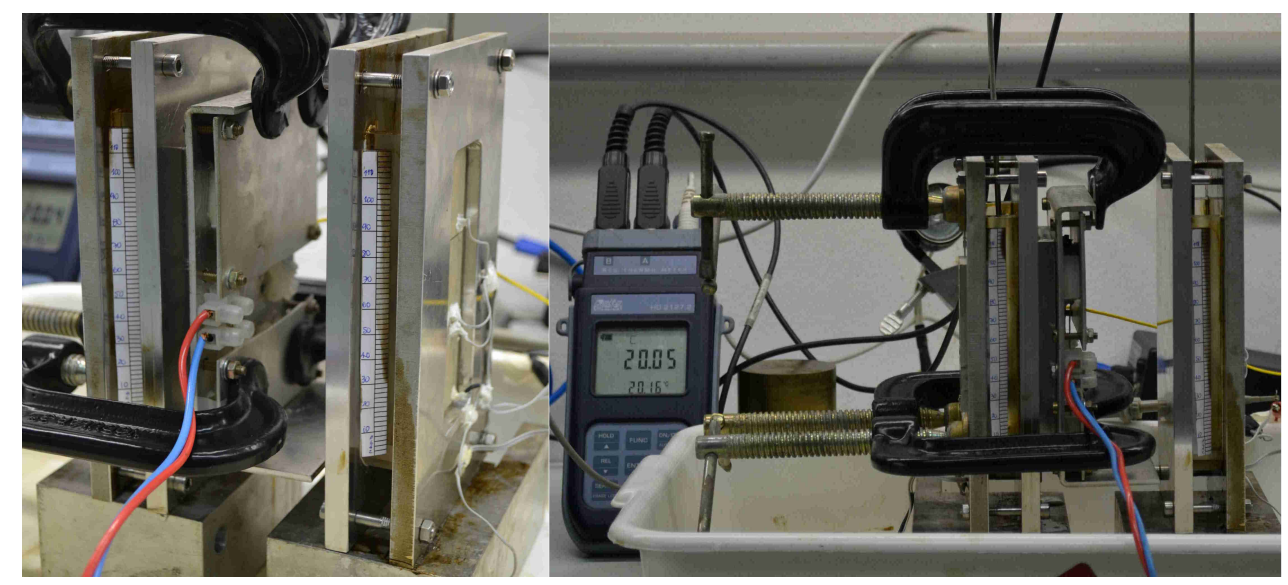

e fixadas às células em uma de suas paredes de acrílico. Nesse caso, não é possível a visualização do fenômeno de coalescência pois a amostra de emulsão é muito turva. No entanto, a temperatura foi medida em uma região fixa das células e parcialmente em contato com a emulsão. Durante os ensaios, a temperatura da emulsão sendo tratada com ultrassom aumenta dependendo da potência aplicada, porém não corresponde a variação máxima no interior das células devido ao posicionamento do sensor. A Figura (38) ilustra como foi feita a visualização da interface de água bem como a posição dos sensores de temperatura no interior das células.

Os ensaios foram realizados à temperatura ambiente de aproximadamente $22{ }^{\circ} \mathrm{C}$. Porém, essa temperatura foi controlada pelo ar condicionado do laboratório que gerava uma grande dispersão nos resultados durante os ensaios. Uma quantidade significativa de ensaios foi desconsiderada já que a temperatura influenciava na eficiência de separação. $A$ Figura (39) ilustra a bancada de ensaio mostrando a disposição dos equipamentos.

Figura 39 - Foto geral da bancada de ensaio.

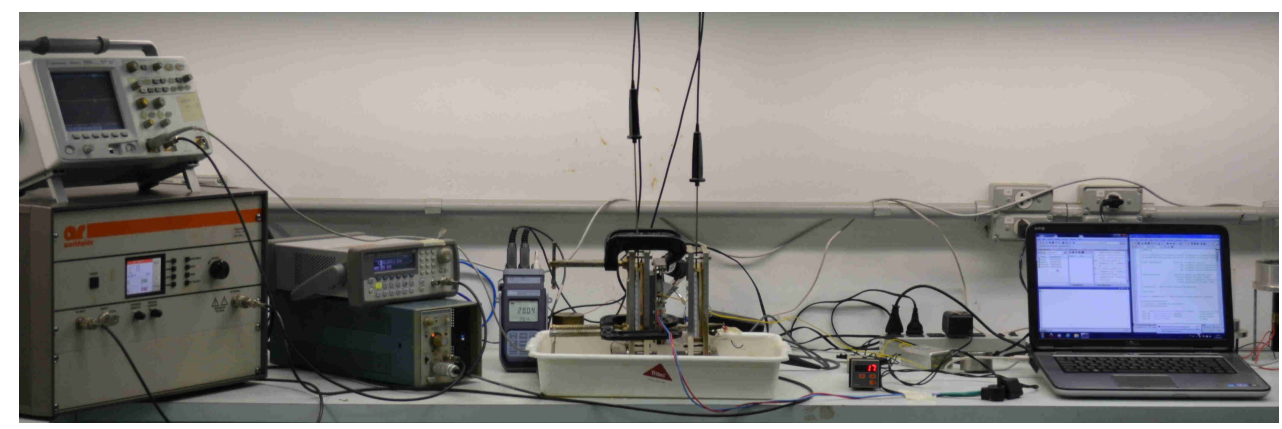

\subsubsection{Resultados do ensaios}

Diversos ensaios foram realizados variando frequência, potência e quantidade de desemulsificante para um quantidade fixa de $120 \mathrm{ml}$ de emulsão. São apresentados os resultados 
compilados através de gráficos que mostram a fração em volume de água separada (\%) em função da evolução no tempo.

Figura 40 - Exemplo de monitoramento de temperatura.

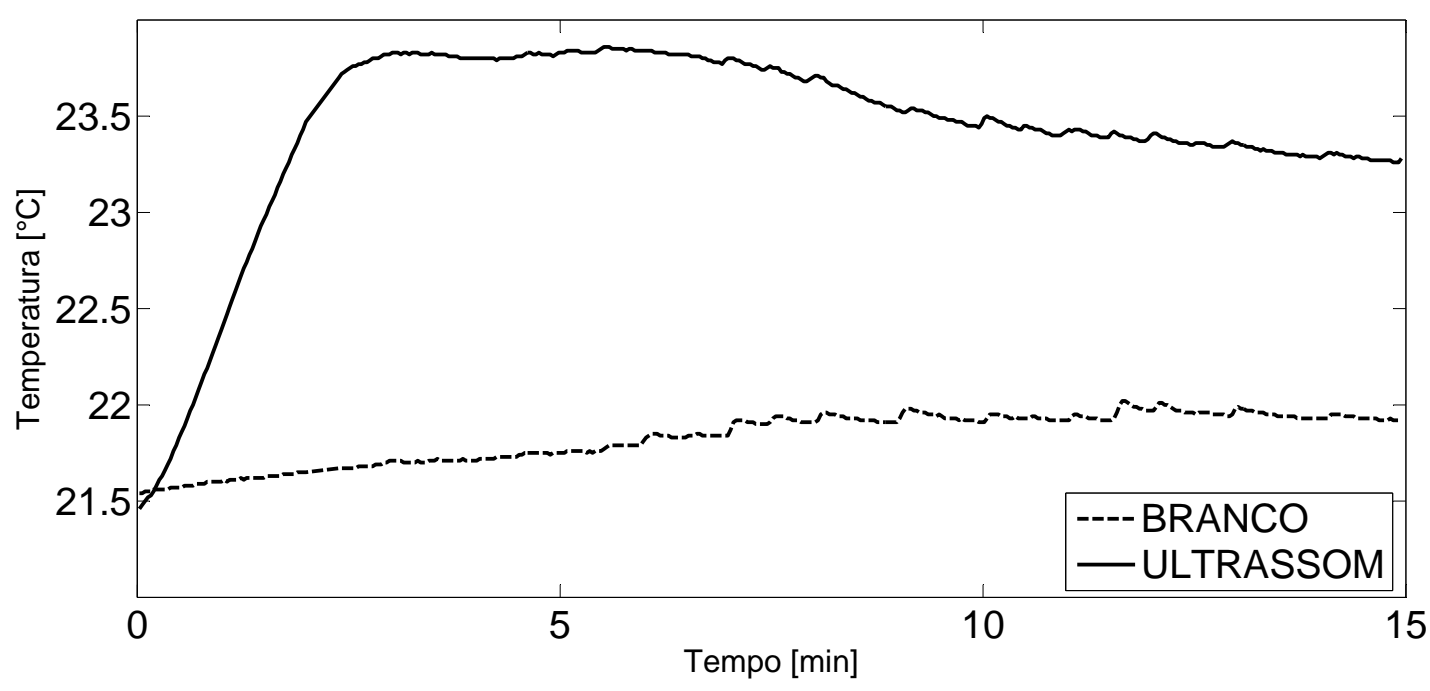

A variação máxima de temperatura foi em média de 3,6 e $9{ }^{\circ} \mathrm{C}$ para as potências de 25 , 50 e $75 \mathrm{~W}$, respectivamente. O gráfico da Figura 40 mostra a evolução da temperatura no tempo durante um dos ensaios, no qual a origem do eixo do tempo corresponde ao início da aplicação do ultrassom. Nessa figura, a linha contínua e tracejada indicam os valores da temperatura medida no interior da célula com aplicação de ultrassom e do branco, respectivamente.

As frequências de operação utilizadas foram: $0.85 \mathrm{MHz}, 1.08 \mathrm{MHz}$ e $1.52 \mathrm{MHz}$. Todas as frequências escolhidas são próximas da frequência de anti-resssonância do transdutor e foram utilizados os mesmos parâmetros de controle para todos os ensaios. A seguir, as Figuras 41) a 43 mostram os gráficos de comparação entre ensaios com características diferentes realizados em triplicata. Cada ponto colorido no gráfico corresponde à média da fração em volume de água separada e as barras verticais indicam o seu respectivo desvio padrão. Nas legendas, as séries temporais identificadas pelas palavras ULTRASSOM e BRANCO significam a presença e ausência, respectivamente, da aplicação de ultrassom segundo as características indicadas. Durante todos os ensaios o ultrassom foi aplicado entre o primeiro e o terceiro minuto.

A Figura (41) compara os resultados dos ensaios com a célula de $1 \mathrm{MHz}$ nas potências de 25, 50 e $75 W$, utilizando 10 ppm de desemulsificante. Na Figura (42), são mostrados três pares de ensaios com a célula de $1 \mathrm{MHz}$ a uma potência de $50 \mathrm{~W}$, utilizando 10 , 15 e 20 ppm de desemulsificante. Uma comparação entre a evolução dos ensaios com branco e $10 \mathrm{ppm}$ de desemulsificante e com ultrassom a $1 \mathrm{MHz}$ e a $75 \mathrm{~W}$ é mostrada na Figura (44). Por último, a Figura (43) mostra uma comparação entre as frequências de 0.8, 1 e $1.5 \mathrm{MHz}$ a uma potência de $50 \mathrm{~W}$ e utilizando $10 \mathrm{ppm}$ de desemulsificante. 
Figura 41 - Evolução dos ensaios de comparação entre potências aplicadas.

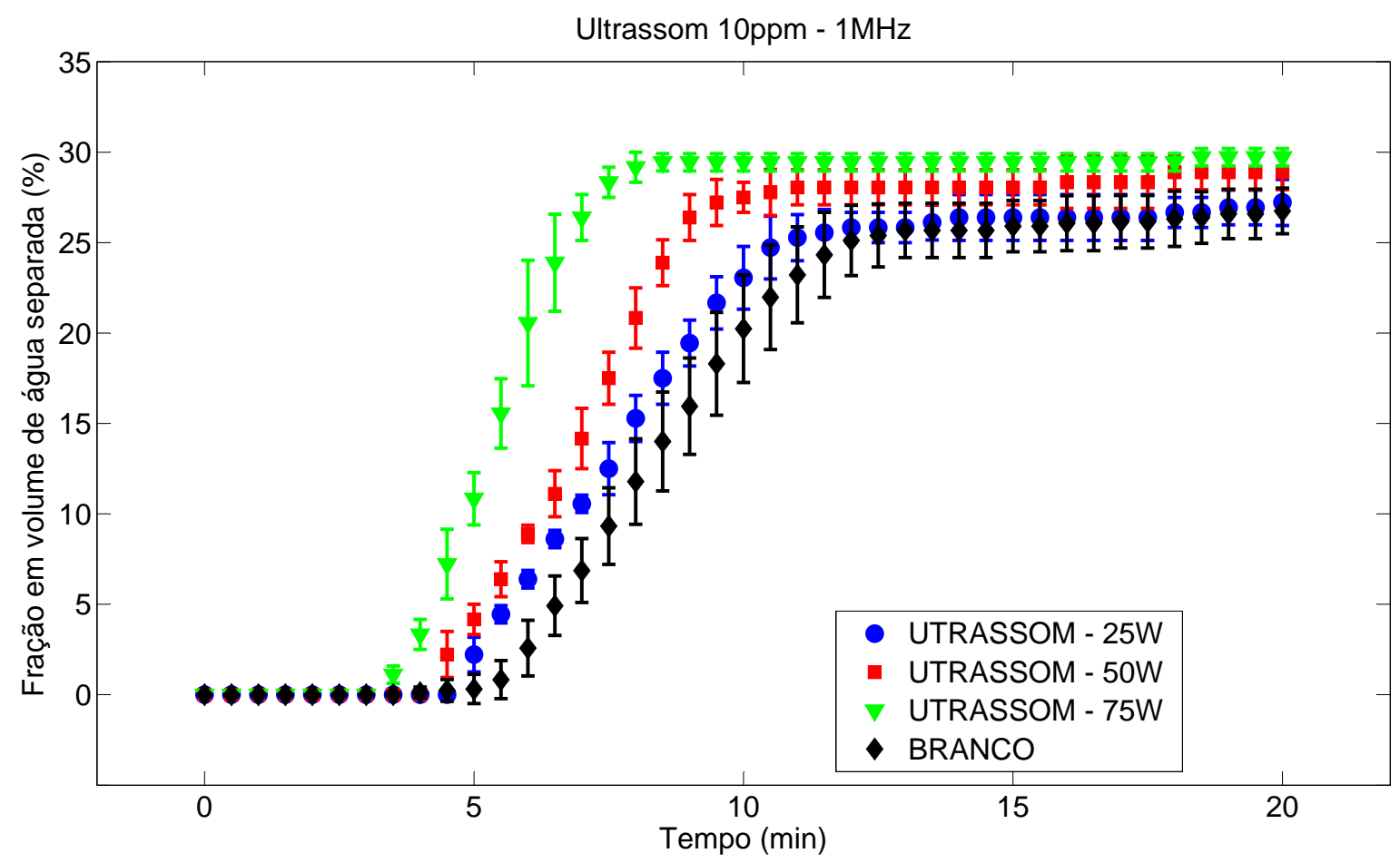

Figura 42 - Evolução dos ensaios de comparação entre quantidade de desemulsificante.

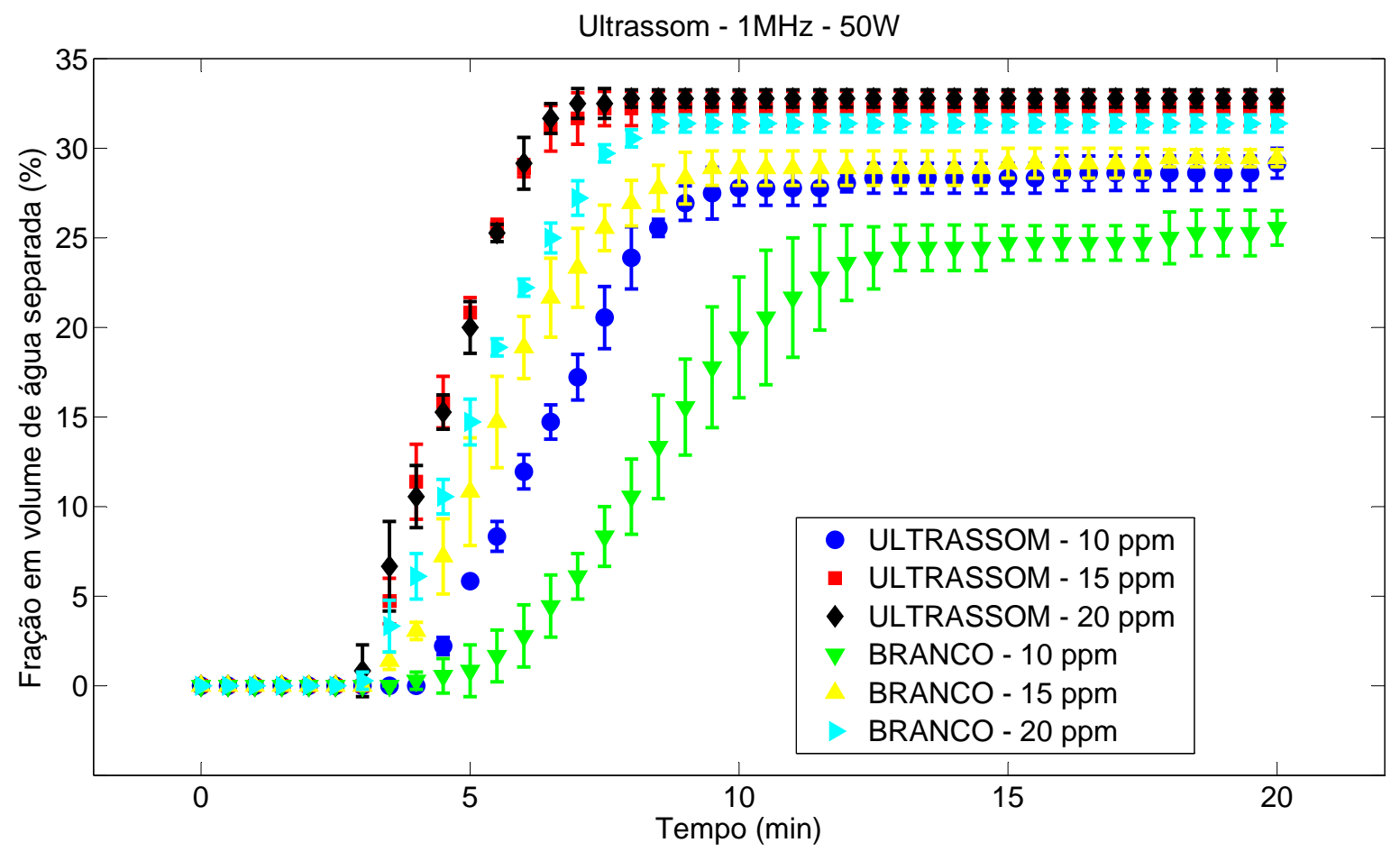


Figura 43 - Evolução dos ensaios de comparação entre frequências aplicadas.

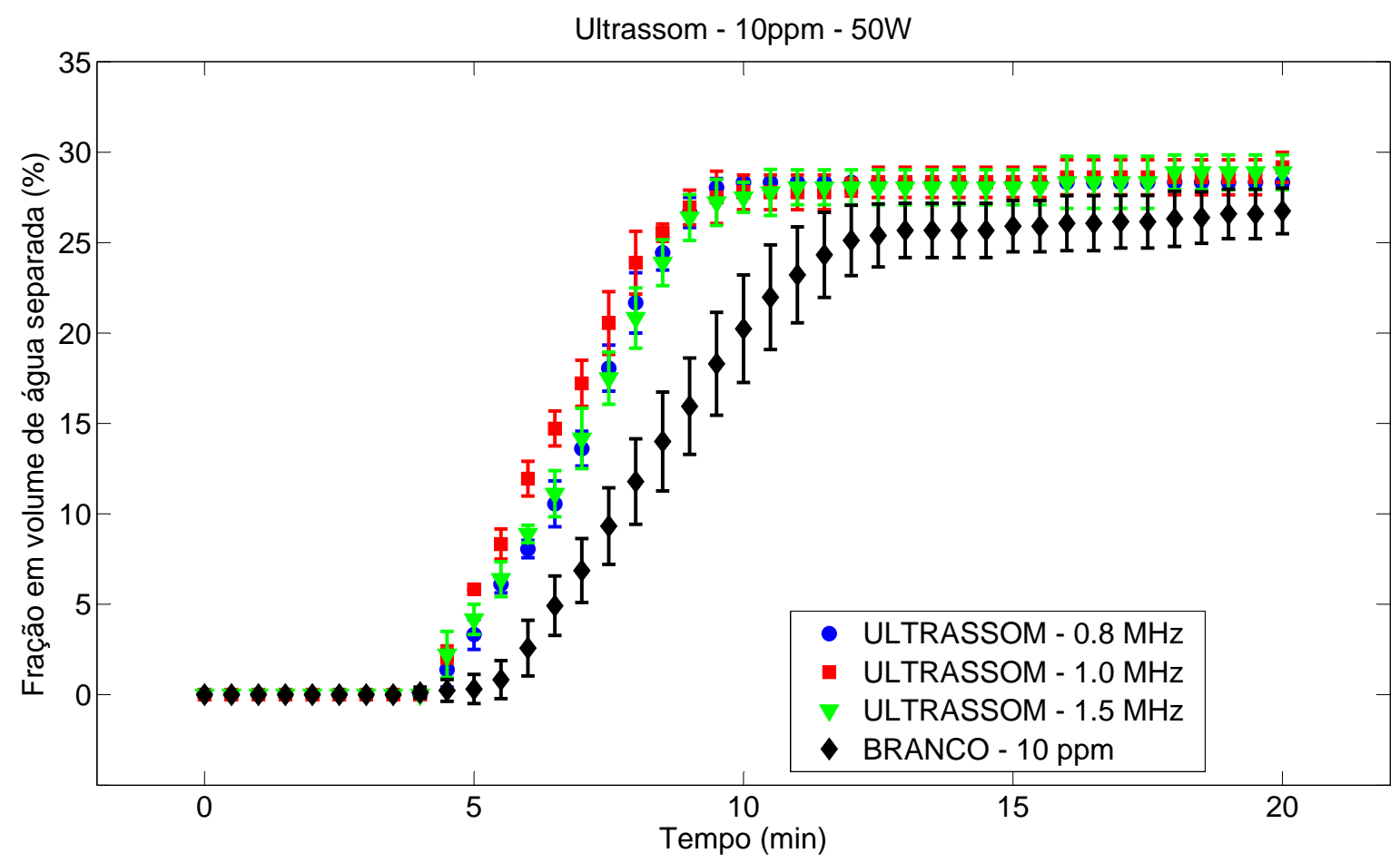

Figura 44 - Evolução dos ensaios de comparação entre tratamento por ultrassom.

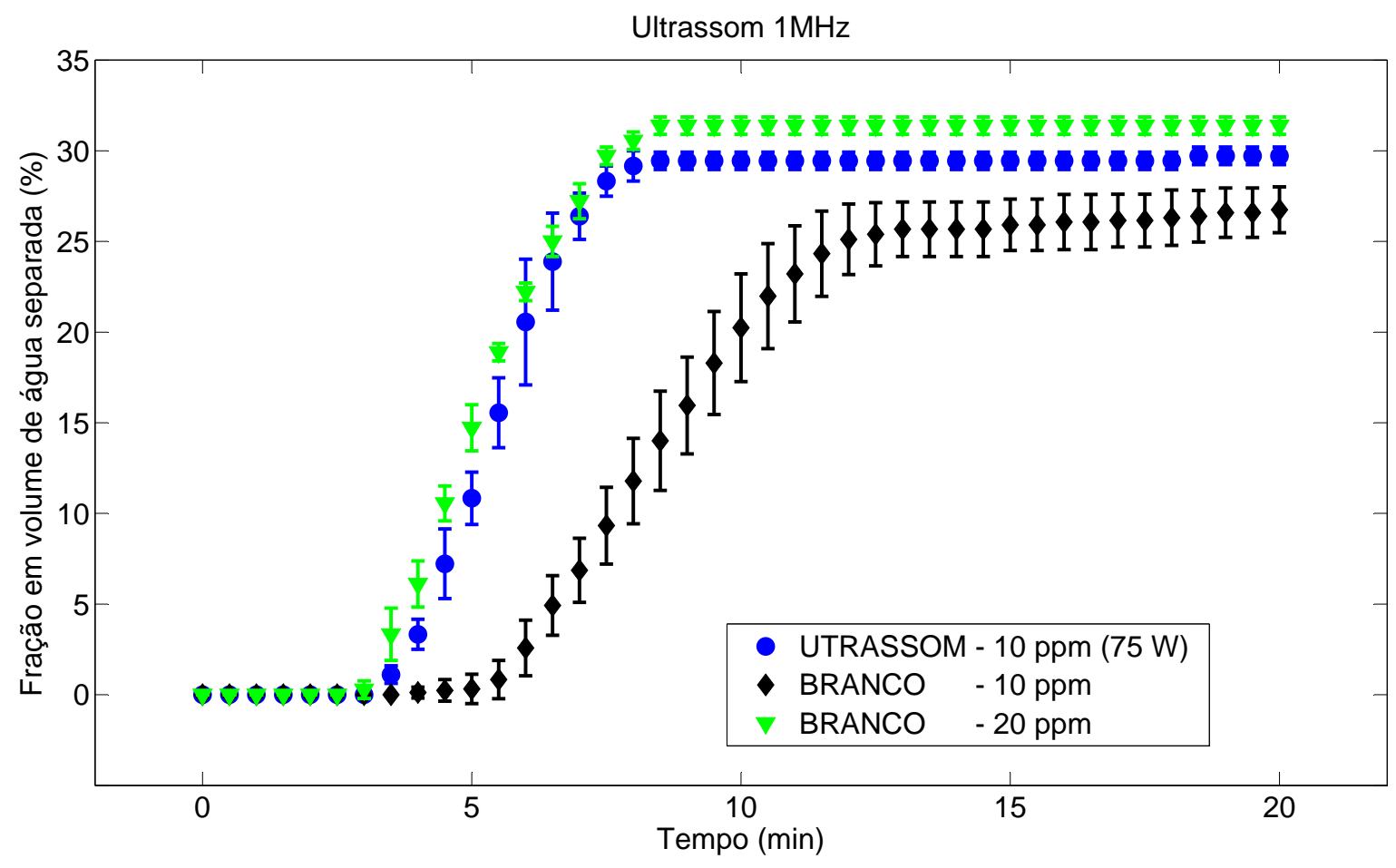




\subsection{ANÁLISE DOS RESULTADOS}

Foi verificado através do espectro de impedância da célula que uma carga atenuante elimina alguns pontos de frequência de operação de máxima transmissão de energia real. Isso ocorre pois a fase correspondente às faixas de frequência onde ocorrem ressonância da câmara não possuem cruzamento com o zero. Uma solução para esse problema seria utilizar um circuito de compensação de fase para adicionar ao espectro frequências de máxima transferência de energia real que também correspondam à frequências de ressonância da câmara (GROSCHL, 1998b).

Através da montagem experimental, foi possível analisar o efeito do ultrassom na coalescência de emulsões de petróleo. Porém, não foi suficiente para avaliar quanto desse aumento de eficiência foi devido ao fenômeno de radiação acústica e quanto foi devido à mudança de temperatura. O sistema de rastreamento de frequência foi crucial na comparação dos resultados pois permitiu que fosse estabelecido um padrão de aplicação de potência para todos ensaios realizados. Os resultados indicam que ainda há necessidade de ser implementado um sistema de controle de temperatura e com o objetivo de comparar a influência da temperatura na eficiência de desemulsificação.

A Figura (41) mostra que os ensaios nos quais ocorreram máxima separação de água foram os que utilizaram o tratamento de ultrassom com maior potência. A Figura (42) mostra que os ensaios que resultaram em maior eficiência comparado com o branco foram os que utilizaram menor quantidade de desemulsificante. Além disso, durante o intervalo de tempo considerado a separação total das fases somente ocorreu no ensaio utilizando uma quantidade acima de $15 \mathrm{ppm}$ e aplicando ultrassom a uma potência de $50 \mathrm{~W}$. A Figura (43) mostra que diferentes frequências não apresentaram variação significativa de eficiência de desemulsificação. No entanto, o resultado médio da célula de $1.0 \mathrm{MHz}$ indica que sua eficiência é ligeiramente maior do que as outras.

Além disso, foi verificado que os resultados obtidos com o tratamento por ultrassom eventualmente são comparáveis aos obtidos nos testes brancos com menor quantidade de desemulsificante. A Figura (44) mostra que a aplicação de ultrassom com potência de $75 \mathrm{~W}$, utilizando $10 \mathrm{ppm}$ de desemulsificante, aumenta aproximadamente 5 vezes o desempenho da desemulsificação no sexto minuto de ensaio. Dessa forma, é possível reduzir o uso de desemulsificante químico de 20 para $10 \mathrm{ppm}$ ou diminuir o tempo de residência de 20 para $8 \mathrm{~min}$. 


\section{CONCLUSÕES E TRABALHOS FUTUROS}

\subsection{CONCLUSÕES}

O modelo unidimensional desenvolvido é suficiente para projetar as células de acordo com as características elétricas e energéticas desejadas. Os resultados do modelo indicam que a impedância elétrica da célula é dada pela sobreposição dos modos de vibração de cada camada. A distribuição de amplitude de velocidade revela que há formação de uma onda estacionária parcial ao longo das camadas. Os resultados de fluxo energético mostram que as frequências de fase nula próximos a anti-ressonância do transdutor produzem uma aplicação de energia mais eficiente ao longo da camada líquida. No entanto, se o meio líquido é altamente atenuante, a análise do fluxo de energia mostra que não há diferença significativa na eficiência entre os pontos de operação de máxima transmissão de energia.

Os resultados da análise do potencial de radiação acústica mostram que a modelagem através do MEF prevê com melhor aproximação os fenômenos que ocorrem no interior das câmaras. A propagação de ondas laterais devido as condições de contorno das paredes da célula, além da distribuição não uniforme da superfície da fonte, geram um campo acústico segundo um padrão de franjas, que é visível nos ensaios realizados com partículas sólidas. Portanto, o modelo de elementos finitos pode ser utilizado para analisar o comportamento mais geral das células considerando a propagação de ondas bidimensionais e de superfície. No entanto, é necessário que seja feita uma caracterização experimental das propriedades do material piezelétrico PZT4 para obter um resultado mais próximo do experimental.

Através da síntese e caracterização das emulsões de petróleo foi possível obter com boa concordância uma estimativa do espectro de impedância elétrica da célula preenchida com carga de baixo fator de qualidade acústico. Esse resultado indica que o modelo unidimensional é suscetível a variações de carga e permite prever mudanças das características elétricas de acordo com a aplicação desejada. Porém, considerando a análise energética para meios com alto coeficiente de atenuação, o modelo não diferencia a eficiência entre os pontos de operação proposto neste trabalho. Além disso, a influência da onda progressiva atenuada no campo acústico estacionário em termos de potencial de radiação acústico não foi estudada neste trabalho.

Adotando os procedimentos dos ensaios realizados com emulsões de petróleo foi possível avaliar o desempenho da técnica de intensificação da coalescência por ultrassom em laboratório. Ainda há necessidade de implementação de um sistema de controle de temperatura para verificar sua influência na eficiência do processo. Mas, o desenvolvimento da montagem do aparato experimental e da instrumentação do controle de frequência garantiu que diversas análises fossem realizadas para diferentes condições de ensaio.

Nos ensaios com petróleo, o ultrassom foi aplicado em $120 \mathrm{ml}$ de emulsão com 33\% 
de água, por um período de $2 \min$ a uma potência de até $75 \mathrm{~W}$. O desempenho da desemulsificação foi analisado em um período total de 20 min e foi verificado um aumento de até 5 vezes em \% de água separada para o mesmo período de aplicação de ultrassom. A análise dos resultados mostra que a técnica empregada pode reduzir pela metade o uso de desemulsificante químico ou diminuir o tempo de residência em até $60 \%$. Um estudo da influência da frequência na eficiência de desemulsificação foi feito e indica que o maior desempenho médio é obtido a 1.0 MHz. Porém, ao considerar os desvios estatísticos, não há como afirmar com precisão a frequência que resulta em maior eficiência a uma temperatura ambiente de aproximadamente $22{ }^{\circ} \mathrm{C}$. Foi demonstrado que a técnica de desemulsificação de emulsões água em óleo através de ondas estacionárias pode ser aplicada para manter a cinética de processo e diminuir a quantidade de desemulsificante utilizada.

\subsection{TRABALHOS FUTUROS}

Implementar um modelo de energia em coordenadas bidimensionais para analisar o fluxo de energia das células no plano tranversal. É sugerido que um sistema de controle de temperatura seja desenvolvido para obter maior padronização dos ensaios. Além disso, é sugerido que seja estudada a influência da frequência de aplicação do ultrassom através de ensaios em temperaturas mais altas. A especificação do sistema completo incluindo as células e o controle de frequência poderá ser tomada como base para a construção de um protótipo em fluxo contínuo com vazão de $1 \mathrm{~m}^{3} / \mathrm{h}$. 


\section{REFERÊNCIAS}

ADLER, E. L. Matrix-methods applied to acoustic-waves in multilayers. leee Transactions On Ultrasonics Ferroelectrics and Frequency Control, v. 37, n. 6, p. 485-490, nov. 1990.

ANDRADE, M. A. B. Análise de materiais piezelétricos compósitos para aplicações em transdutores de ultra-som. Dissertação (Mestrado) - Escola Politécnica, University of São Paulo, São Paulo, 2006.

ANDRADE, M. A. B. Estudo da força de radiação acústica em partículas produzida por ondas progressivas e estacionárias. Tese (Doutorado) - Escola Politécnica, University of São Paulo, São Paulo, 2010.

ANDRADE, M. A. B. et al. Development of ultrasonic cylindrical cells for trapping of oil droplets. AIP Conference Proceedings, AIP, v. 1433, n. 1, p. 723-726, 2012.

ANTES, F. G. Desemulsificação de ppetróleo assistida por ultrassom e posterior caracterização das fases água e óleo. Tese (Doutorado) - Curso de Pós-Graduação em Química, Universidade Federal de Santa Maria, Rio Grande do Sul, 2011.

AULD, B.; AULD, B. Acoustic fields and waves in solids. [S.I.]: Wiley, 1973. (Acoustic Fields and Waves in Solids, v. 1). ISBN 9780471037026.

BARMATZ, M.; COLLAS, P. Acoustic radiation potential on a sphere in plane, cylindrical, and spherical standing wave fields. Journal of the Acoustical Society of America, v. 77, n. 3, p. 928-945, 1985.

BENES, E. et al. Ultrasonic separation of suspended particles. 2001 leee Ultrasonics Symposium Proceedings, Vols 1 and 2, p. Ultrason, Ferrelect, \& Frequency Control Soc, 2001.

BRESCIANI, A. E.; ALVES, R. M. B.; NASCIMENTO, C. A. O. Coalescence of water droplets in crude oil emulsions analytical solution. Chemical Engineering \& Technology, v. 33, n. 2, p. 237-243, fev. 2010.

BRESCIANI, A. E. et al. Modeling the kinetics of the coalescence of water droplets in crude oil emulsions subject to an electric field, with the cellular automata technique. Computers \& Chemical Engineering, v. 34, n. 12, p. 1962-1968, 2010.

CAVALLO, J. L.; CHANG, D. L. Emulsion preparation and stability. Chemical Engineering Progress, Amer Inst Chemical Engineers, v. 86, n. 6, p. 54-59, jun. 1990.

CRUM, L. A. Acoustic force on a liquid droplet in an acoustic stationary wave. Journal of the Acoustical Society of America, v. 50, n. 1, p. 157-\&, 1971.

CURIE, J.; CURIE, P. Développement, par pression, de l'électricité polaire dans les cristaux hémièdres à faces inclinées. v. 91, p. 294-295, 1880.

DOINIKOV, A. A. Acoustic radiation pressure on a compressible sphere in a viscous fluid. Journal of Fluid Mechanics, v. 267, p. 1-22, 5 1994. ISSN 1469-7645.

DYE, D. W. The piezo-electric quartz resonator and its equivalent electrical circuit.

Proceedings of the Physical Society, v. 38, p. 399-458, 1926. 
EOW, J. S.; GHADIRI, M. Electrostatic enhancement of coalescence of water droplets in oil- a review of the technology. Chemical Engineering Journal, v. 85, n. 2-3, p. 357-368, jan. 2002.

FRISING, T.; NOIK, C.; DALMAZZONE, C. The liquid/liquid sedimentation process: From droplet coalescence to technologically enhanced water/oil emulsion gravity separators: A review. Journal of Dispersion Science and Technology, Taylor \& Francis Inc, v. 27, n. 7, p. 1035-1057, 2006.

GARDNER, E. A.; APFEL, R. E. Using acoustics to study and stimulate the coalescence of oil drops surrounded by water. Journal of Colloid and Interface Science, v. 159, n. 1, p. 226-237, ago. 1993.

GARY, J.; HANDWERK, G. Petroleum Refining: Technology and Economics. [S.I.]: M. Dekker, 2001. ISBN 9780824704827.

GORKOV, L. P. Forces acting on a small particle in an acoustic field within an ideal fluid. Doklady Akademii Nauk Sssr, v. 140, n. 1, p. 88-\&, 1961.

GORKOV, L. P. On the forces acting on a small particle in an acoustical field in an ideal fluid. Soviet Physics - Doklady, v. 6, n. 9, p. 773-775, 1962. Cited By (since 1996)1.

GROSCHL, M. Ultrasonic separation of suspended particles - part i fundamentals. Acustica, v. 84, n. 3, p. 432-447, maio 1998.

GROSCHL, M. Ultrasonic separation of suspended particles - part ii design and operation of separation devices. Acustica, v. 84, n. 4, p. 632-642, jul. 1998.

GUPTA, S.; FEKE, D. L.; MANAS-ZLOCZOWER, I. Fractionation of mixed particulate solids according to compressibility using ultrasonic standing wave fields. Chemical Engineering Science, v. 50, n. 20, p. 3275-3284, out. 1995.

HAAKE, A. Micromanipulation of small particles with ultrasound. Tese (Doutorado) Diss., Technische Wissenschaften ETH Zürich, Nr. 15681, 2004.

HASEGAWA, T.; YOSIOKA, K. Acoustic-radiation force on a solid elastic sphere. The Journal of the Acoustical Society of America, ASA, v. 46, n. 5B, p. 1139-1143, 1969.

HAVLICE, J.; BOND, W. L.; WIGTON, L. B. "elastic"poynting vector in a piezoelectric medium. Sonics and Ultrasonics, IEEE Transactions on, v. 17, n. 4, p. 246-248, 1970. ISSN 0018-9537.

HILL M. ANDSHEN, Y. J.; HAWKES, J. J. Modelling of layered resonators for ultrasonic separation. Ultrasonics, v. 40, n. 1-8, p. PII S0041-624X(02)00127-0, maio 2002.

HODGE, P. Continuum mechanics: an introductory text for engineers. [S.I.]: McGraw-Hill, 1970. (Advanced engineering series).

HOLLAND, R. Representation of dielectric, elastic, and piezoelectric losses by complex coefficients. Sonics and Ultrasonics, IEEE Transactions on, v. 14, n. 1, p. 18-20, 1967. ISSN 0018-9537. 
IEEE. leee standard on piezoelectricity. IEEE Transactions On Ultrasonics Ferroelectrics and Frequency Control, leee-inst Electrical Electronics Engineers Inc, v. 43, n. 5, p. A1-A54, set. 1996.

JEFFREYS, H. Cartesian tensors. [S.I.]: The University Press, 1931.

KING, L. V. On the acoustic radiation pressure on spheres. Proceedings of the Royal Society of London. Series A - Mathematical and Physical Sciences, v. 147, n. 861, p. 212-240, 1934.

KINO, G. Acoustic waves: devices, imaging, and analog signal processing. [S.I.]:

Prentice-Hall, 1987. - p. ISSN 9780130030474.

KINSLER, L. Fundamentals of acoustics. [S.I.]: Wiley, 2000. ISBN 9780471847892.

KOKAL, S. Crude-oil emulsions: A state-of-the-art review. Spe Production \& Facilities, Soc Petroleum Eng, v. 20, n. 1, p. 5-13, fev. 2005.

KUMAR, K.; NIKOLOV, A. D.; WASAN, D. T. Mechanisms of stabilization of water-in-crude oil emulsions. Industrial \& Engineering Chemistry Research, v. 40, n. 14, p. 3009-3014, jul. 2001.

LANDAU, L.; LIFSHITS, E. Fluid mechanics. [S.I.]: Pergamon Press, 1959. (A-W series in advanced physics).

LERCH, R. Simulation of piezoelectric devices by two- and three-dimensional finite elements. Ultrasonics, Ferroelectrics and Frequency Control, IEEE Transactions on, v. 37, n. 3, p. 233-247, 1990. ISSN 0885-3010.

LISSANT, K. Demulsification: industrial applications. [S.I.]: M. Dekker, 1983. (Surfactant science series). ISSN 0081-9603. ISBN 9780824718022.

MANDRALIS, Z. et al. Enhanced synchronized ultrasonic and flow-field fractionation of suspensions. Ultrasonics, v. 32, n. 2, p. 113-121, mar. 1994.

MARSTON, P. L.; APFEL, R. E. Acoustically forced shape oscillation of hydrocarbon drops levitated in water. Journal of Colloid and Interface Science, v. 68, n. 2, p. 280-286, 1979.

MORSE, P. Vibration and sound. [S.I.]: American Institute of Physics for the Acoustical Society of America, 1981. ISBN 9780883182871.

NII, S.; KIKUMOTO, S.; TOKUYAMA, H. Quantitative approach to ultrasonic emulsion separation. Ultrasonics Sonochemistry, v. 16, n. 1, p. 145-149, jan. 2009.

NOWOTNY, H.; BENES, E. General one-dimensional treatment of the layered piezoelectric resonator with 2 electrodes. Journal of the Acoustical Society of America, v. 82, n. 2, p. 513-521, ago. 1987.

NOWOTNY, H.; BENES, E.; SCHMID, M. Layered piezoelectric resonators with an arbitrary number of electrodes general one-dimensional treatment. Journal of the Acoustical Society of America, v. 90, n. 3, p. 1238-1245, set. 1991.

NYE, J. Physical properties of crystals: their representation by tensors and matrices. [S.I.]: Clarendon Press, 1985. (Oxford science publications). ISBN 9780198511656. 
PAL, R. Techniques for measuring the composition (oil and water-content) of emulsions - a state-of-the-art review. Colloids and Surfaces A-physicochemical and Engineering Aspects, v. 84, n. 2-3, p. 141-193, maio 1994.

PANGU, G. D.; FEKE, D. L. Acoustically aided separation of oil droplets from aqueous emulsions. Chemical Engineering Science, v. 59, n. 15, p. 3183-3193, ago. 2004.

PANGU, G. D.; FEKE, D. L. Droplet transport and coalescence kinetics in emulsions subjected to acoustic fields. Ultrasonics, v. 46, n. 4, p. 289-302, nov. 2007.

PANGU, G. D.; FEKE, D. L. Kinetics of ultrasonically induced coalescence within oil water emulsions modeling and experimental studies. Chemical Engineering Science, v. 64, n. 7, p. 1445-1454, abr. 2009.

PéREZ, N. et al. Identification of elastic, dielectric, and piezoelectric constants in piezoceramic disks. Ultrasonics, Ferroelectrics and Frequency Control, IEEE Transactions on, v. 57, n. 12, p. 2772-2783, 2010. ISSN 0885-3010.

RAYLEIGH, J. The theory of sound. [S.I.]: Macmillan and co., 1878. (The Theory of Sound, v. 1).

ROSENBAUM, J. Bulk acoustic wave theory and devices. [S.I.]: Artech House, 1988. (The Artech House acoustics library). ISBN 9780890062654.

ROYER, D.; DIEULESAINT, E. Elastic Waves in Solids: Free and guided propagation. [S.I.]: Springer, 2000. (Advanced Texts in Physics). ISBN 9783540659327.

RUDNICK, I. Measurements of the acoustic radiation pressure on a sphere in a standing wave field. Journal of the Acoustical Society of America, v. 23, n. 5, p. 633-634, 1951.

RUDNICK, I. Measurements of acoustic radiation pressure on a sphere in a standing wave field. Journal of the Acoustical Society of America, v. 62, n. 1, p. 20-22, 1977.

SCHRAMM, L. L. Petroleum emulsions - basic principles. Emulsions : Fundamentals and Applications In the Petroleum Industry, v. 231, p. PETR RECOVERY INST, 1992.

SILVA, A.; ANDRADE, M.; ADAMOWSKI, J. Ultrasonic separation monitoring by near-infrared light scattering. In: Ultrasonics Symposium (IUS), 2012 IEEE International. [S.I.: s.n.], 2012. p. 1714-1717. ISSN 1948-5719.

THOMAS, J. Fundamentos de engenharia de petróleo. [S.I.]: Interciência, 2004. ISBN 9788571930995.

TIERSTEN, H. Linear piezoelectric plate vibrations: elements of the linear theory of piezoelectricity and the vibrations of piezoelectric plates. [S.I.]: Plenum Press, 1969.

TIERSTEN, H. F. Thickness vibrations of piezoelectric plates. Journal of the Acoustical Society of America, Amer Inst Physics, v. 35, n. 1, p. 53-\&, 1963.

TIERSTEN, H. F. Hamiltons principle for linear piezoelectric media. Proceedings of the Institute of Electrical and Electronics Engineers, v. 55, n. 8, p. 1523-\&, 1967.

TOBIN, T. et al. Determination of coalescence frequencies in liquid-liquid dispersions effect of drop size dependence. Chemical Engineering Science, v. 45, n. 12, p. 3491-3504, 1990. 
TOLT, T. L.; FEKE, D. L. Separation of dispersed phases from liquids in acoustically driven chambers. Chemical Engineering Science, v. 48, n. 3, p. 527-540, fev. 1993.

WOODSIDE, S. M. et al. Acoustic force distribution in resonators for ultrasonic particle separation. Aiche Journal, v. 44, n. 9, p. 1976-1984, set. 1998.

ZHENG, X. Y.; APFEL, R. E. Acoustic interaction forces between two fluid spheres in an acoustic field. Journal of the Acoustical Society of America, v. 97, n. 4, p. 2218-2226, abr. 1995. 


\section{APÊNDICE A - CARACTERÍSTICAS DA EMULSÃO DE PETRÓLEO}

\section{A.1 INTRODUÇÃO}

Neste apêndice é descrito como é feita a caracterização das propriedades acústicas do material utilizado nos ensaios de coalescência de emulsão de petróleo. A técnica de transmissão de onda pulsada é utilizada para caracterização da atenuação e da velocidade de propagação da onda. Esse método faz uso de dois transdutores de ultrassom alinhados e com suas faces voltadas para a amostra.

\section{A.2 TÉCNICA DE TRANSMISSÃO RECEPÇÃO}

Nessa técnica, um transdutor funciona como gerador de pulso e o outro como receptor. É utilizado um par de transdutores cuja frequência de ressonância é $f_{r} \approx 1 \mathrm{MHz}$, modelo V314-SU (Panametrics), um equipamento pulsador modelo 5072 PR (Olympus) e um osciloscopio modelo DSO5032A (Agilent). Para a caracterização das propriedades da emulsão de petróleo utilizada nos ensaios, são realizados 3 ensaios: um com uma amostra de água destilada, outro com uma amostra de petróleo e por último a emulsão a $33 \%(v / v)$ de água. A Figura (45) ilustra o princípio dessa técnica.

Figura 45 - Técnica transmissão recepção utilizada para caracterização das propriedades da emulsão.

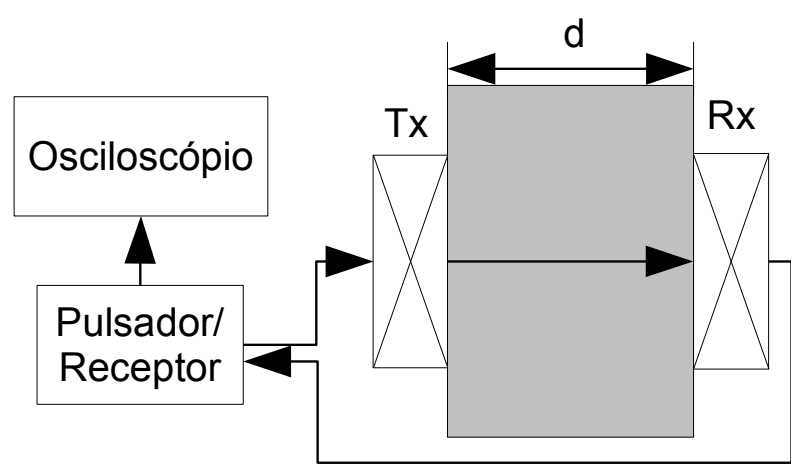

É necessário calibrar a montagem do conjunto de transdutores através da medição do tempo de vôo, $t_{v}$ do sinal adiquirido com a amostra de água. A partir do valor da velocidade do som em água, calcula-se a distância $d$. A partir de relação da Equação (2.30), define-se a amplitude de pressão máxima transmitida para o receptor, $A_{P}$ como sendo :

$$
A_{P}=\max p=P_{0} \exp ^{-\alpha x}
$$

onde $\alpha$ pode ser obtido a partir da relação entre os valores de amplitudes obtidos experimentalmente através da expressão 


$$
\begin{aligned}
\alpha^{r l} & =\frac{1}{d} \ln \left(\frac{A_{P}^{r f}}{A_{P}^{a m}}\right)[N p / m] \\
\alpha^{r l} & =\frac{1}{d} 20 \log _{10}\left(\frac{A_{P}^{r f}}{A_{P}^{a m}}\right)[d B / m]
\end{aligned}
$$

onde $d$ é a distância entre os trandutores e $\alpha^{r l}$ denota o coeficiente de atenuação relativo obtido experimentalmente. A distância, $d$, pode ser obtida através da medição do tempo de vôo, $t_{v}$, da velocidade de propagação na água através da seguinte expressão

$$
d=\frac{c_{f} \delta t}{2}
$$

Subsitituindo a Equação (A.1) na Equação (A.2), obtém-se o coeficiente de atenuação da amostra.

$$
\begin{aligned}
\alpha^{r l} & =\frac{1}{d} \ln \left(\frac{P_{0} \exp ^{-\alpha^{r f} d}}{P_{0} \exp ^{-\alpha^{a m} d}}\right) \\
\alpha^{r l} & =\frac{1}{d} \ln \left(\exp ^{-\left(\alpha^{r f}-\alpha^{a m}\right) d}\right) \\
\alpha^{a m} & =\alpha^{r l}+\alpha^{r f}
\end{aligned}
$$

onde $\alpha^{r f}$ e o $\alpha^{a m}$ denotam os coeficientes de atenuação de referência (água) e da amostra. O coeficiente de atenuação em líquidos pode ser usado para calcular o fator de qualidade, $\mathcal{Q}$ (AULD; AULD, 1973) através da expressão:

$$
\mathcal{Q}=\frac{k}{2 \alpha}
$$

As propriedades obtidas através dessa técnica são utilizadas para obter ajustar o cálculo de impedância elétrica das células no modelo unidimensional. $O$ fator de qualidade effetivo pode ser calculado considerando o um coeficiente effetivo de atenuação. A onda que se propaga em um líquido no interior de um ressonador pode sofrer atenuação tanto através da absorção $\alpha$ como através de perdas adicionais $\alpha_{\text {eff }}$ (GROSCHL, 1998a), segundo a relação

$$
\mathcal{Q}_{e f f}=\frac{k}{2\left(\alpha+\alpha_{e f f}\right)}
$$

Utilizando como referência um fator de qualidade effetivo obtido através de verificações experimentais com água, é possível estimar qual seria o seu valor para cada amostra caracterizada. A partir da Equação (A.7), obtém-se uma expressão para o fator de qualidade effetiva da amostra, $\mathcal{Q}_{\text {eff }}^{a m}$ :

$$
\mathcal{Q}_{\text {eff }}^{a m}=\frac{k^{a m}}{2\left(\alpha^{a m}-\alpha^{r f}\right)+k^{r f} / \mathcal{Q}_{\text {eff }}^{r f}}
$$




\section{A.3 RESULTADOS}

O valor do coeficiente de atenuação de referência, $\alpha^{r f}$ em $1 \mathrm{MHz}$ e da velocidade de propagação, $c_{f}$, a um temperatura de $23{ }^{\circ} \mathrm{C}$ da água são obtidos da literatura (KINSLER, 2000). A Figura (46) ilustra o resultado da técnica mostrando os pulsos obtidos utilizando amostras de água, petróleo e emulsão a $33 \%$ de água. A distância $d$ obtida a partir da calibração é de aproximadamente $17.6 \mathrm{~mm}$.

A Tabela (8) mostra os resultados obtidos experimentalmente através da balança e da técnica de transmissão recepção de ultrassom. O valor da amplitude de pressão é obtido em função da tensão pico a pico, $V_{p p}$ medida pelo osciloscópio. A Tabela (9) apresenta os valores de de densidade, velocidade e atenuação de referência da água e os valores calculados para o petróleo e a emulsão.

Tabela 8 - Dados experimentais obtidos para a caracterização das propriedades dos líquidos

\begin{tabular}{cccc}
\hline Material & $\begin{array}{c}\text { Densidade } \\
\rho\left(k g / m^{3}\right)\end{array}$ & $\begin{array}{c}\text { Tensão pico a pico } \\
V_{p p}(V)\end{array}$ & $\begin{array}{c}\text { Tempo de vôo } \\
t_{v}(\mu s)\end{array}$ \\
\hline Água & 998 & 4.76 & 11.81 \\
Petróleo & 888 & 4.55 & 12.72 \\
Emulsão & 925 & 3.46 & 12.29 \\
\hline
\end{tabular}

Figura 46 - Resposta da técnica transmissão recepção para caracterização dos líquidos.

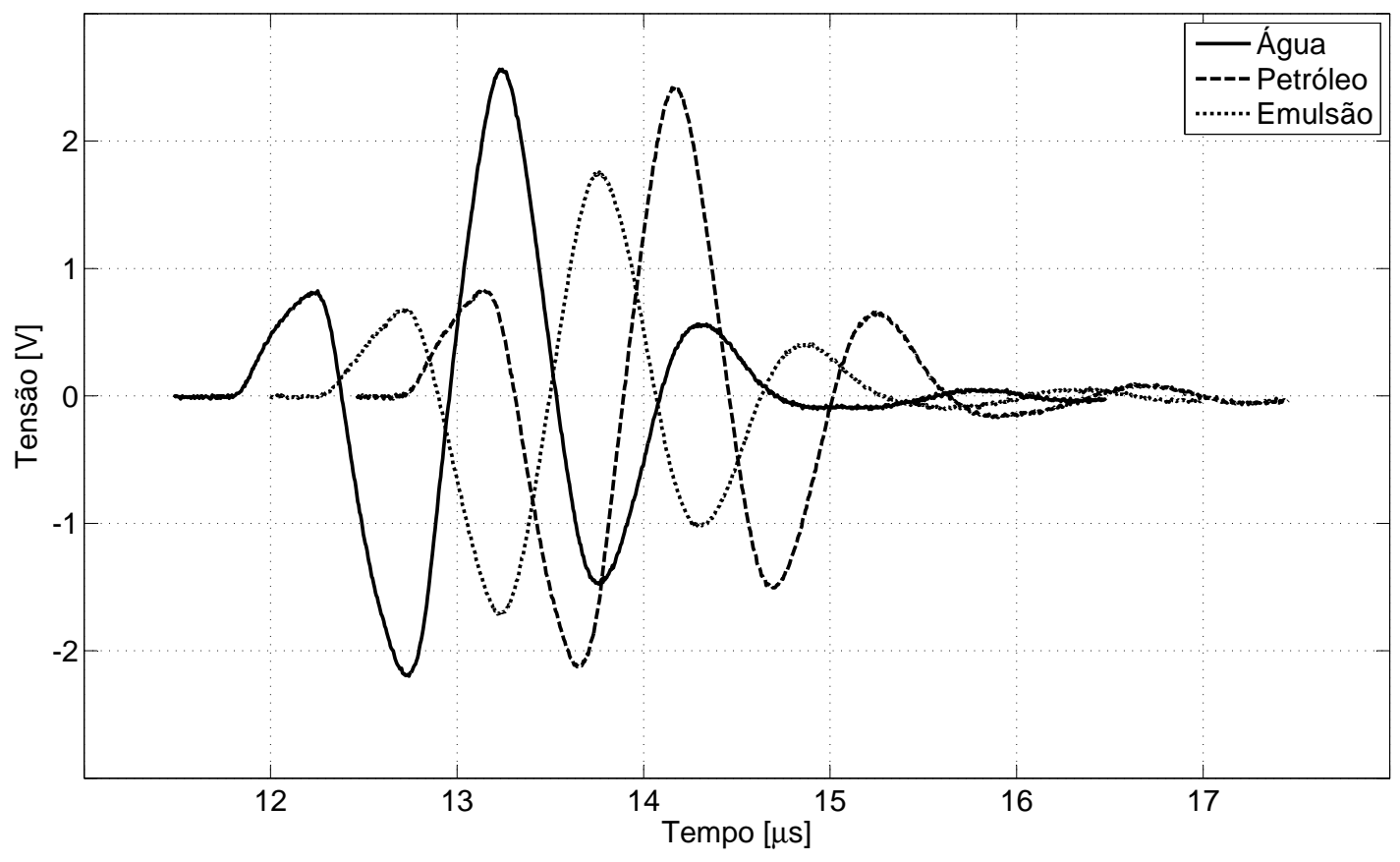


Tabela 9 - Caracterização das propriedades acústicas dos líquidos envolvidos à $23^{\circ} \mathrm{C}$ e $1 \mathrm{MHz}$

\begin{tabular}{lcccc}
\hline Material & Velocidade & \multicolumn{2}{c}{ Atenuação } & Fator de Qualidade \\
& $c_{f}(\mathrm{~m} / \mathrm{s})$ & $\alpha(\mathrm{dB} / \mathrm{m})$ & $\alpha(\mathrm{Np} / \mathrm{m})$ & $\mathcal{Q}$ \\
\hline Água & 1491 & 0.2 & 0.022 & 95777 \\
Petróleo & 1385 & 22.5 & 2.584 & 877 \\
Emulsão & 1433 & 157.5 & 18.135 & 121 \\
\hline
\end{tabular}




\section{APÊNDICE B - SISTEMA DE CONTROLE DE FREQUÊNCIA}

\section{B.1 INTRODUÇÃO}

O sistema de controle de frequência foi desenvolvido devido a necessidade de buscar a eficiência máxima de transmissão de potência elétrica durante os ensaios de desemulsifição, conforme está descrito na seção 6.3.1. Durante a operação do ressonador, a frequência de ressonância pode variar principalmente devido a mudança de velocidade de propagação da onda no líquido causado pela variação de temperatura (GROSCHL, 1998b). Esse sistema foi projetado de forma que o usuário possa configurar um valor de referência para a diferença de fase em um intervalo de frequência cujo limite é determinado pelos instrumentos de medição.

\section{B.2 IMPLEMENTAÇÃO}

A malha de controle, que está ilustrado na Figura (47), foi implementada por um software desenvolvido em MATLAB que recebe os valores das grandezas medidas pelos sensores e envia os comandos para o gerador de potência via Ethernet. São utilizados uma ponta de corrente com um amplificador modelo AM503 (Tektronix) e uma ponta de tensão de um osciloscópio modelo DSO6052A (Agilent Technologies) para medir a corrente e a tensão aplicada na célula.

Os parâmetros do controlador PI são determinados dependendo da sensibilidade da resposta da célula no ponto de operação escolhido. O procedimento utilizado na calibração desses parâmetros é descrito a seguir. De acordo com a Figura (47), a expressão da frequência instantânea $f_{i}$ é dada pela seguinte equação

$$
f_{i}-f_{\text {ini }}=K_{P}\left[\left(\theta_{i}-\theta_{\text {ref }}\right)+\frac{1}{T_{i}} \sum_{j=1}^{i}\left(\theta_{j}-\theta_{\text {ref }}\right)+T_{d}\left(\theta_{i}-\theta_{i-1}-\theta_{\text {ref }}\right)\right]
$$

one $f_{\text {ini }}$ denota a frequência inicial arbitrária correspondente ao estado inicial do sis-

Figura 47 - Malha de controle de frequência.

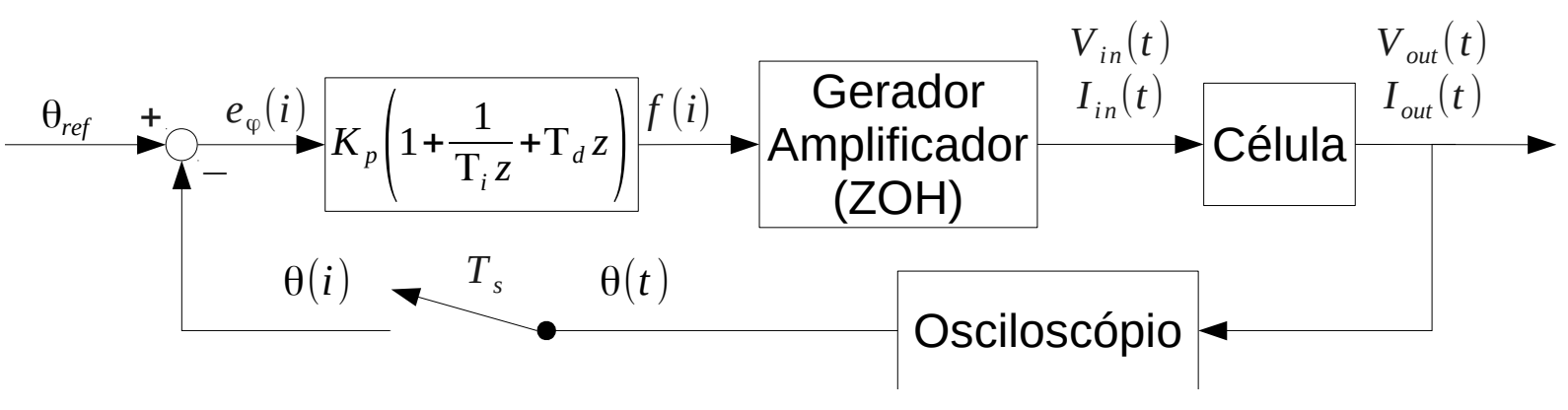


tema. Considerando $\theta_{\text {ref }}=0$ como referência, a Equação (B.1) torna-se:

$$
\Delta f=K_{P}\left[\theta_{i}+\frac{1}{T_{i}} \sum_{j=1}^{i} \theta_{j}+T_{d}\left(\theta_{i}-\theta_{i-1}\right)\right]
$$

onde $\Delta f=f_{i}-f_{\text {ini }}$ denota a diferença de frequência aplicada pelo sistema.

\section{B.3 CALIBRAÇÃO}

O método Ziegler-Nichols foi utilizado para calibração experimental do controlador PID. Esse método utiliza um valor de ganho, $K_{\nu}$, e um período de oscilação, $P_{\nu}$, resultado de um ensaio de calibração para calcular o valor de ganho $K_{P}$ do controlador. As outras constantes do controlador $T_{i}$ e $T_{d}$ são obtidas a partir de $P_{\nu}$.

Para determinar o valor de ganho $K_{\nu}$ é necessário encontrar o valor do ganho proporcional que faça com que o circuito de controle oscile indefinidamente em regime estacionário. Isso significa que os ganhos do controlador integral e derivativo são zerados de modo que a influência do controlardor proporcional pode ser determinada. Outro valor importante associado a esse método de ajuste de controle proporcional é o período $P_{\nu}$. Esse período determina o tempo necessário para completar uma oscilação completa, enquanto o sistema oscila em estado estacionário. Esses dois parâmetros, $K_{\nu}$ e $P_{\nu}$, são usados para encontrar as constantes de calibração do controladores P, PI ou PID. O seguinte procedimento foi utilizado para calcular as constantes de ajuste:

- Remover ação integral e derivativa definindo o período do controlador integral.

- Criar uma pequena perturbação no circuito mudando o ponto de referência. Ajustar o ganho proporcional $K_{P}$, alterando-o até que as oscilações resultante tenham amplitude constante e entre em regime estacionário.

- Anotar o valor do ganho $\left(K_{\nu}\right)$ e do período de oscilação $\left(P_{\nu}\right)$.

- Inserir esses valores nas equações de Ziegler-Nichols mostradas na Tabela 10] e determinar os parâmetros calibrados do controlador PID.

Tabela 10 - Cálculo dos parâmetro $K_{c}, T_{i}$ e $T_{d}$ do controlador em malha fechada

\begin{tabular}{llll}
\hline & $K_{P}$ & $T_{i}$ & $T_{d}$ \\
\hline $\mathrm{P}$ & $K_{\nu} / 2$ & & \\
$\mathrm{PI}$ & $K_{\nu} / 2.2$ & $P_{\nu} / 1.2$ & \\
$\mathrm{PID}$ & $K_{\nu} / 1.7$ & $P_{\nu} / 2$ & $P_{\nu} / 8$ \\
\hline
\end{tabular}

O procedimento de calibração deve ser feito para cada tipo de célula e de carga. Para aplicação descrita no Capítulo (6), configura-se no controlador a frequência de inicial $f_{\text {inicial }}=f_{r}$, onde $f_{r}$ é uma frequência de ressonância de operação. 


\section{B.4 EXEMPLO DE APLICAÇÃO}

A Figura (48) apresenta um exemplo de espectro de impedância elétrica medido em um ensaio com a célula de $1.5 \mathrm{MHz}$. Nesse caso, a frequência inicial escolhida foi $f_{i} \approx$ $1.52 \mathrm{MHz}$. Os parâmetros de ganho e período de oscilação encontrados foram, $K_{\nu}=85$ e $P_{\nu}=0.3$. Para um controlador PI, foi calculado os valores de $K_{P}=40$ e $T_{i}=0.25$. Como os espectros de impedância elétrica obtidos possuem sensibilidade da fase muito próximas na região de cruzamento com o zero, esses parâmetros foram utilizados em todos os ensaios realizados.

A seguir, a Figura (49) apresenta um exemplo de atuação do sistema de controle em um intervalo de $2 \mathrm{~min}$. Nota-se que durante os primeiros $20 \mathrm{~s}$ o sistema de controle atua no sentido de buscar a fase nula com características visíveis de overshoot e tempo de subida. A partir dos $20 s$ o sistema atua mantendo a fase nula e variando a diferença de frequência para compensar a variação de frequência de ressonância prevista devido a mudança de temperatura no ressonador.

Figura 48 - Exemplo de espectro de impedância elétrica medido durante os ensaios com emulsão de petróleo.

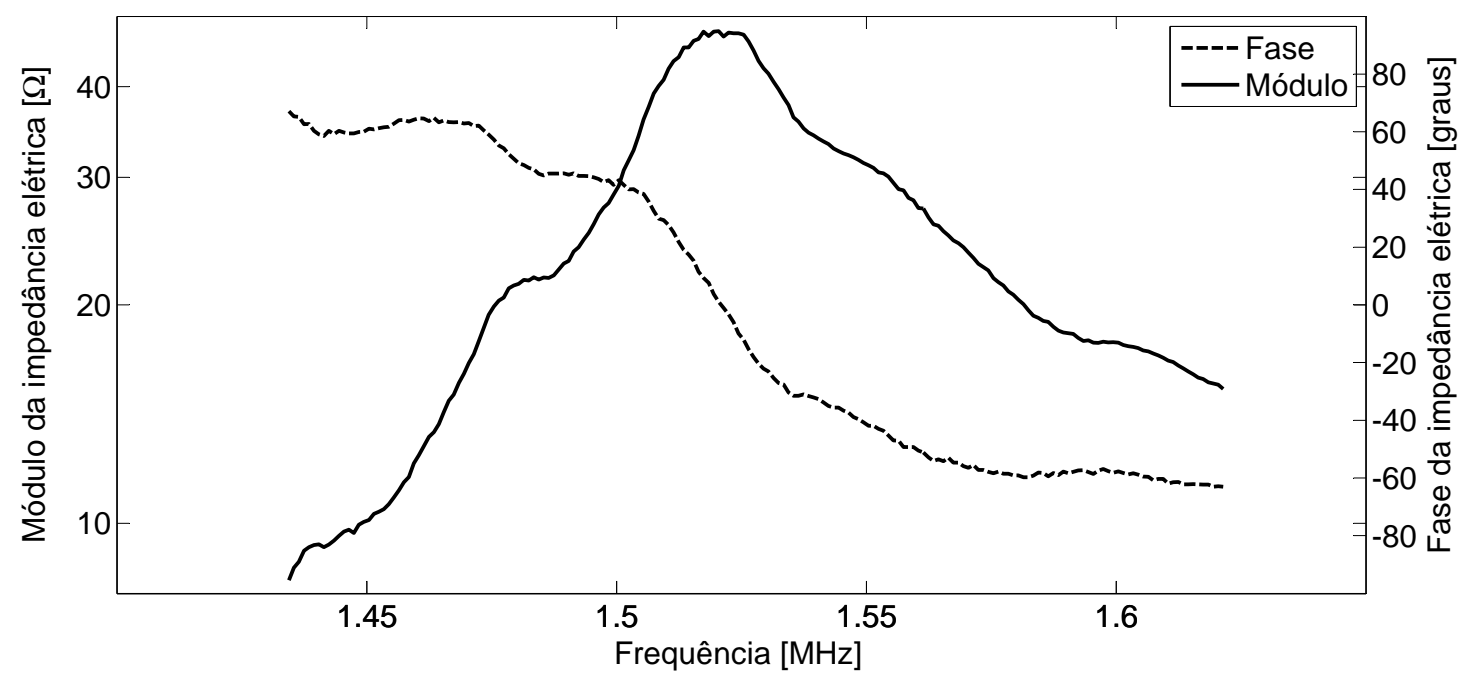


Figura 49 - Exemplo de atuação controle de frequência de operação.

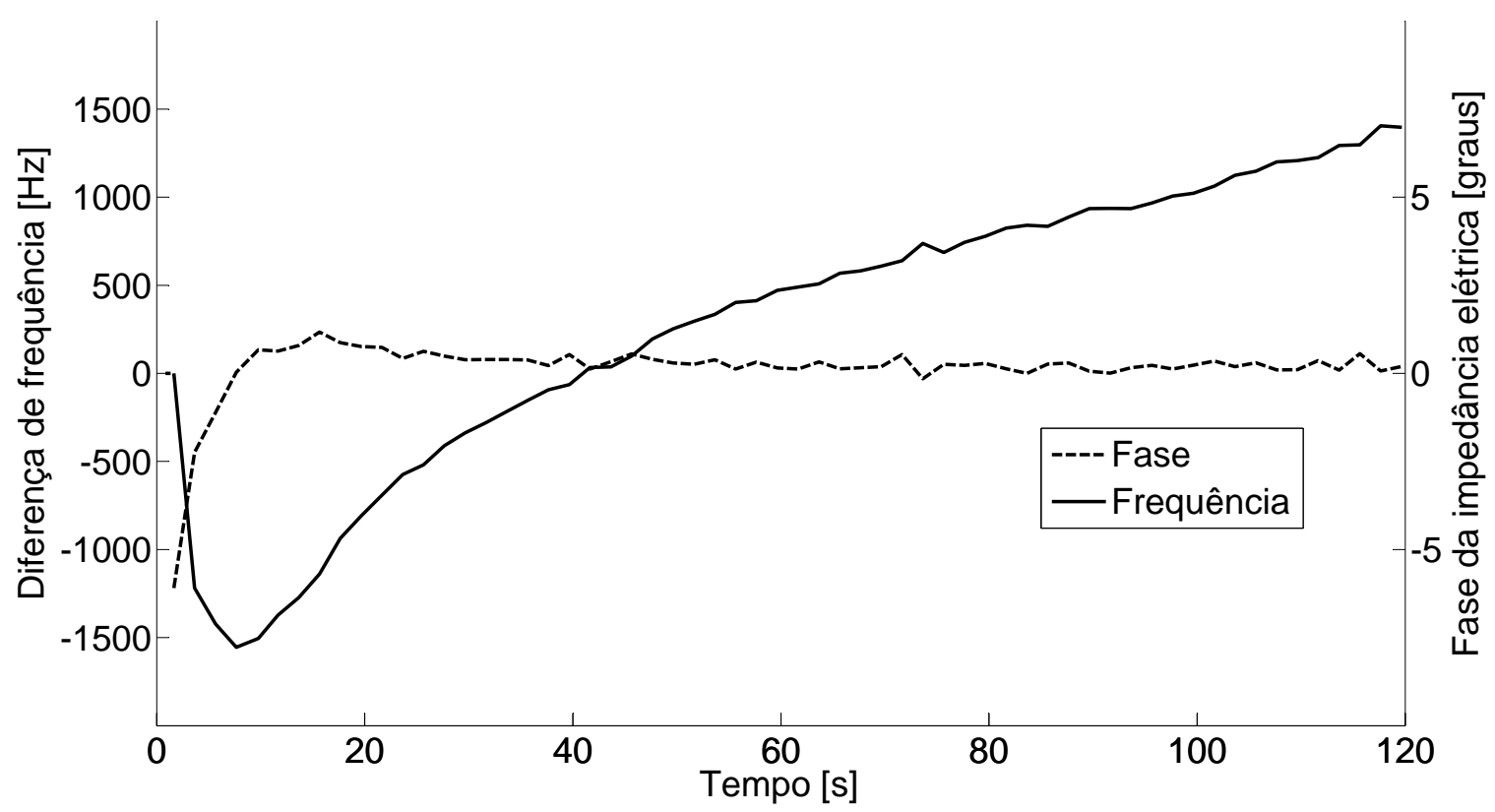




\section{APÊNDICE C - SÍNTESE DE EMULSÃO}

\section{C.1 INTRODUÇÃO}

O preparo de emulsões visando aplicação na indústria de petróleo deve ser realizado com solução salina. Utiliza-se uma solução de $50 \mathrm{~g} / \mathrm{L}$ de cloreto de sódio e água deionizada. A incorporação das fases foi realizada manualmente e antes do processo de homogeneização, utilizando o equipamento misturador (modelo T25 basic da IKA Labortechnik).

\section{C.1.1 Síntese}

Solução salina Para o preparo de emulsões a uma quantidade estabelecida $500 \mathrm{ml}$, pesar uma quantidade de $25 \mathrm{~g}$ de cloreto de sódio e adicionar pequena quantidade de água deionizada em um bécker $(500 \mathrm{ml})$ e agitar até que se dissolva visualmente. Acrescentar água deionizada até completar $500 \mathrm{ml}$. Filtrar com auxílio de um filtro de papel simples e reservar.

Incorporação Homogeneizar levemente o galão de óleo e separar $600 \mathrm{ml}$ em um bécker. Separar em provetas $450 \mathrm{ml}$ de óleo e $50 \mathrm{ml}$ de solução salina. Juntar os dois em um recipiente de vidro com tampa de volume de no mínimo $1 \mathrm{l}$. Adicionar o tenso ativo na medida especificada pela emulsão. Reservar em uma estufa à $60{ }^{\circ} \mathrm{C}$ por $40 \mathrm{~min}$. Incorporar a mistura fazendo um movimento pendular garantindo que haja contato no fundo do recipiente a cada período por $5 \mathrm{~min}$. Até que não haja 2 fases visualmente.

Homogeneizador Para utilizar o Turrax, separar em um bécker de plástico ou de vidro com volume de no mínimo $1 \mathrm{l}$. Ligar o Turrax com a hélice dentro da mistura na velocidade especificada e realizar movimentos rotativos atingindo as diversas alturas do recipiente. Utilizar o tempo determinado para cada diâmetro de gota requerido. Limpar a hélice do Turrax com tolueno reservado em vials em duas etapas, primeiro com um tolueno sujo e em seguida com tolueno limpo.

\section{C.1.2 Procedimentos de análise}

Titulação Medir a porcentagem de água utilizando o Karl Fischer. Separa amostra em seringa, pesar a amostra e tarar a balança, adicionar pequena quantidade de amostra no titulador e pesar a diferença. Informar o valor da massa adicionada no programa e verificar o resultado. Caso haja algum problema repetir o ensaio até obter uma faixa de amostra de água especificada pelo equipamento. Repetir a medição do teor de água 2 a 3 vezes para avaliar o desvio. 
Medição de diâmetro de gota (DTG) Usar equipamento Malvern.

Medição de densidade Usar equipamento Aston Paar.

Otimização do preparo Observar se há formação de gotas no fundo da amostra. Verificar a DTG se resulta em uma curva gaussiana com $d_{0.5} \simeq D[3,2] \simeq D[4,3]$. Caso haja surgimento de gotas utilizar tenso ativos na preparação da emulsão. Aumentar o tempo de aplicação do homogeinizador. Aumentar o teor de água para o mesmo óleo e repetir os procedimentos de síntese, para obter emulsões com maiores frações de água.

\section{C.2 OTIMIZAÇÃO}

São apresentadas as características de cada óleo fornecido, bem como os procedimentos e resultados realizados para cada emulsão.

\section{C.2.1 Bright Stock}

Figura 50 - Óleo Bright Stock.

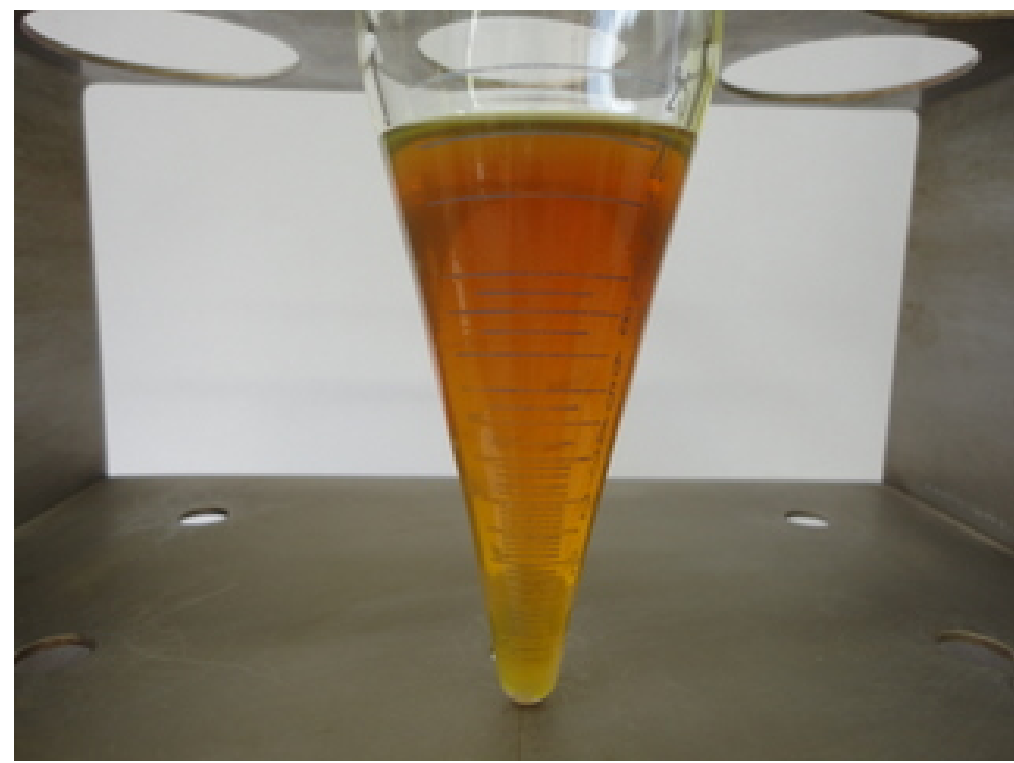

Caracterísiticas Forma emulsão amarelada, viscosidade alta: $\mu=2300 S S U$, densidade: $\rho=0.892 \mathrm{~g} / \mathrm{cm}^{3}$. A Figura (50) ilustra o óleo Bright Stock.

\section{Composição -}

- $1^{\text {a }}: 450 \mathrm{ml}$ de óleo Bright Stock $+50 \mathrm{ml}$ de solução salina $(50 \mathrm{~g} / \mathrm{L})+15 \mathrm{ml}$ de detergente $+5 \min$ de incorporação $\left(T=60^{\circ} \mathrm{C}\right)+10 \min$ de homogeneização (24000 rpm). 
- $2^{\mathrm{a}}$ : $400 \mathrm{ml}$ de óleo $+100 \mathrm{ml}$ de solução salina $(50 \mathrm{~g} / \mathrm{L})+15 \mathrm{ml}$ de detergente + 5 min de incorporação $\left(T=60{ }^{\circ} \mathrm{C}\right)+7 \mathrm{~min}$ de homogeneização $(24000 \mathrm{rpm})$.

\section{Resultados -}

- $1^{\text {a: }}$ Consolidação da emulsão 1 , após $7 h$ verificou-se o aparecimento de pequenas gotas de água.

- $2^{\mathrm{a}}$ : Consolidação da emulsão 2. Verificação de gotas de óleo na superfície livre da amostra de emulsão após quantidade indeterminada de horas.

\section{C.2.2 Neutro Leve}

Figura 51 - Óleo Neutro Leve.

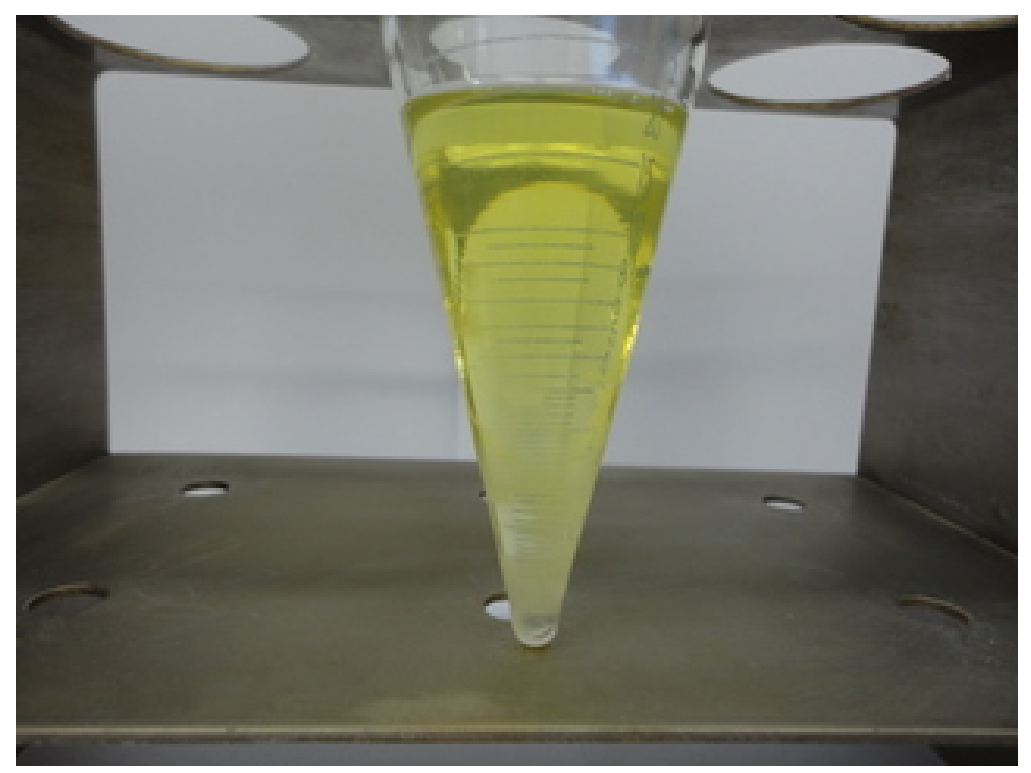

Caracterísiticas Forma emulsão esbranquiçada, viscosidade média: $\mu=160 S S U$, densidade: $\rho=0.863 \mathrm{~g} / \mathrm{cm}^{3}$. A Figura 51 ilustra o óleo Neutro leve.

Composição $225 \mathrm{ml}$ de óleo Neutro Leve $+225 \mathrm{ml}$ de óleo Bright Stock $(1: 1)+50 \mathrm{ml}$ de solução salina $(50 \mathrm{~g} / L)+15 \mathrm{ml}$ de detergente $+5 \mathrm{~min}$ de incorporação $\left(T=60^{\circ} \mathrm{C}\right)$ + 15 min de homogeneização (24000 rpm).

Resultados Consolidação da emulsão 3 e avaliação do tempo de estabilidade antes de completar $1 \mathrm{hr}$.

\section{C.3 RESULTADOS CONSOLIDADOS}

Após a análise exaustiva dos resultados da otimização do preparo de emulsões, foram consolidadas 3 tipos de emulsão relativamente estáveis. As emulsões consolidadas podem ser caracterizadas de acordo com sua composição, aspecto e tempo de estabilidade. 
O procedimento padrão adotado foi de adição de $15 \mathrm{ml}$ de detergente comum comercial, incorporação da mistura por $5 \mathrm{~min}$ a uma temperatura de $60{ }^{\circ} \mathrm{C}$ e homogeneização utilizando o equipamento Turrax por um período de $15 \mathrm{~min}$ a uma velocidade indicada pela marca de $2400 \mathrm{rpm}$. Os dados coletados referentes a essas emulsões possuem carater comparativo quanto ao tempo de estabilidade de cada uma delas. A padronização dos procedimentos de coleta dizem respeito apenas ao dicernimento quanto ao posicionamento da seringa, sendo no TOPO ou no FUNDO do bequer. O tipo de análise e o intervalo entre cada coleta varia de acordo com as características e o tempo de estabilidade de cada emulsão. Além disso, foram realizados testes com banho de ultrassom (35 KHz) para verificação qualitativa da eficiência de separação e análise do volume da fase livre. Os procedimento desses testes são baseados no trabalho de Antes (2011)

\section{C.3.1 Emulsão 1 - (óleo Bright Stock)}

Composição $450 \mathrm{ml}$ de óleo Bright Stock + $50 \mathrm{ml}$ de solução salina $(50 \mathrm{~g} / L)+15 \mathrm{ml}$ de detergente;

Aspecto Coloração amarelada e pastosa. A Figura (52) ilustra o aspecto emulsão 1.

Esbalidade $\sim 3 h$;

Análise Medição do teor de água, conforme ilustra a Figura (53), e de DTG, conforme ilustra as Figuras (54) e (55), de hora em hora nas posições TOPO e FUNDO, durante um período de $5 h$.

Figura 52 - Emulsão 1 após o preparo.

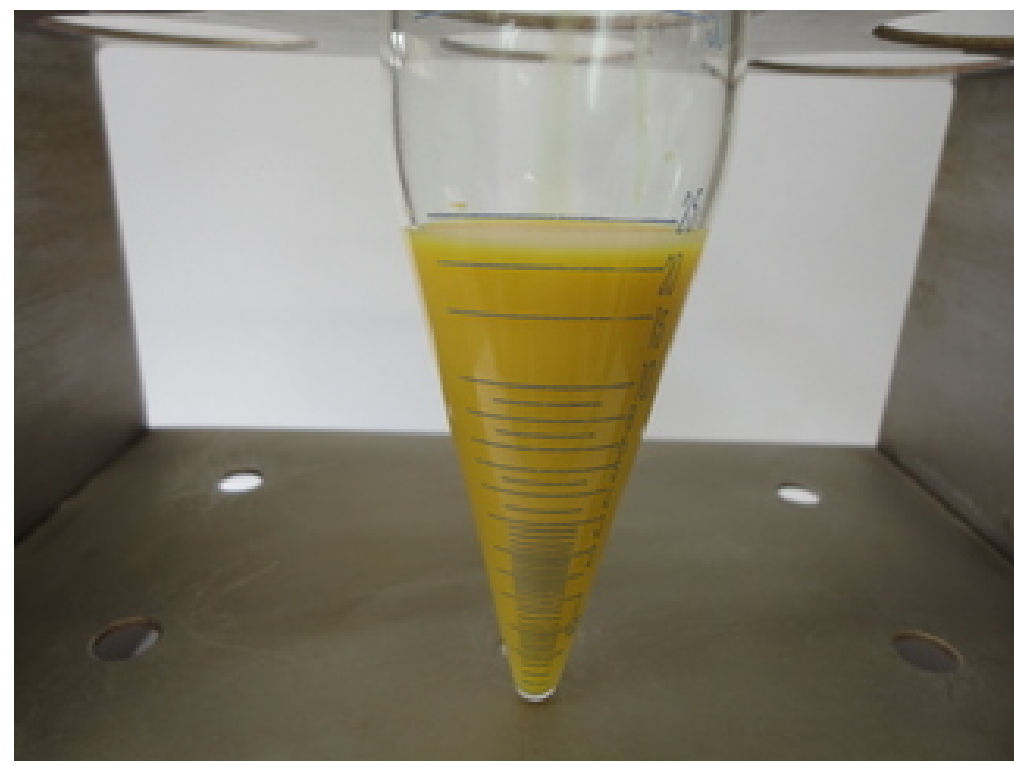


Figura 53 - Gráfico comparativo dos teores de água das amostras TOPO e FUNDO da emulsão 1.

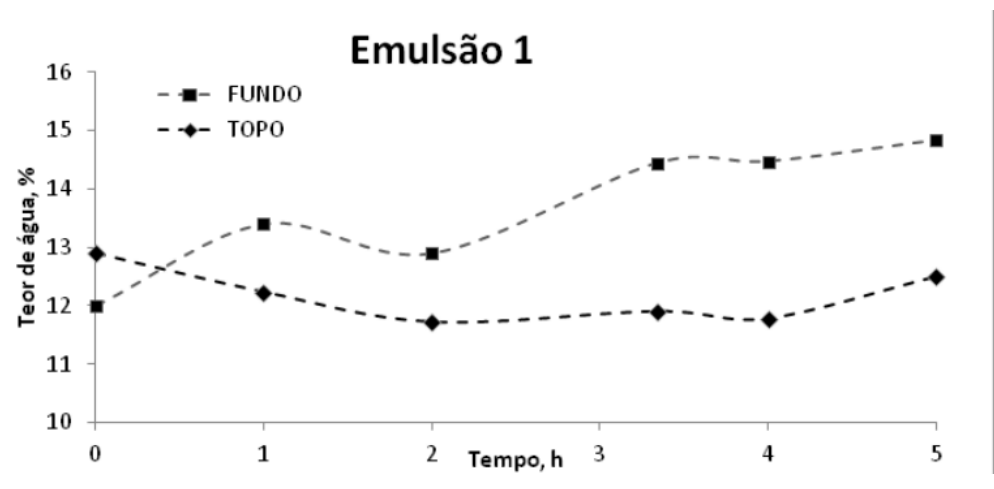

Figura 54 - Gráfico comparativo dos DTG da amostra TOPO da emulsão 1.

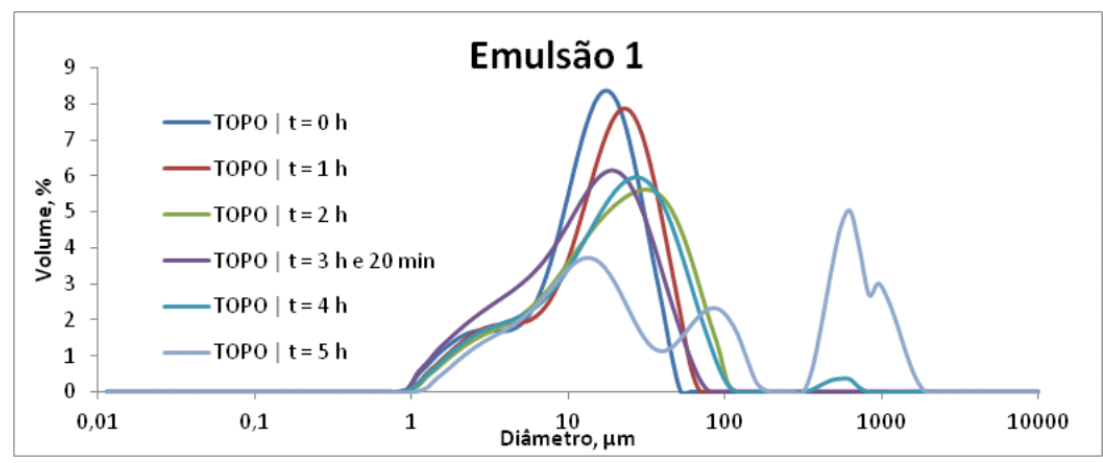

Figura 55 - Gráfico comparativo dos DTG da amostra FUNDO da emulsão 1.0.

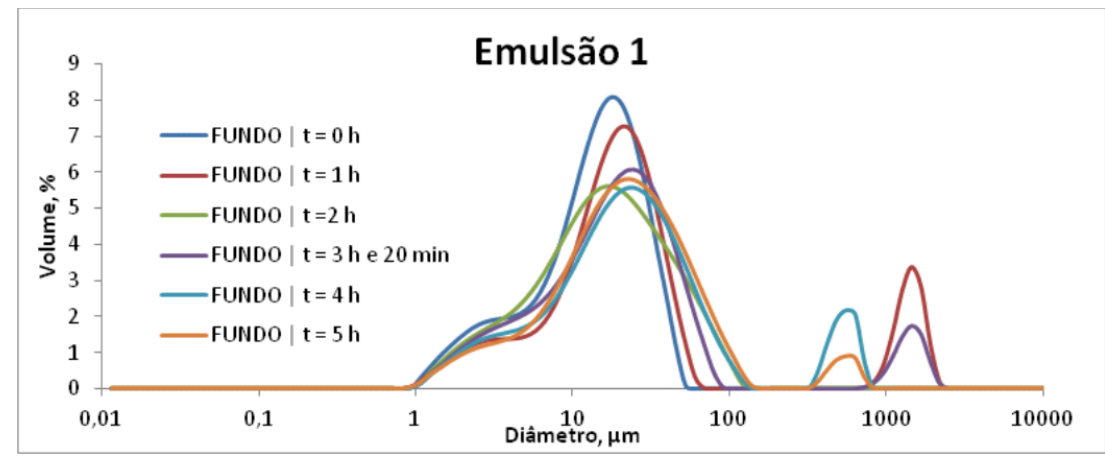

Observações Após $2 h$ de repouso a emulsão foi submetida ao banho de ultrassom (35 $K H z, 25^{\circ} \mathrm{C}, 100 \%$ amplitude). Foi separado um frasco BS\&W com a emulsão sem aplicação de banho de ultrassom durante o mesmo tempo. Não houve separação de água e não foram observadas manchas. A Figura (56) ilustra o aspecto da emulsão 1 antes e após aplicação de ultrassom. A Tabela (11) apresenta o resultados da aplicação de ultrassom na emulsão 1. 
Figura 56 - Emulsão 1 antes e após aplicação de banho por ultrassom.

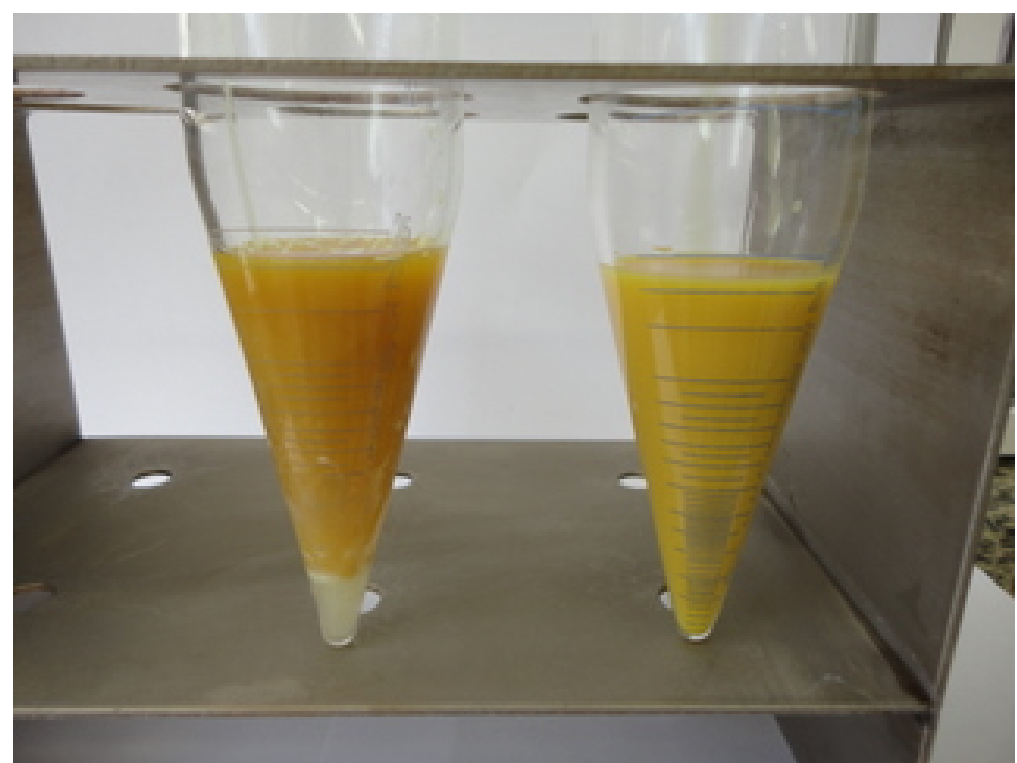

Tabela 11 - Ensaio com banho de ultrassom da emulsão 1

\begin{tabular}{ll}
\hline Tempo & Observações \\
\hline Após $1 \mathrm{~min}$ & Aparecimento de manchas \\
Após $5 \mathrm{~min}$ & Aparecimento de gotas e mais manchas \\
Após $10 \mathrm{~min}$ & Separação de $50 \mu \mathrm{l}$ de água e mais manchas \\
De 15 à $30 \mathrm{~min}$ & Separação de $250 \mu \mathrm{l}$ de água bastante turva \\
\hline
\end{tabular}

\section{C.3.2 Emulsão 2 - (óleo Bright Stock + óleo Neutro Leve)}

Composição $150 \mathrm{ml}$ de óleo Neutro Leve $+300 \mathrm{ml}$ de óleo Bright Stock (1:2) $+50 \mathrm{ml}$ de solução salina $(50 \mathrm{~g} / L)+15 \mathrm{ml}$ de detergente;

Aspecto Coloração amarelada, pastosa e viscosidade média. A Figura (57) ilustra o aspecto emulsão 2.

\section{Esbalidade $\sim 3 h$;}

Análise Medição do teor de água, conforme ilustra a Figura (58), e de DTG, conforme ilustra as Figuras (59) e (60), de hora em hora nas posições TOPO e FUNDO, durante um período de $4 h$. 
Figura 57 - Emulsão 2 após o preparo.

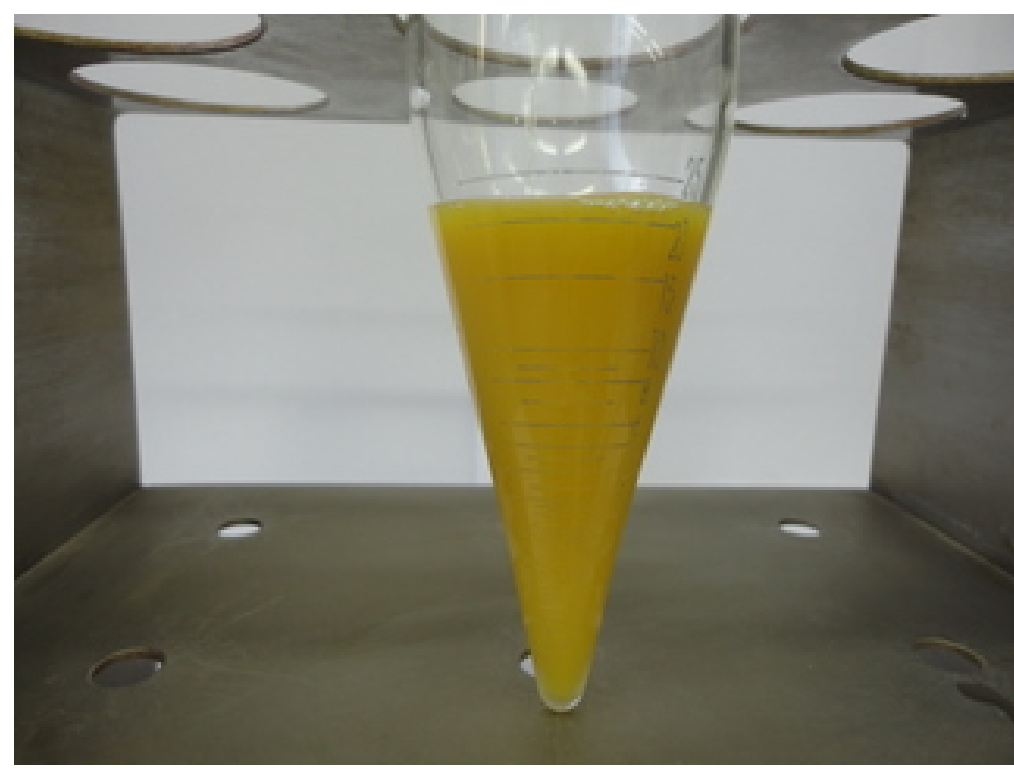

Figura 58 - Gráfico comparativo dos teores de água das amostras TOPO e FUNDO da emulsão 2.

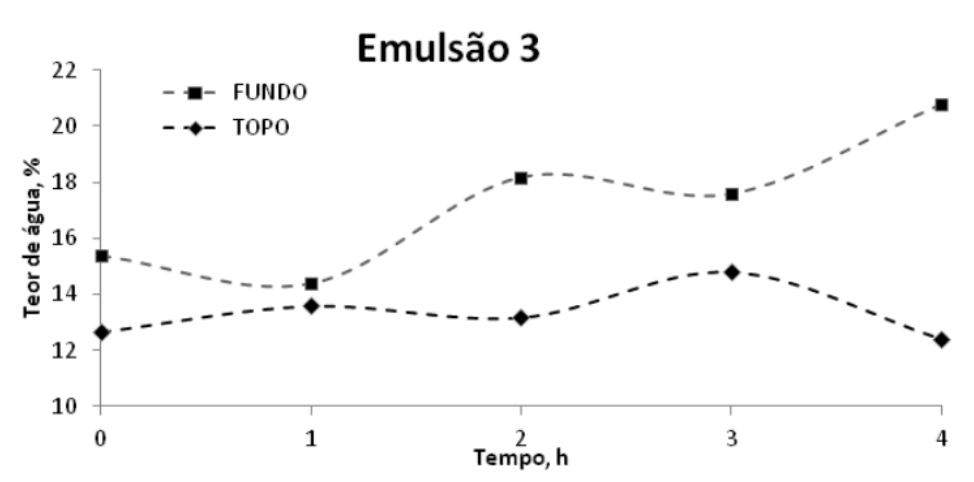

Figura 59 - Gráfico comparativo dos DTG da amostra TOPO da emulsão 2.

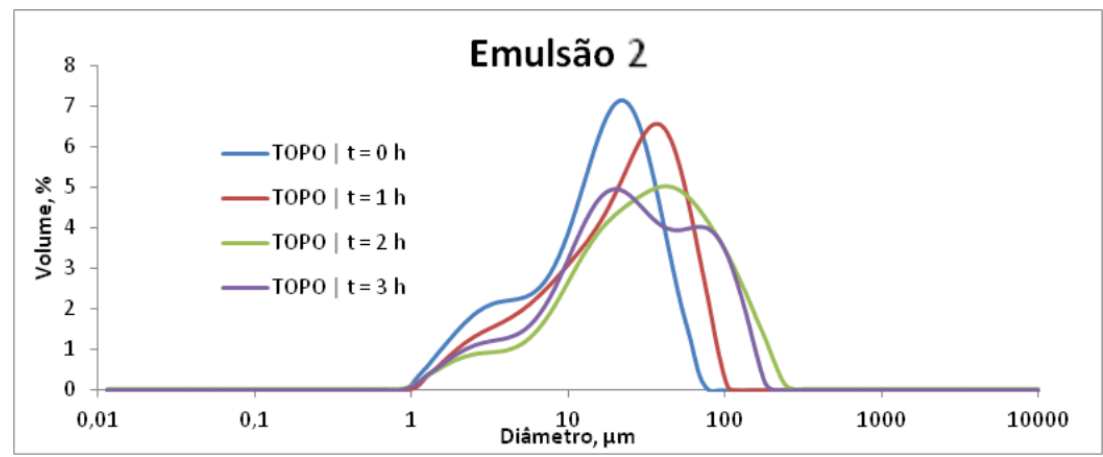


Figura 60 - Gráfico comparativo dos DTG da amostra FUNDO da emulsão 2.

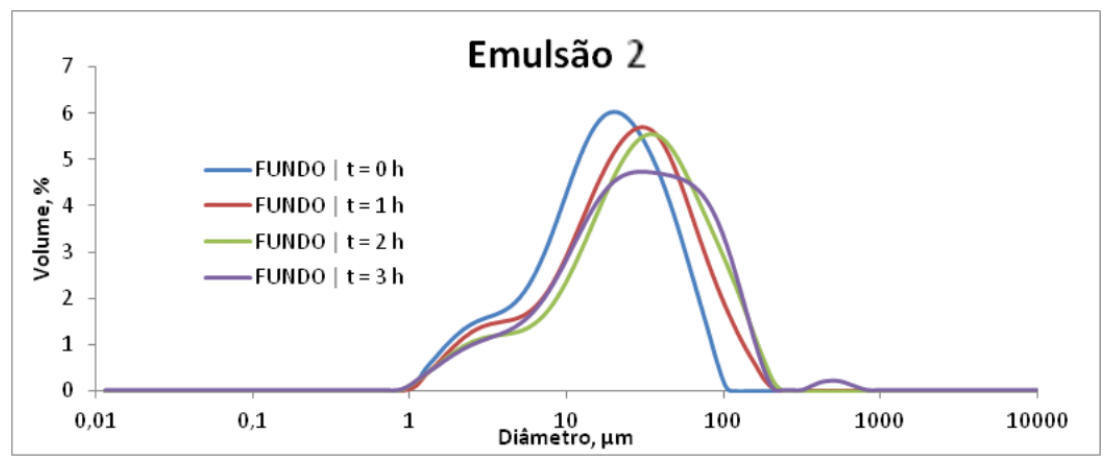

Observações Após $2 h$ de repouso a emulsão foi submetida ao banho de ultrassom (35 $K H z, 25{ }^{\circ} \mathrm{C}, 100 \%$ amplitude). Foi separado um frasco BS\&W com a emulsão sem aplicação de banho de ultrassom durante o mesmo tempo. Não houve separação de água e não foram observadas manchas. A Figura (61) ilustra o aspecto da emulsão 2 antes e após aplicação de ultrassom. A Tabela (12) apresenta o resultados da aplicação de ultrassom na emulsão 2.

Figura 61 - Emulsão 2 antes e após aplicação de banho por ultrassom.

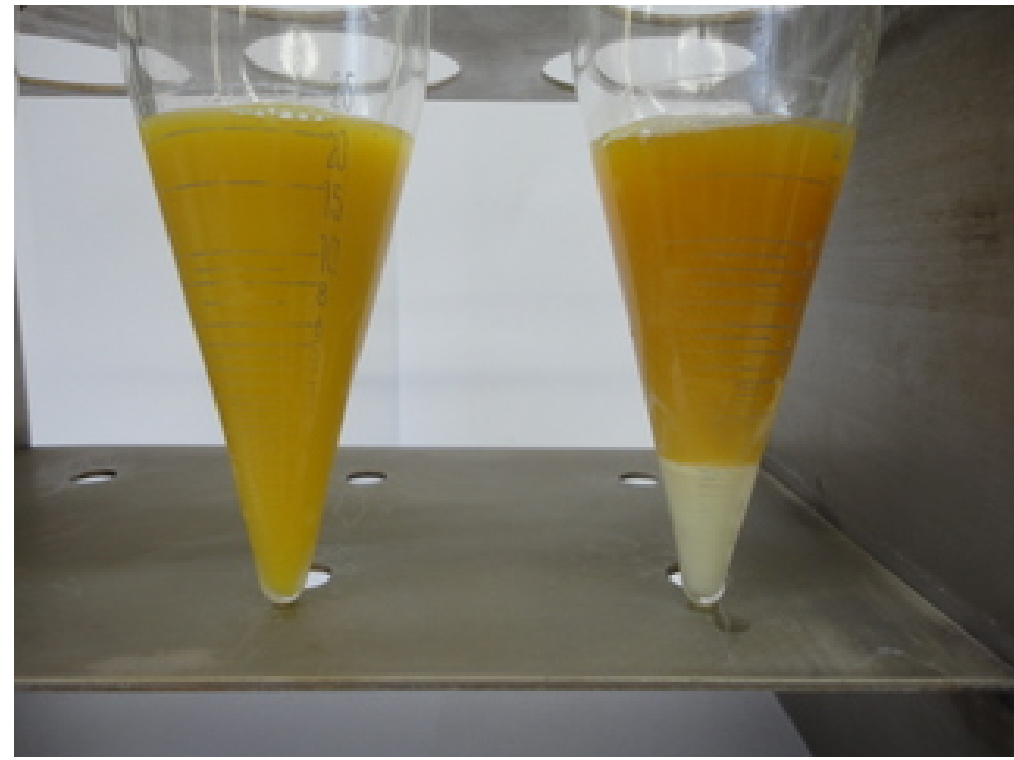

Tabela 12 - Ensaio com banho de ultrassom da emulsão 2

\begin{tabular}{ll}
\hline Tempo & Observações \\
\hline Após $6 \mathrm{~min}$ & Separação de $250 \mu l$ de água \\
Após $15 \mathrm{~min}$ & Separação de $400 \mu l$ de água \\
Após $18 \mathrm{~min}$ & Separação de $500 \mu l$ de água \\
Após $25 \mathrm{~min}$ & Separação de $1 \mathrm{ml}$ de água \\
\hline
\end{tabular}


Figura 63 - Gráfico comparativo dos teores de água das amostras TOPO e FUNDO da emulsão 3.

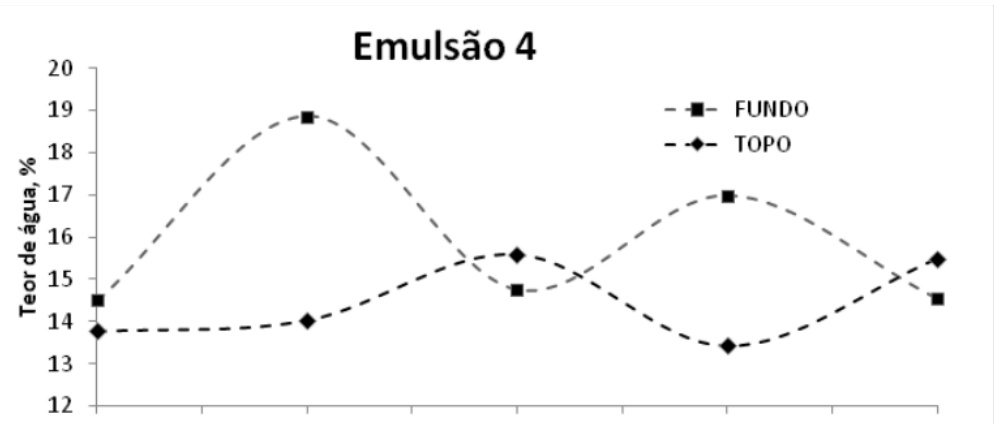

\section{C.3.3 Emulsão 3 - (óleo Bright Stock + óleo Neutro Leve)}

Composição $225 \mathrm{ml}$ de óleo Neutro Leve $+225 \mathrm{ml}$ de óleo $3(1: 1)+50 \mathrm{ml}$ de solução salina $(50 \mathrm{~g} / L)+15 \mathrm{ml}$ de detergente;

Aspecto Coloração amarelada, pastosa e viscosidade baixa. A Figura (62) ilustra o aspecto emulsão 3.

Figura 62 - Emulsão 3 após o preparo.

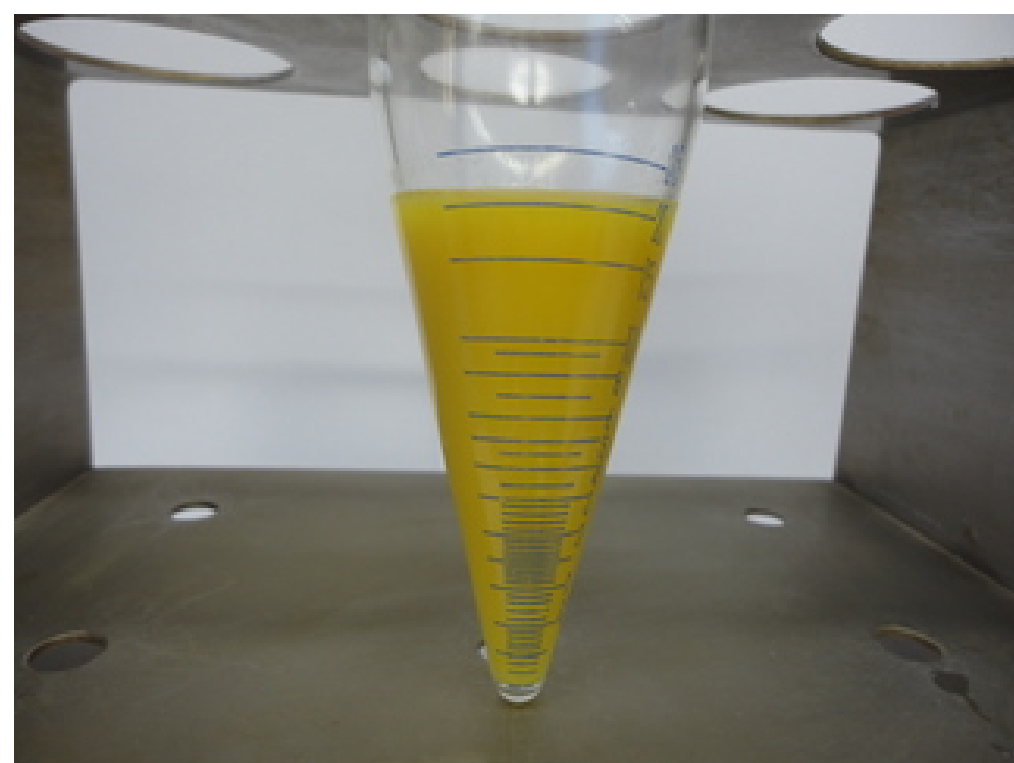

Esbalidade 30 min;

Análise Medição do teor de água, conforme ilustra a Figura (63), de 10 em 10 min nas posições TOPO e FUNDO, durante um período de 40 min.

Observações Após o preparo, a emulsão foi submetida ao banho de ultrassom (35 KHz, $25{ }^{\circ} \mathrm{C}, 100 \%$ amplitude). Foi separado um frasco BS\&W com a emulsão sem aplicação de banho de ultrassom durante o mesmo tempo. Não ocorreu separação de 
água e não foram observadas manchas. A Figura (64) ilustra o aspecto da emulsão 3 antes e após aplicação de ultrassom. A Tabela (13) apresenta o resultados da aplicação de ultrassom na emulsão 3

\begin{tabular}{|c|c|}
\hline Tempo & Observações \\
\hline Após $3 \mathrm{~min}$ & Separação de $20 \mu l$ de água \\
\hline Após $5 \mathrm{~min}$ & Separação de $250 \mu l$ de água \\
\hline Após $10 \mathrm{~min}$ & Separação de $500 \mu l$ de água \\
\hline Após $15 \mathrm{~min}$ & Separação de $800 \mu l$ de água \\
\hline Após 20 min & Separação de $1 m l$ de água \\
\hline Após 25 min & Separação de $1.5 \mathrm{ml}$ de água \\
\hline
\end{tabular}

Figura 64 - Emulsão 3 antes e após aplicação de banho por ultrassom.

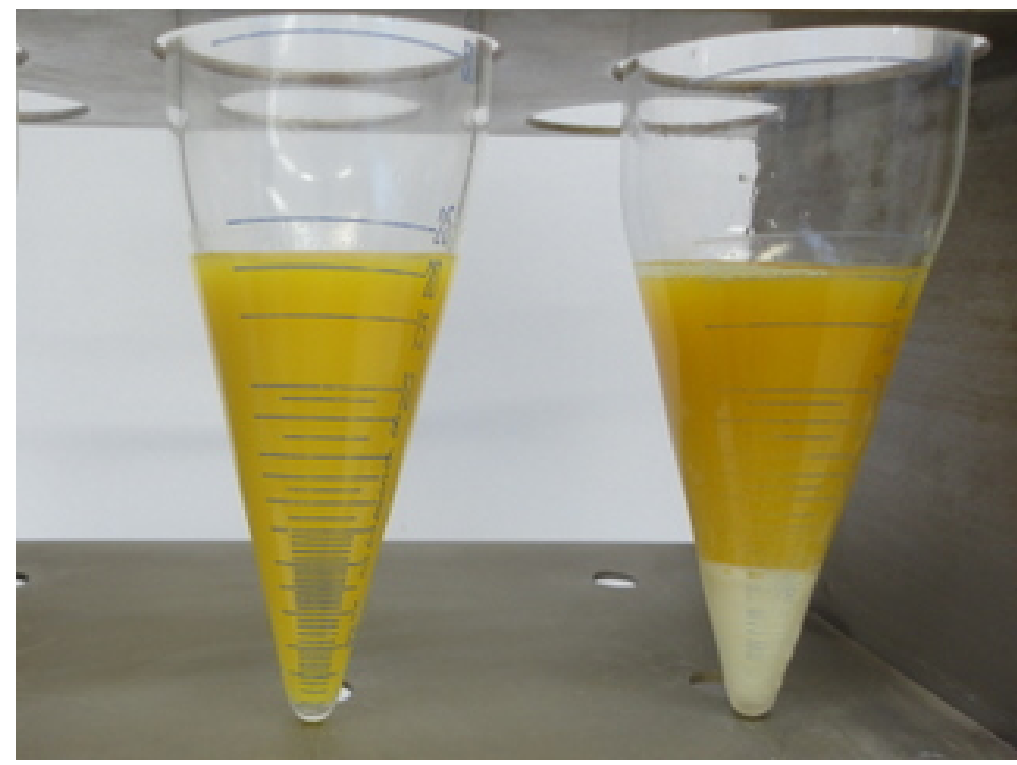

\section{C.4 DISCUSSÃO E CONCLUSÃO}

A estabilidade das emulsões consolidadas foi estimada com base nos resultados obtidos do teor de água e do DTG. Para o óleo Bright stock, uma emulsão estável foi obtida utilizando adição de detergente, 5 min de agitação manual a $60{ }^{\circ} \mathrm{C}$, seguida de $10 \mathrm{~min}$ a 2400 rpm no Turrax (emulsão 1: teor de água $=12 \%$ e $D_{0,5}=13 \mu \mathrm{m}$ ). Para essa emulsão, o teor de água determinado em alíquotas coletadas no fundo do frasco aumentou de 12 para $14 \%$ após $\sim 3 h$ de sedimentação. Após $4 h$, foi possível observar a formação de população de gotas com diâmetro maior de acordo através da DTG obtida de alíquotas coletadas no topo do frasco. A separação de água foi visualizada apenas após $7 \mathrm{~h}$ de sedimentação. Dessa forma, esta emulsão demonstrou uma estabilidade de até $\sim 3 h$. 
Considerando o óleo Neutro leve, uma emulsão estável foi obtida somente através da mistura com o óleo Bright stock. Um exemplo deste tipo de emulsão de composição de relação 1:2 em volume foi obtida utilizando o mesmo procedimento anterior (emulsão 2: teor de água $=12 \%$ e $\left.D_{0,5}=16 \mu \mathrm{m}\right)$. Seguindo a mesma análise, o teor de água determinado em alíquotas coletadas no fundo do frasco aumentou de 15 para $18 \%$ após $\sim 2 h$ de sedimentação. Após $3 h$, foi possível observar a formação de população de gotas com diâmetro maior. Não houve relato visual de separação de água após $4 h$ de sedimentação. Neste caso, há uma estabilidade de até $\sim 3 h$.

Os experimentos com US demonstraram que as emulsões obtidas apresentaram estabilidade adequada para os experimentos, visto que, nas alíquotas utilizadas para os testes em branco (sem a aplicação do US), nenhuma alteração visual foi observada. 


\section{ANEXO A - PROPRIEDADES DOS MATERIAIS NO MEF}

Tabela 14 - Propriedades dos materiais usados no modelo de elementos finitos

\begin{tabular}{cccccc}
\hline Propriedades & Água & Alumínio & Acrílico & Epóxi & Borracha \\
\hline$c_{f}(\mathrm{~m} / \mathrm{s})$ & 1490 & & & & \\
$\rho\left(\mathrm{kg} / \mathrm{m}^{3}\right)$ & 998 & 2654 & 1180 & 1126 & 1200 \\
$E\left(10^{10} \mathrm{~N} / \mathrm{m}^{2}\right)$ & & 7.43 & 8 & 0.38 & 0.00025 \\
$\nu$ & & 0.33 & 0.39 & 0.37 & 0.35 \\
$\mathcal{Q}$ & & 100 & 1000 & 50 & 20 \\
\hline
\end{tabular}

Tabela 15 - Propriedades do material PZT8 utilizadas no MEF

\begin{tabular}{cccc}
\hline Propriedade & Valor & Propriedade & Valor \\
\hline$c_{11}^{E}\left(10^{10} \mathrm{~N} / \mathrm{m}^{2}\right)$ & 13.7 & $e_{33}\left(\mathrm{C} / \mathrm{m}^{2}\right)$ & 13.8 \\
$c_{12}^{E}\left(10^{10} \mathrm{~N} / \mathrm{m}^{2}\right)$ & 6.97 & $e_{15}\left(C / \mathrm{m}^{2}\right)$ & 10.4 \\
$c_{13}^{E}\left(10^{10} \mathrm{~N} / \mathrm{m}^{2}\right)$ & 7.16 & $\varepsilon_{11}^{S} / \varepsilon_{0}$ & 898 \\
$c_{33}^{E}\left(10^{10} \mathrm{~N} / \mathrm{m}^{2}\right)$ & 12.4 & $\varepsilon_{33}^{S} / \varepsilon_{0}$ & 582 \\
$c_{44}^{E}\left(10^{10} \mathrm{~N} / \mathrm{m}^{2}\right)$ & 3.14 & $\rho\left(\mathrm{kg} / \mathrm{m}^{3}\right)$ & 7600 \\
$e_{31}\left(\mathrm{C} / \mathrm{m}^{2}\right)$ & -4 & $\mathcal{Q}$ & 1700 \\
\hline
\end{tabular}

Tabela 16 - Propriedades do material PZT4 utilizadas no MEF

\begin{tabular}{cccc}
\hline Propriedade & Valor & Propriedade & Valor \\
\hline$c_{11}^{E}\left(10^{10} \mathrm{~N} / \mathrm{m}^{2}\right)$ & 13.9 & $e_{33}\left(C / \mathrm{m}^{2}\right)$ & 15.1 \\
$c_{12}^{E}\left(10^{10} \mathrm{~N} / \mathrm{m}^{2}\right)$ & 7.78 & $e_{15}\left(C / \mathrm{m}^{2}\right)$ & 12.7 \\
$c_{13}^{E}\left(10^{10} \mathrm{~N} / \mathrm{m}^{2}\right)$ & 7.43 & $\varepsilon_{11}^{S} / \varepsilon_{0}$ & 1475 \\
$c_{33}^{E}\left(10^{10} \mathrm{~N} / \mathrm{m}^{2}\right)$ & 11.5 & $\varepsilon_{33}^{S} / \varepsilon_{0}$ & 1300 \\
$c_{44}^{E}\left(10^{10} \mathrm{~N} / \mathrm{m}^{2}\right)$ & 2.56 & $\rho\left(\mathrm{kg} / \mathrm{m}^{3}\right)$ & 7500 \\
$e_{31}\left(C / \mathrm{m}^{2}\right)$ & -5.2 & $\mathcal{Q}$ & 500 \\
\hline
\end{tabular}

